\title{
CLINICAL NURSE LEADERS \\ WITHIN A NEW ZEALAND SETTING: \\ THE CULTURE OF BUSINESS AND THE PROFESSION OF NURSING
}

by

Suzanne Mary Frances Gardner (nee Wybrow)

A thesis submitted to the Victoria University of Wellington in fulfilment of the requirements for the degree of Master of Nursing

Victoria University of Wellington

2008 


\begin{abstract}
This thesis reports on an action research project undertaken to explore the role of the Clinical Nurse leader (CNL) in a District Health Board (DHB) in New Zealand. The CNL role has evolved against a backdrop of significant reforms that took place in the country in the 1990s. These reforms altered how public health services were funded, organised and delivered. Nursing leadership positions at both executive and clinical level were challenged in the reforms, as health services were expected to function using a market model. Not surprisingly, this clashed with the humanism of nursing. The action research project involved seven CNLs researching with the principal investigator to explore the role and establish how support afforded the role could be further improved. The research had two phases: Phase One involved each CNL being interviewed one-on-one and Phase Two involved a series of 10 action research meetings and related activities. The findings of the interviews consisted of 24 themes that related to the role of the CNL, the attributes of the $\mathrm{CNL}$, the skills and knowledge requirements of the CNL, and the experience of being a CNL. These themes were presented by the principal researcher at the second action research meeting as the starting point for the group to decide its agenda. After three meetings, the group chose to focus on two themes: the conflict experienced between the leadership and management aspects of the role; and professional development afforded the role. The group identified what was important, agreeing the role was one of leadership and management as well as patient care. Plans for role development for themselves and for the advancement of new CNLs were also created. The project provides an important contribution to our understanding of the work of the CNL. Not only did it produce outcomes related to role, support and scope but it also shed light on the importance of the relationship between the role and its context of the DHB. The culture of business and the profession of nursing and a shared understanding of responsibilities as a way forward were recommended.
\end{abstract}

\title{
Key words: Leadership, clinical leadership, role, action research
}




\section{ACKNOWLEDGEMENTS}

I would like to thank my parents, Nora and John Wybrow, for showing and teaching me an Irish/Maori worldview (County Cork/Ngai Tahu). You remain two of the most significant people in my life - in part this is for you both. I would like to acknowledge Bruce for his unfailing love and support of my research and the three beautiful young adults who are our children, Graeme, Lucy and Alice. To Tessa, my two year old mentor, and Joshua her Dad I thank you both. For any future mokopuna I look forward to telling you my story. Jackie Maggie Gabby-tanx as a Irish woman would say!

I would like to thank my magnificent supervisors Dr Cheryle Moss and Dr Kathy Nelson as well as Dr Jan Duke, Dr Jackie Crisp, Dr Ken Walsh and Dr Pamela Wood. I would like to acknowledge Mary Baldwin who first encouraged me to further my education and my fellow Masters students for their critique and humour. I would like to acknowledge Dr Beverley Taylor for her expert input and Dr Jill White for sharing her work so willingly. I wish to thank Dr Jan White for her encouragement, the Waikato District Health Board, Lynda Pryor, Angela Broring, Sharon Cornwall, Carolyn Bruce and Trish Houchen. I wish to thank my team, office family and all the colleagues that I work with who have offered encouragement over this time. I am grateful for the input of Lorraine Reid and Jeremy Tritt and would like to thank and acknowledge the expertise of Catherine Morrison.

Lastly, I would like to acknowledge Tana Umaga (ex Captain of the New Zealand All Black rugby team) who advised the referee in a crucial game "This is not tiddlywinks" and Sir Edmund Hilary who conquered Everest. This was my crucial time, climb, my ascent - like Tana and Sir Ed I knew who else to have with me - the seven CNLs. Gloriously, proudly we had the answers - this has always been for you. 


\section{TABLE OF CONTENTS}

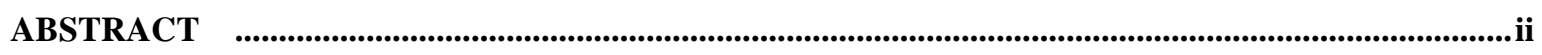

ACKNOWLEDGEMENTS ........................................................................................................................iii

TABLE OF CONTENTS ...........................................................................................................................................iv

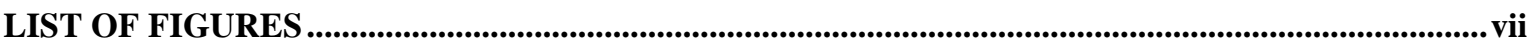

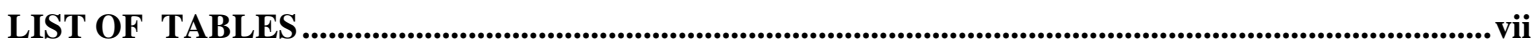

CHAPTER 1. SETTING THE CONTEXT.....................................................................................................

1.1. Introduction.............................................................................................................................

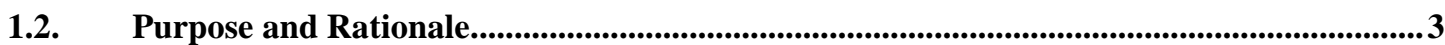

1.3. The District Health Board: The Setting ............................................................................................6

1.4. The CNL Within the District Health Board ................................................................................

1.5. The CNL Within the New Zealand Nursing Environment ................................................11

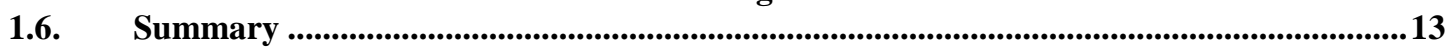

CHAPTER 2. LITERATURE REVIEW ........................................................................................ 16

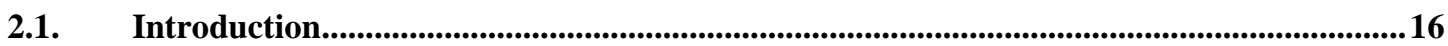

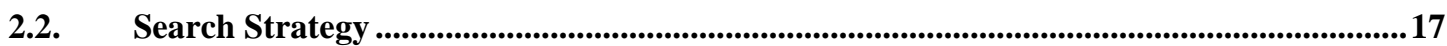

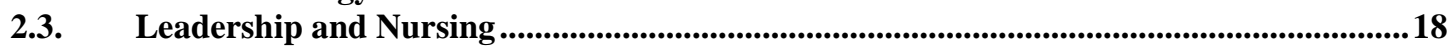

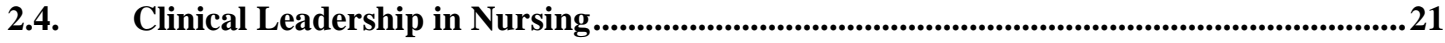

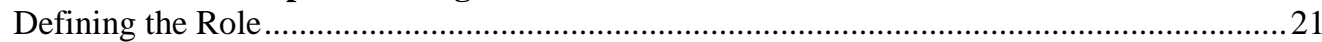

2.5. Effective Attributes and Competencies..............................................................................23

2.6. Pivotal Nature of the Role .............................................................................................................24

2.7. Professional Development ..........................................................................................25

2.8. Conclusion ....................................................................................................................26

CHAPTER 3. METHODOLOGY .............................................................................................................. 28

3.1. Introduction..............................................................................................................................28

3.2. Qualitative and Quantitative Research.......................................................................................28

3.3. The Beginning of Action Research ........................................................................................30

3.4. Agreed Features of Action Research ...................................................................................................34

3.5. Action Research and Nursing Research.......................................................................................35

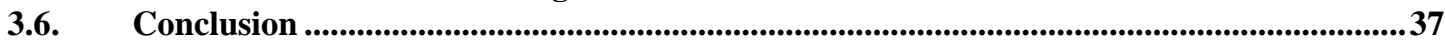

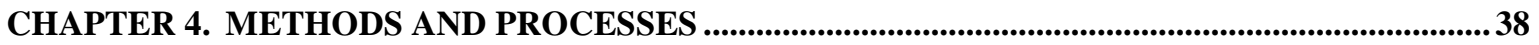

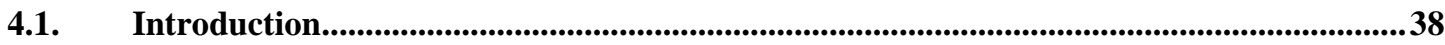

4.2. Recruitment of Participants...........................................................................................................39

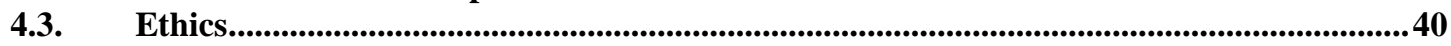

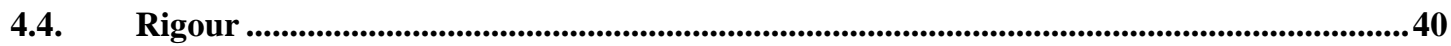

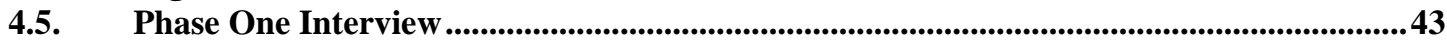

4.6. Analysis of the Interview Data..................................................................................................44

4.7. Phase Two Action Research Group Process...................................................................................46

4.8. Action Research Meetings....................................................................................................................48

Analysis of Action Research Meetings .............................................................................4

4.9. Summary …...................................................................................................................................49 


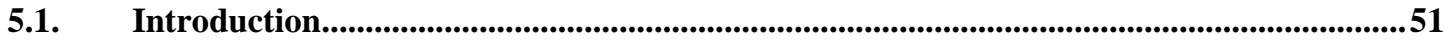

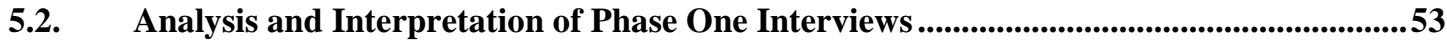

5.3. The Role of the Clinical Nurse Leader ....................................................................................53

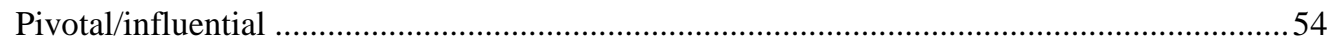

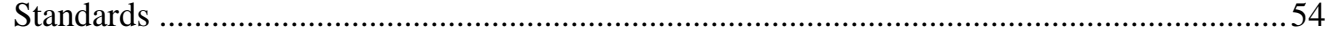

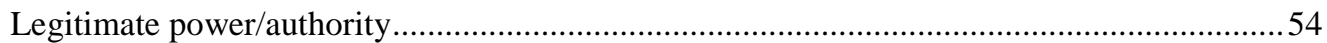

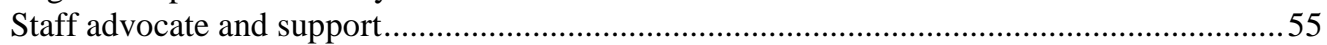

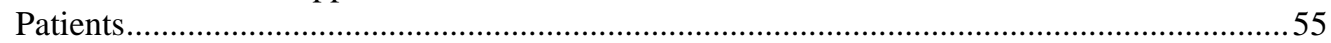

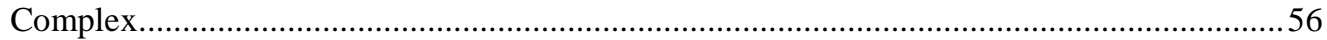

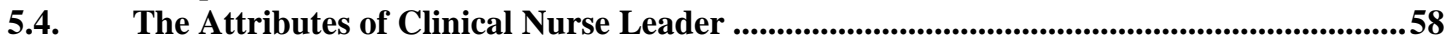

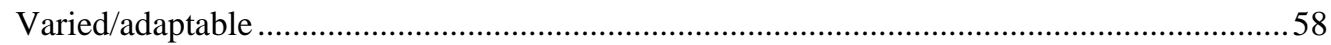

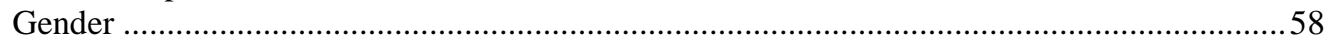

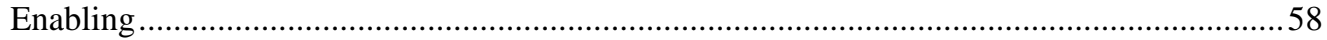

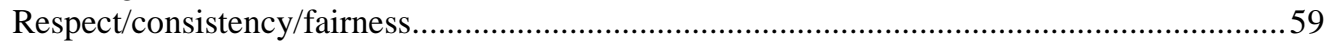

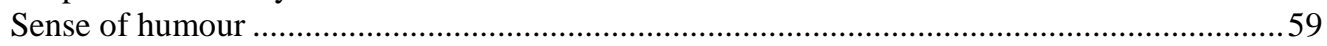

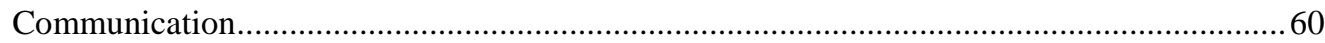

5.5. Skills and Knowledge Requirements of a Clinical Nurse Leader .......................................60

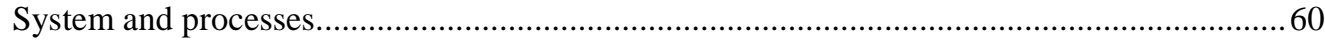

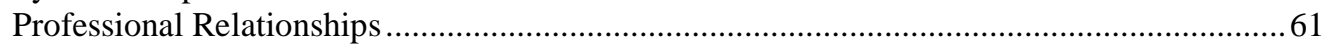

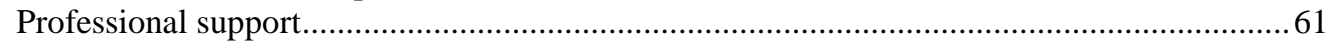

5.6. The Experience of being a Clinical Nurse Leader....................................................................662

Conflicting management and leadership.......................................................................62

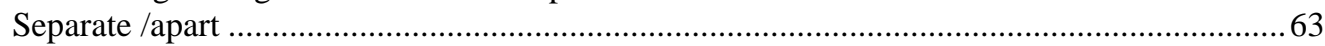

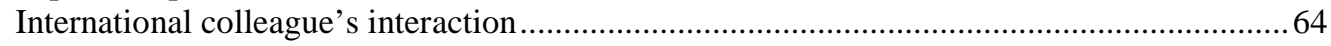

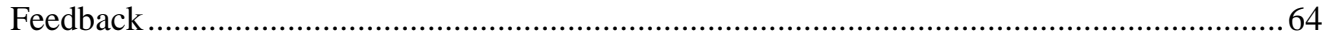

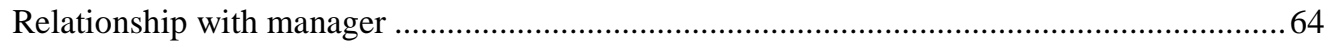

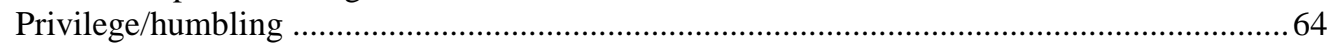

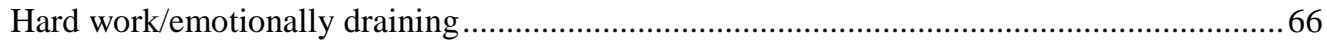

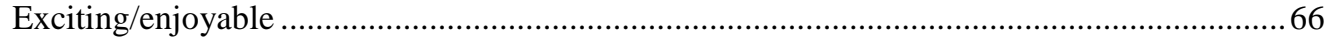

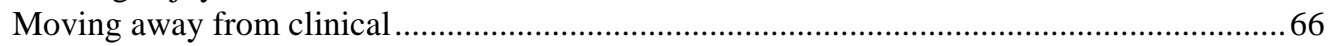

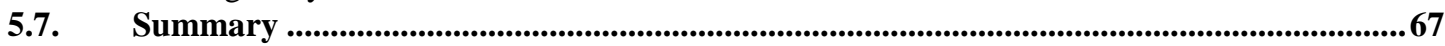

CHAPTER 6. ANALYSIS AND INTERPRETATION OF PHASE TWO MEETINGS........................69

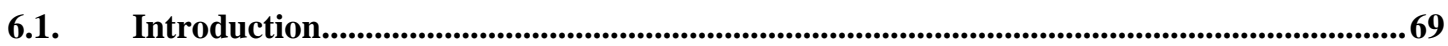

6.2. Meeting One (December 2005): Establishing the Group......................................................70

6.3. Meeting 2 January 2006: Presentation of 24 Themes .......................................................73

6.4. Meeting Three (February 2006): Reduction of Focus.............................................................78

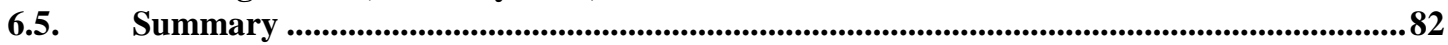

CHAPTER 7. IN THE THICK OF IT - SHARING AND LEARNING FROM EACH OTHER HOW

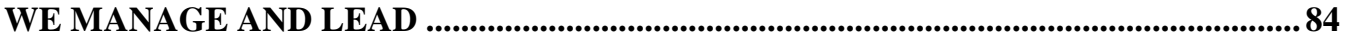

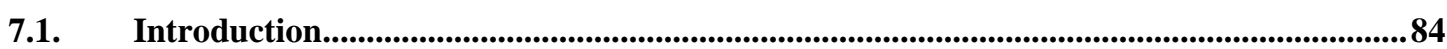

7.2. Meetings Four and Five: Management versus leadership..............................................86

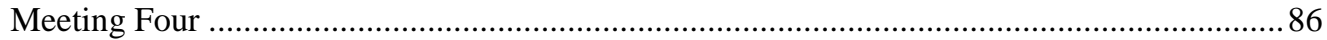

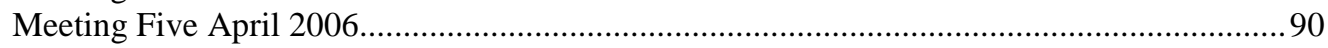

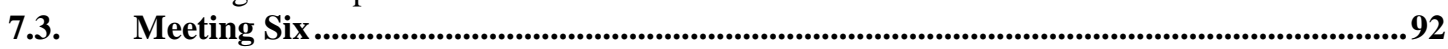

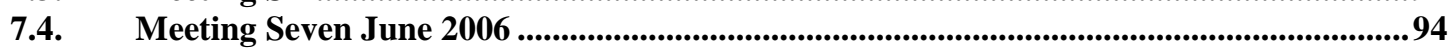

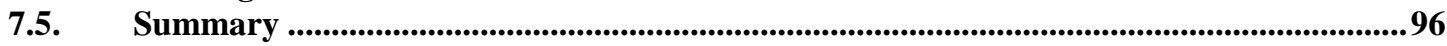


CHAPTER 8. COALESCING FOR THE FUTURE CNL COMMUNITY: PROFESSIONAL DEVELOPMENT AND SUPPORT...............................................................................................98

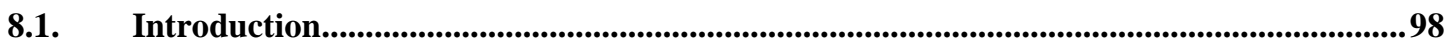

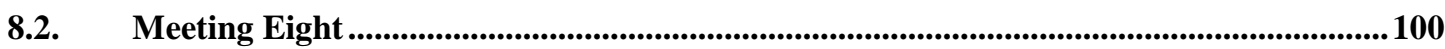

8.3. Meeting Nine ...................................................................................................101

8.4. Meeting 10 Evaluation..................................................................................................106

8.5. Summary …................................................................................................................................... 108

CHAPTER 9. DISCUSSION, RECOMMENDATIONS AND REFLECTIONS ....................................110

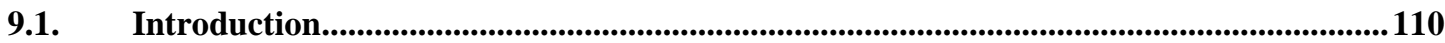

9.2. Thesis Overview ...................................................................................................110

9.3. Discussion ..........................................................................................................113

9.4. Insight and Recommendations for Stakeholders .......................................................................118

The District Health Board and Clinical Nurse Leaders- Inextricably Linked.......................118

9.5. Directorate and Nurse Educators.................................................................................................120

9.6. Challenges and Limitations........................................................................................121

9.7. Future Research.................................................................................................................123

9.8. Closing Reflections................................................................................................................... 125

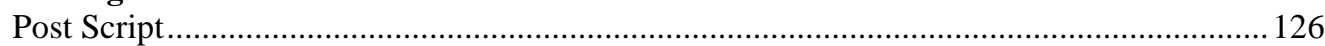

APPENDICES

APPENDIX 1:HUMAN ETHICS APPROVAL.............................................................................................. 128

APPENDIX 2:LETTER OF PERMISSION: CEO........................................................................................ 130

APPENDIX 3:ELECTRONIC INVITATION .................................................................................................. 131

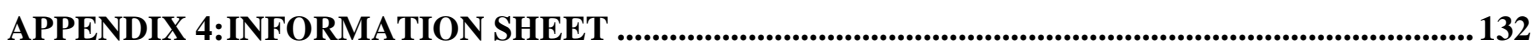

APPENDIX 5:CONSENT FORM...................................................................................................................... 134

APPENDIX 6:PICTORIAL IMAGE (PARTICIPANT) .................................................................. 135

APPENDIX 7:PROFESSIONAL DEVELOPMENT PROPOSAL................................................................136

APPENDIX 8:FURTHER CEO PERMISSION ................................................................................................. 138

REFERENCES 


\section{LIST OF FIGURES}

Figure 1: Ground rules agreed on by clinical nurse leaders in action research group................................. 49

Figure 2: Towards Phase One of the research - the interviews ............................................................52

Figure 3: Phase Two - first three action group meetings .......................................................................... 72

Figure 4: The 24 themes presented to the Clinical Nurse Leaders............................................................. 74

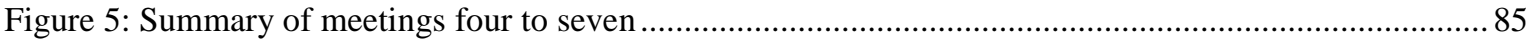

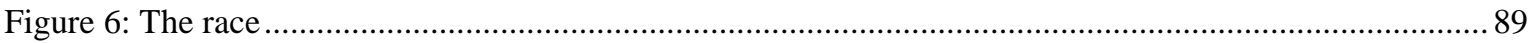

Figure 7: Summary of last action research meetings - Phase One and Two complete................................ 99

Figure 8: Proposal - preparation, professional development and support/Clinical Nurse Leader role.......... 103

\section{LIST OF TABLES}

Table 1: Thematic content of clinical nurse leaders' interviews by key groupings .53 


\section{CHAPTER 1. SETTING THE CONTEXT}

Can you love or respect the people and assist their/our inquiry without imposition of your will Can you intervene in the most vital matters and yield to events taking their course

Can you attain deep knowing and know you do not understand

Conceive, give birth and nourish without retaining ownership

Trust action without knowing outcome

Guide by being guided

Exercise stewardship without control.

(Interpretation of words attributed to Lao Tzu, c. 550 BC in Wadsworth, 2001, p. 420)

\subsection{Introduction}

This thesis defines the project I began in October 2005 when I set out to explore clinical leadership in nursing within a District Health Board (DHB) in New Zealand. This exploration was to be achieved through a study based on the principles of action research (research which is cyclic, qualitative and participatory). My objective for undertaking this study was twofold: to inform the ongoing evolution of the role; and to improve the support afforded the role. Research surrounding clinical leadership in nursing has been generated from various parts of the globe, including the United Kingdom, Spain, Singapore, Israel, America and Australia (Oroviogoicoehea, 1996; Cook, 2001; Duffield, Wood, Franks, \& Brisley, 2001; Firth, 2002; Connelly, Yoder, \& Miner-Williams, 2003; Stanley, 2004; Mills, 2005; Stanley, 2006). There has also been a minimal amount of New Zealand research carried out including but not limited to Drummond (2002), Kan (2002) and Williams (2004). White (2004), although not concentrating solely on leadership, outlined the loss of nursing leadership positions in New Zealand when the health reforms of the nineties were introduced. These reforms saw a change in the relationship the government had with the public service, including health. Simply put, the market model was applied to the delivery of health services throughout the country (Upton, 1991).

Nursing leadership at executive and clinical level was not exempt from such a model. White (2004) explains that in the early 1990s many hospitals chose not to employ a 
Director of Nursing and the then Charge Nurse role was often devolved into Clinical Nurse Specialist or Resource Manager positions. Executive level appointments of nurses to lead the profession are now back in place, with DHBs continuing to function within a market model responsible for distributing allocated resources to its population. Some 15 years after the reforms, having evolved from such significant changes, the title used at this DHB to lead clinical areas is Clinical Nurse Leader (CNL), and at the executive level it is the Director of Nursing. The CNL role carries formal accountabilities within this DHB as a health care provider structure.

The CNL is the nurse responsible for the leadership and management of one defined clinical or geographical area within the DHB setting. This could be, but is not limited to, an acute ward, clinic or a mobile community service. Clinical Nurse Leaders work across a myriad of specialities within primary, secondary and tertiary settings. Their patient population may require intervention of a medical/surgical nature, for example within a hospital, or a primary follow up within their homes. They can function in relative isolation, for example as a district nurse based in a remote rural setting, or within the confines of a ward, unit, clinic, theatre or department within a hospital. They lead nursing teams of various sizes and are responsible and accountable for the entire seven day week, 24 hours of the day, although most are usually physically present for only five days. The CNL, in whatever environ, is responsible for the maintenance of not only clinical standards, but also the implementation of relevant organisational policy whilst being mindful of the budgetary responsibilities. They are in charge of nursing staff in their setting and attend to this same staff by appraising their clinical performance on a regular basis. Cumulatively there are expectations of the role from the patients, the nursing staff, the multidisciplinary team, the organisation and the profession of nursing.

The DHB where the research was undertaken is one of 21 District Health Boards that service a New Zealand population of just over four million people. District Health Boards are charged with giving effect to governmental health policy and responding to the health needs of their defined population (New Zealand Public Health and Disability Act, 2000). 
New Zealand has approximately 45,000 nurses; 40,442 of them are Registered Nurses and just over half of all nurses work in DHBs (Clark, 2006).

I am one of these Registered Nurses. I am presently employed as a Nurse Manager responsible for Education and Professional Development in the DHB where the research was carried out. It was hoped that findings from this study around the role of CNL would support and inform any further development of this pivotal role during ongoing role reforms. The predicted benefits were to be the production of useful outcomes both professionally and to the organisation where the role was carried out. It was hoped that the project would result in the creation of new ways to support the nursing workforce to be more effective within the context of where they practiced. I advertised for six to 10 participants in clinical leadership positions to join me in examining the role of the CNL. Eight of us would research this senior nursing role within the nursing structure of a DHB setting. In addition, it was hoped that the seven CNLs as co-researchers would gain something useful from the research process and the production of knowledge.

I sought to research with this group of CNLs to create opportunities to solve problems for themselves and for other CNLs. Early, in the preparatory phase, when reading one of the works of Yoland Wadsworth (2001), I discovered the opening words quoted at the beginning of this chapter. Wadworth's inclusion captures beautifully what I wanted to achieve with this research. The remainder of this first chapter includes the purpose and reasoning behind the research, the situational context (the DHB) and its connection to the role of CNL. The practice and professional domains in which the CNL function within are also described. The chapter concludes with an overview of each chapter of the thesis.

\subsection{Purpose and Rationale}

There were two questions that underpinned this research project: how can the evolution of the role of CNL be further informed and how can the support of the role be further improved? These led to subsequent questions: what is the role of the CNL presently, and who should define this? Malterud (2001) states: “a researcher's background and position will affect what they choose to investigate, the angle of investigation, the methods judged 
most adequate for the purpose, the findings considered most appropriate and the framing and communication of conclusions" (p. 483). Action research was the methodology I chose to conduct this enquiry because central to this methodology is participation. Coghlan and Brannick (2005) assert that action researchers are concerned with the structure the knowledge will have, how it will be collected, who chooses the research agenda and who profits from it. Greenwood and Levin (2005) argue action research is a method of researching a question or line of inquiry that is committed to several basic elements, the endorsement of participation with a strong emphasis on democracy and action.

The potential for a partnership between myself as the action researcher (Coghlan \& Brannick, 2005; Greenwood \& Levin, 2005) and a group of CNLs resonated with my objective for the project. In order to look at how the evolution and support of the role could be both informed and improved, I wanted those in the role to collaboratively inquire with me. I would be inquiring as a researcher whilst an employee of the organisation where the research was conducted. From this position of employee, I had both observed and participated in clinical leadership roles. I had witnessed the effect of the reforms of the 1990s on clinical leadership as summarised by White (2004). White found that "the business model has left a legacy of economic accountability and an expectation that all aspects of healthcare provision are or will be able to be costed and this includes nursing care" (p. 192). I had considered how the selection and subsequent preparation for the role of CNL differed significantly throughout the organisation. Historically, the professional development component attached to the role was varied in content and informed by mainstream leadership/management theories. I was not convinced clinicians in the role were well supported or that a recent investment had been made to actually review the role and its accountabilities, although the position had been reviewed nationally in relation to salary (New Zealand Nursing Organisation, 2007). These perspectives, combined with my long standing interest in clinical leadership, resulted in the formation of the research questions and subsequent line of inquiry.

An amount of research preceding this inquiry has been completed. There is international agreement that the role of an effective clinical leader in nursing is key to the successful 
implementation of present and future transmission of health care (Cook, 2001; DrachZahavy \& Dagat, 2002; Doherty, 2003; Williams, 2004). Not only does the role act as an agent for success for the implementation of key organisational strategies but, as Cook argues, such leadership can directly impact on staff morale. Staff morale can decrease by constant change, a feature evident in health care (Tourangeau \& McGilton, 2004). Tourangeau and McGilton argue that continued instability and change through the delivery of health care will see tension persist between the supply of cost effective health care and the corresponding demand for health care workers. Clegg (2001) analyses this constant adaptation and classifies it as an ongoing stressor for nurses. Leadership style, Clegg asserts, is associated with a reduction in such stressors.

International research while acknowledging the pivotal place that the clinical nurse leader occupies, and the dual functions of the role (leadership and management), also points out the need to formalise the requisite professional development (Oroviogoicoehea, 1996; Cook, 2001; Duffield et al., 2001; Firth, 2002; Connelly et al., 2003; Stanley, 2004). These researchers have employed various qualitative and quantitative methodological approaches to direct their inquiry. There is international consensus about the significance of the role and the need to enhance the functions of the role with education on fiscal management (Mills, 2005; Kupperschmidt \& Barnhouse, 2006). The limited New Zealand research carried out on this role describes, similarly to international researchers, that the role is key in the successful implementation of organisational changes or initiatives (Drummond, 2002; Kan, 2002; Williams, 2004).

It is fair to say understanding about the role has grown from such work. This project aimed to contribute to this existing body of knowledge by working alongside those in the role to define the role. The background to the research objective was that I believed that role evolution and support should be cognisant of this vital perspective. The research outcomes from the project needed to be accessible to the communities they practised within and written in language that they could readily interpret. Communication of intent and usefulness of knowledge is extremely important to me. Greenwood and Levin (2005) reinforce my belief when they encapsulate the importance of the applicability of research. 
They criticised the number of university social scientists who interact as little as possible with the public on issues that are socially relevant and conduct research confined by language that is baffling to the people who are the recipients of it. Wallis (1998) sees action research as a plausible alternative to the more traditional approaches. The combination of the two commentaries of Greenwood and Levin and Wallis affirmed action research as my methodology of choice.

Significantly, and what positions the importance of this research, is a very recent editorial on clinical nursing leadership by Hyrkäs and Dende (2008). These writers observed from their review of clinical leadership in nursing that "we have not found a body of work that has captured the essence of the clinical nurse leader, the environment in which they operate or how and where the impact is felt" (p. 495). This project addresses some of these knowledge gaps.

Ethics approval for the project was granted by the Victoria University of Wellington Human Ethics Committee (see Appendix 1). In addition, I received permission from the Chief Executive Officer of the District Health Board (see Appendix 2) with a request to inform the Director of Nursing at the District Health Board of the research progress and outcome.

\subsection{The District Health Board: The Setting}

The responsibility for the provision of most public health services within New Zealand is devolved from the government to the DHBs. These organisations have evolved from the health service structure of the 1990s which, as already outlined, resulted in significant change for nursing. It is important to gain an understanding about the function of this DHB and its relationship with the role of CNL against the backdrop of such alterations. The formation of the DHBs was a direct result of the New Zealand Public Health and Disability Act (2000), as the legislative response by the government of the day to strengthen the public health system. The intention of the government was stipulated within the following objectives of the above Act:

- to establish DHBs across the country; 
- to require the creation of the New Zealand Health Strategy and the New Zealand Disability Strategy with an annual report to Parliament on the progress of these strategies;

- to foster co-operation between the health care agencies; and

- to encourage local community input to decision-making about health and disability support services.

The DHBs are charged with responding and giving effect to health related policy from government. The elected and government appointed boards are answerable to the Minister of Health for the appointment and tracking of the performance of the Chief Executive, the strategic direction of the board, and the compliance with the law and the Crown expectations relating to health service. The Minister of Health is accountable to Parliament for the outcomes in the health and disability sector. The main focus of each district is on their region's population, working within the apportioned resources to improve, advance and safeguard the health of their population. The DHB has dual functions, as both funder and provider of services.

The DHB where this research was conducted is directed by three central advisory committees one of which is a Hospital Advisory Committee. This advisory committee monitors the performance of its hospital and related services. There are a range of responsibilities which the DHB must meet, including but not limited to, making public their District Strategic Plan and their Annual Plan, both of which include their strategic direction and intentions (New Zealand Public Health and Disability Act, 2000). The Strategic Plan of 2002 - 2011 was developed to deliver on the community's perception of their health needs and the systematic health needs analysis relating to the region's population. The then Chief Executive Officer (CEO), in introducing the Strategic Plan, stipulated that the strategy needed to have a strong focus on the community and involve providers and consumers in decision-making. This focus arose from extensive consultation about the way the providers, consumers and staff wanted their health organisation to operate. The Strategic Plan addressed issues that the community and needs assessment deemed important and identified five specific regional health needs priorities. Nurses have 
a key role in addressing the community's needs and in helping DHBs deliver on the government and local health priorities. Essentially, the structure of the DHB can be summarised by describing three: levels that of governance, management and service provision.

The governance remains the function of the board of the DHB. This board is advised by various councils and committees, including the three core advisory committees, as dictated by the New Zealand Public Health and Disability Act (2000). The management function is overseen by the CEO, with the service provision including the provider division. This division provides community, secondary and tertiary health services and it is the division of the DHB with which most members of the public will have had interaction. The provider division encompasses hospital and community health settings, which members of the public may need to access through any one given health episode. Within the provider arm, there are differing management positions but the structure encompassing the role of the CNL can fall within either a hospital setting or community setting. The position of $\mathrm{CNL}$ is a number of management layers away from the board of directors that govern this DHB and are responsible for working within apportioned resources from the government. Although significantly removed from the board, Chief Executive and general management, it could be argued that the people of the district may perceive this head nurse, the sister, the $\mathrm{CNL}$ of the ward, clinic or department, community setting as a recognisable face in such a structure.

\subsection{The CNL Within the District Health Board}

The role of the CNL in the $\mathrm{DHB}$ and the recognition this role carries for the public, is largely due to the CNL being the conduit to the delivery of health services within a multiplicity of settings. For example, all members of the multidisciplinary team operating within their specific clinical area such as doctors, physiotherapists, social workers, and dieticians can relay various pieces of information to the CNL sometimes all within an eight hour shift. The CNL is the clinician with whom the patients and families may communicate in respect to a health care episode, expecting them to be possessive of all facets of the admission. It could be assumed within the context of a health-related episode 
requiring intervention that very few individuals would even think about the wider DHB structure.

The CNLs' duties and responsibilities include, but are not limited to, retaining information about patients' progress throughout the patient health episodes, contributing the nursing perspective of patient care to the multidisciplinary team discussion, and guiding nursing staff in clinical standards. This DHB, in parts of its provider arm, operates a patient placement system. Some CNLs oversee the placement of patients after assessing her or his available bed status and responding to requests for both arranged and urgent admissions of patients. Consequently, this particular group may organise the admitting of patients requiring acute medical intervention and those requiring pre arranged or elective intervention. A ward may well include several patients who are not connected to the designated speciality of that ward. Therefore, some CNLs need to possess a clinical portfolio that not only includes the ward speciality profile and accompanying nursing standards, but also covers the patient who may be admitted to their area outside of this designation.

These types of duties or responsibilities of the role are typically defined within a position description on which performance is measured usually on an annual basis. Most, if not all CNLs are party to a collective senior nurse agreement which determines the employment conditions. This is complemented by a position description covering general role expectations. Such a document, from within the DHB where the research was undertaken, dated 2005 shows the nature and scope of the role. At the beginning of the document the purpose of the position includes: "the primary responsibility of the Nurse Leader is to lead, guide and manage the clinical nursing team in the promotion and delivery of safe and effective patient care and outcomes" (p.2). This purpose is linked to various accountabilities, one of which is the "provision of quality, comprehensive care and ward and unit team co-ordination" (p. 2). This accountability has 14 performance measures, which include the responsibility of managing workload, monitoring nurses, managing beds and co-ordinating meetings with the multidisciplinary team and the patients' families. Another accountability includes ensuring effective staff management and development, 
and has 10 matching performance measures, These measures include monitoring of the annual and sick leave of their nursing staff, as well as completion of their annual performance reviews. Also, the CNL should "provide leadership, guidance and support to staff" (p. 3) with a separate accountability that refers to managing a cost centre. Eight performance measures match this one and include managing the clinical area budget within agreed parameters in conjunction with their manager. A further accountability refers to the provision of clinical support and guidance by the clinical nurse leader to the nursing staff. This sees performance measured against three criteria: provision of clinical support advice, guidance to ward/unit/team staff and provision of direct expert patient care (p. 4). There are in total 10 accountabilities with 69 matching performance measures, including but not limited to, the responsibility of the role to implement a 'Continuous Quality Improvement' programme, as well as an effective 'Risk Management' programme. There is also an expectation that the CNL will consult with the Director of Nursing on nursing matters of DHB significance.

Towards the end of the position description are four descriptors listed under the heading "problem complexity" (p. 8) of the role. Two of the four include that "the incumbent will be responsible and accountable for the clinical service delivery, staff and financial management of their clinical area" (p. 8). Secondly, there is the need to balance clinical expertise and mentoring of staff with the demands of a multidisciplinary service and budget. The role requires extensive use of problem solving skills and knowledge as well as intense interpersonal interactions with patients, family, the public, staff and management in often demanding situations.

Selection to the role is not entirely dependent on formal academic qualifications and ongoing professional development is individualised. Upon successful appointment, orientation differs widely both in content and duration. Opportunities to attend yearly education days are promoted and encouragement plus funding support may be accessed to commence or continue post registration qualifications. Regular forums are held to update changes to all facets of service delivery that may affect the areas the CNL leads. In addition to this situational context in or of the DHB, the CNL is also part of the 
professional context of nursing in New Zealand. Nursing as a profession has seen not only the cost corporate model being introduced to health in the nineties but has encompassed changes to how nurses are trained.

\subsection{The CNL Within the New Zealand Nursing Environment}

The role of CNL has and will continue to develop in response to change. The health reforms of the early 1990s resulted in a tension developing between the humanism of nursing and the managerialism expected with these changes (Bamford \& Porter-O'Grady, 2000). The notable changes to the preparation to practise as a nurse in New Zealand can be traced back to the release of the Carpenter Report (1971). This report recommended transferring training of Registered Nurses from a hospital base to a polytechnic education. This resulted in the closure of the last hospital based nursing school in 1992 (Keith, Peat, \& Marwick, 2001). As these authors further describe, the 1990s ushered in more rapid changes with a degree programme replacing the diploma qualification. As of 2001, all New Zealand nursing programmes leading to registration as a Registered Nurse were at degree level.

The settings and how the students of such programmes work alongside existing registered nurses have changed in response to internal and external political forces. The transfer of internal politics into policy can be exemplified by strategies such as health of older people (Ministry of Health, 2002), Maori health (Ministry of Health, 2002), and primary health care (Ministry of Health, 2001). The commitment to cultural safety and the Treaty of Waitangi as the nation's founding document explained within the Nursing Council of New Zealand (2002) guidelines for cultural safety also direct the preparation to nurse and present practise. The Health Practitioners Competence Assurance [HPCA] Act 2003 was introduced to protect the safety of the public by providing mechanisms that ensure the life long competence of health practitioners, including nurses (HPCA Update, 2003). The Nursing Council of New Zealand, the licensing body of New Zealand nurses, released a set of competencies that Registered Nurses must satisfy in order to continue to practise. In addition to satisfying these competencies, the nurse seeking renewal of an annual practising certificate must declare hours practised and professional development. 
Emanating from these internal factors is the influence the international nursing community has on the New Zealand nursing body. New Zealand nurses are active in attuning and responding to international nursing dialogue. They contribute to topics that include the cultivation of magnet hospitals (Huerta, 2003) and the potential blurring of professional boundaries as described by Melling and Hewitt-Taylor (2003). Other examples include involvement in global nursing research that examines and contributes to the work surrounding reconstruction of health care as outlined by Schulz (2004). Nurses in New Zealand in 2008 constantly assimilate all of this variety and some of these nurses practise as clinical nurse leaders.

Clegg (2001) although not from this New Zealand perspective, acknowledges that clinical leadership of nurses is a crucial role in the maintenance of equilibrium within the constant of change. Whilst it is necessary to be equipped to manage resources and lead nurses, much more will be necessary and expected of the CNL to sustain nurses through such activity. Nurses will increasingly need to possess sound business skills, financial planning and quality assessment skills (Keith, Peat Marwick, 2001). New Zealand nurses, as summarised in their Strategic Review of Undergraduate Nursing Education report to the Nursing Council of New Zealand, will have to be culturally safe, flexible, knowledgeable and consultative in their approach. Nurses will have to respond to even greater accountability of their utilisation of the health dollar. This responsibility will be coupled with the diverse settings in which nurses and nurse leaders will practise. The nurse could be a sole practitioner or a nurse in a large hospital environment.

Lastly, the CNL, when sustaining their teams through such progress, do so within various locations and are charged with the care of aging communities and populations facing increasing social complexities. In my 28 years' association with this DHB, I have noticed that it is now common practice within the acute care environment to see signs stating: "Verbal or physical abuse will not be tolerated". Clinical areas are locked after certain hours and all staff, not just clinicians employed in the acute care environment, require visible personal identification. Security guards are now often present within this setting and monitoring includes the use of video surveillance. CNLs in remote rural settings have 
similar challenges but to a differing degree, with the need to lead their teams and educate them on their personal safety when visiting patients. CNLs will need to have a myriad of skills within the cost competitive model caring for a society of ever increasing complexities whilst providing framing, interpretation and support for the nurses they lead.

\subsection{Summary}

In this thesis I document all stages of the action research project I began in October 2005 when I set out to explore clinical leadership in nursing within a New Zealand setting. In the first chapter I have identified my objective for this study, plus the purpose and reasoning behind the inquiry and approach chosen. I have offered a general explanation of the role and where it is positioned within a DHB. In addition, the relationship of the role to the delivery of health care, the nursing profession and the practice domain is discussed.

In Chapter 2, I include and expand on the indicative literature on leadership in nursing and on clinical leadership. The relationship the literature review has to the research inquiry is discussed as well as how the review findings relate to the aim of this project. The value this inquiry would have to the existing body of knowledge is also considered.

Chapter 3 details the action research methodology, opening with an overview of qualitative and quantitative research. The diverse origins of action research and agreed features of this approach are described. Action research and its application to nursing inquiry in general and its suitability in researching the role of CNL are discussed.

Chapter 4 examines the methods and processes relating to the application of action research to the data collection and analysis phases. The two phases of the research (interview and action research meetings) are introduced. The recruitment of the participants and the processes attached to the interviews and action research group meetings are presented. The chapter also explores issues of ethics, rigour and the author's worldview. This includes the perspective of conducting research within an organisation where you are employed. 
Chapter 5 sets out the analysis and interpretation of Phase One of the research - the individual interviews. This interpretation of interviews from the voices of the individual CNLs revealed content relating to the role, attributes, skills and knowledge requirements and the experience of being a CNL. This interpretation took the form of themes to be presented to the action research group.

Chapter 6 introduces the next three chapters which cover the start of Phase Two the action research meetings. This chapter accounts for the establishment of the action research group and lays out how the group narrowed their focus in the first three meetings from the large number of themes presented down to two themes. The group/facilitator dynamic is highlighted with planning, acting, observing and reflecting (action research) activities being illustrated in this and the remaining chapters. Significant changes, represented pictorially, are traced from this chapter onwards as well as inclusion of quotations from group dialogue.

Chapter 7 describes the group's analysis of one of the two interview themes. This was related to the conflict that occurs in the role between the leadership and management accountabilities. The chapter presents the interpretation of meetings four to seven which concentrated on this conflict and the agreement reached by the group as to the components of the role of clinical nurse leader.

Chapter 8 details the remaining action research meetings and describes the group's activities in relation to coalescing for the future CNL community. The preparation, professional development and support afforded the role is examined with a proposal for further professional development for the future agreed upon. Consultation about this proposal with the wider organisational stakeholders is discussed. This chapter also presents the details of the evaluation of the process by the group.

Chapter 9 presents an overview of the thesis and a discussion on the findings as they relate to recent relevant literature around this clinical leadership role in nursing. The insight and recommendations for stakeholders in this research as well as opportunities for future 
research are examined. The challenge of conducting research in the organisation where you are employed is explored further. Reflections draw the thesis to a close. 


\section{CHAPTER 2. LITERATURE REVIEW}

\subsection{Introduction}

This chapter introduces the literature review and its importance to the research. The search strategy employed to look at leadership in nursing and clinical leadership is discussed. How and why certain literature was accessed is explained and how the results relate to the research inquiry is outlined.

The initial literature review from 1993 to 2004 was not intended to be a saturated representation of the existing literature surrounding both subjects. Rather it was intended as the foundation to launch the action research project. The literature from 2005 to present was accessed after exiting the field in 2006 in order to obtain the recent research findings and recommendations regarding clinical nursing leadership. The earlier literature is presented in this chapter, while the latter literature is included in the concluding chapters at the end of the thesis.

The decision to access only indicative literature developed from my already described ongoing interest in the topic and subsequent beliefs about leadership in nursing and clinical leadership. Parallel to observing the effect on clinical leadership from the reforms of the 1990s and my summation of the lack of a recent role review, or support for nursing leadership in the DHB, I became aware of an interesting trend. This trend related directly to professional development of clinical leaders in nursing. I believe that the concept of leadership in nursing as well as clinical leadership has been influenced by mainstream non nursing leadership or management theories and this influence has shaped the professional development. This has also led to a limited approach in the exploration of nursing leadership as some research utilises these as theoretical frameworks to define what type of leadership may be effective in clinical leadership. These results, albeit limited and not representative of all research, when blended with the non nursing influence on leadership in general produce an interesting combination.

Nurse leaders clinical and otherwise, I have observed, are encouraged to define their leadership style based on mainstream theories. Curriculum content or professional 
development offered to nursing leaders is drawn from recent non-nursing leadership management theories such as transformational leadership. Texts indicating the curriculum to be used in nursing leadership education draw on such theories. I had also questioned whether this defining of leadership style and education based on mainstream non-nursing management and leadership was particularly useful for clinical nursing leaders and I was interested in whether my claims and assumptions were reasonable to make. My continued interest, my observations, my lived experience and, in parallel, my awareness of this trend for restricted research focus and subsequent professional development all informed my objective for the research. To reiterate, this was how can the evolution of the CNL role be further informed and how can the support of the role be further improved? Questions encompassed in this include what is the role and who should define it?

This literature review therefore concentrated on describing what literature was already informing the evolution of the role and what support was recommended. In addition, who was involved in these studies, how were they involved and what were the reference points or framework that knowledge claims were made from are referred to where appropriate. If there were studies shifting the focus away from non nursing leadership theory to unique nursing related recommendations I was interested in their aims, design and usefulness for nursing leaders in a clinical setting.

\subsection{Search Strategy}

The purpose of the review was therefore to draw on the literature that sought to define and advise on nursing and clinical leadership against such personal beliefs and my ongoing inquiry. The dates 1993 to 2004 were significant in that that they covered the period of notable change to the health care delivery model in New Zealand in which I had also observed and studied the changing role of the CNL. I was interested in literature that linked to nursing leadership in general, not only literature that specifically stated the term clinical nurse leader, thus at the outset a broad search was undertaken. The databases accessed were Cumulative Index in Nursing and Allied Health Literature (CINAHL), Proquest, Medicine and Allied Health collections. The keyword 'nursing leadership' combined with the time frame and full text availability resulted in 1084 hits. Leadership and nursing both 
as major subject headings resulted in 247 hits and when further limited to publication type 'research' saw 29 articles displayed. Clinical leadership and nursing as keywords combined with the pre-selected dates plus research and in full text access equalled 65 hits.

Variation in titles such as nurse leaders, clinical nurse leader, head nurse, ward sister, nurse manager and charge nurse were used to search for clinical leadership in particular. These were also combined with particular publications including but not limited to the Journal of Advanced Nursing, Journal of Nursing Management and Journal of Nursing Administration. Further advanced search parameters, such as country specific, database specific headings, research only and thesis work were applied, which resulted in the inclusion of some opinion led commentary. A search was run on the National Bibliographic Database (Te Puna) of New Zealand to access thesis work. Additionally, I pursued the writings of prominent authors nationally and internationally in the field of clinical leadership within the dates described. Recently published texts on leadership/management theories and their application to nursing were accessed to determine what, if any, non nursing leadership/management theory informed curriculum content of nursing leadership courses.

The articles obtained were read and key concepts extracted with the intent of seeing from what or whose perspective they had been completed. In addition, how the research informed the existing knowledge base and what recommendations had been made for future inquiry were captured.

\subsection{Leadership and Nursing}

The search strategy produced results that upheld my claim that the broad topic of leadership and mainstream management leadership theories had a link to nursing. It also produced others that did not. Some time ago McCormack and Hopkins (1995) suggested that like other areas of nursing, external sources of knowledge have influenced the growth of nursing leadership and management theories. This assertion has been endorsed by Marquis and Huston (2000) and Moiden (2002). The history of development of such theories and acknowledgement of leadership styles is outlined in the nursing text Roles and 
Management Functions in Nursing: Theory \& Application by Marquis and Huston (2003). Leadership theories such as servant leadership (Greenleaf, 1970), transformational leadership (Burns, 1978) interactional leadership or reengineering management (Hammer \& Champy, 1993) are referred to in this book. This publication exemplifies how readily accessed nursing leadership texts refer to these mainstream theories when introducing the content of their books. Greenleaf, Burns and Hammer and Champy are not nurses but, as Moiden suggests, their theories are often used when discussing the attributes that allow effective nursing leadership to take place.

Evidence of utilisation of such theories can be found in several studies. Bowles and Bowles (2000) sought to compare the degree to which first line nurse managers in a Nursing Development Unit and a non Nursing Development Unit demonstrated transformational leadership behaviour. The results indicated that Nursing Development Unit leaders have higher degrees of evidence of transformational leadership than their counterparts. Upeniek's (2002) work further exemplifies researching into nursing leadership using non-nursing theory, in this case Kanter's (1977) theory of organisational behaviour. Kanter examined what constituted successful nurse leadership and if there was a link between the level of success and existing organisational infrastructure. Sixteen nurse leaders were interviewed for their understanding of leadership traits and a link was made between access to resources and effective nursing leadership. Stordeur, D'Hoore and Vandenberghe's (2001) study looked at the effect of work stress and the nursing leaders' transformational and transactional leadership and the effect on the levels of emotional exhaustion among their staff. Welford (2002) argues that transformational leadership is principally suited to nursing leadership. Tourangeau and McGilton (2004) invited 73 nurses, consisting of pairs made up of leaders and aspiring leaders, to use a 30 item tool called the Leadership Practice Inventory (LPI) to measure their leadership behaviour. This 30-item tool had been developed by non nurses Kouzes and Posner in 1995. The above studies illustrate how the evolution of nursing leadership in general has been influenced by a dialogue derived from mainstream leadership/management theories as explained by McCormack and Moiden and found in works by Marquis and Huston. Some authors, 
however, adopted new approaches to understanding leadership in nursing removed from such instruments or theories.

Antrobus and Kitson's (1999) study examined contemporary nursing leadership in context without reference to general leadership theories. Twenty-four nursing leaders identified by their peers as effective nursing leaders were interviewed. The results questioned the political success that nursing leadership has had when concentrating on "internal professional concern" (p. 747). Antrobus and Kitson recommended that further research is needed into nursing leadership; that consideration should be given to establishing a nursing national policy unit; and that the creation of a career pathway for nursing that includes political, management academic and clinical areas is required. Hennessy and Hicks (2003) conducted a Delphi study in Europe which identified the characteristics considered to be the most pertinent in a Chief Nurse. The experts were drawn from appropriate personnel from government level health departments, senior health professionals alongside other people agreed as having a key perspective on the subject. The results included a profile of characteristics considered to be pivotal to the role of Chief Nurse that could be utilised for selection and the future development of Chief Nurses across European states.

Sullivan, Bretschneider and McClausland (2003) based the design of a leadership programme for nurse managers on results from a qualitative study that used focus groups to collect data from all levels of nursing leaders. This study, with 94 participants, allowed those within the role to be involved with their professional development. Laurent (2000) and Porter O'Grady's (2003) contributions are examples of useful non-research opinionled commentaries. Laurent proposes the use of Ida Orlando's model for nursing to provide a nursing foundation for nursing leaders to use both in management and leadership. PorterO'Grady suggests leaders in health care need to move away from the broad based themes of leadership behaviour and become more self and socially aware. The context in which health care leaders operate in is, he asserts, fast paced and driven by innovation and technological change. He concludes that leaders must craft a new context for workers in order for the profession to connect with the realties of the environs they practice in. These commentaries like Porter-O'Grady, alongside research such as Antrobus and Kitson's 
(1999), Hennessy and Hicks (2003) and Sullivan et al., symbolise the efforts in nursing to move away from historical devotion to mainstream theories of leadership and management. The indicative literature on leadership in nursing contains both nursing research utilising non nursing leadership management theory and studies utilising evidence from those in the role to inform nursing leadership knowledge.

\subsection{Clinical Leadership in Nursing}

The search for literature related to clinical leadership uncovered evidence of devotion to non nursing leadership and management theories but, as above, contained evidence of nurse researchers distancing themselves from this attachment. Exploration of clinical leadership in nursing has been generated from various parts of the globe including the United Kingdom (UK), Spain, Singapore, Israel, United States of America (USA), Australia and New Zealand (Oroviogoichoehea, 1996; Cook 2001; Duffield \& Franks, 2001; Firth, 2002; Kan, 2002; Connelly, Yoder, \& Miner-Williams 2003; Stanley, 2004; Williams, 2004). There were no general differences in the type and focus of research by country. The researchers, employing both qualitative and quantitative approaches, have studied role definition, attributes deemed necessary for effectiveness, the pivotal nature of the role and suggested professional development for the role. Nurse researchers have been made attempts for some time now to define the role.

\section{Defining the Role}

McCormack and Hopkins (1995) concede that although the following definition of clinical leadership is inadequate it does speak to the critical elements of clinical work and the nature of authority and influence. He states: "The vision of providing professional nursing leadership by engaging in clinically based work as an expert practitioner-thereby exerting influence, power and authority effectively consistently and constantly within a specific sphere of influence" (p. 162). Research, undertaken some years later, looked at what literature addressed the role specifically as a separate identity of nursing leadership.

Cook (2001), as a prominent author on leadership and nursing, has completed studies that use mainstream theories and completed further work that does not rely as heavily on such 
references. Firstly, he traced the renaissance of clinical nursing leadership across the UK, the USA and Australia between 1992 and 1997. Cook used in-depth interviews with clinical nurse leaders in the United Kingdom and supplemented his data by study tours to the remaining countries. The study findings indicated that these countries used leadership styles such as transactional, transformational connective and renaissance, and that styles are not necessarily country-specific but are aligned to individual settings. He critically reviewed leadership themes within nursing that were derived from the aforementioned countries.

Firth (2002), from the United Kingdom perspective, explains that various titles such as ward sister, nurse, charge nurse, or ward manager are used to describe the clinical leader of nursing in practice settings. She continues that despite the variation in name, the role of clinical leadership combines clinical and administrative knowledge. Her qualitative study included interviewing and observing 12 ward managers. Findings included that the ward managers found the combination of having to develop staff and improve the quality of services provided can be problematic.

Similarly, Williams, McGee and Bates (2001) when researching senior nursing roles in the United Kingdom, found that ward managers reported difficulties balancing the managerial and clinical practice of their roles. Duffield et al. (2001) study specific to Australia is representative of the evolution of the traditional ward sister into the present model that combines both administration duties with clinical leadership. Nurse managers and charge nurses were observed to examine how much time they spent devoted to direct patient care as opposed to unit related management.

Doherty (2003) and again Porter O'Grady (2003) offer opinion led commentary. Doherty states that: "At the beginning of the $21^{\text {st }}$ century ward sisters and charge nurses are viewed as having a pivotal role in health care, perhaps with little clarity about what this means in practice" (p. 35). Porter O'Grady suggests that in the future, nurse leaders need to be self and socially aware and invest in relationship management. Commentaries such as these and research into role definition accompany information on what is leadership and what is 
management in text devoted to nursing leadership. Leadership Roles and Management Functions in Nursing: Theory \& Application by Marquis, Huston and Jorgensen (2003) is such a text and includes definitions of leadership and management. Discussion on whether clinical leaders are more leaders than managers or whether they should be possessive of both is presented. Non-nursing leadership and management theories feature in this book. Similarly scrutiny has been directed as to what represents effective attributes and competencies in the role of clinical nurse leader.

\subsection{Effective Attributes and Competencies}

The literature review revealed research on attributes and competencies, including the work of Chiok Foong Loke (2001), Cook (2001), Connelly et al. (2003) and Stanley (2004). Chiok Foong Loke surveyed 100 nurses and nurse managers in Singapore and concluded that effective clinical nurse leaders enable others by promoting self belief resulting in a rise in competence. They act as role models, regularly acknowledging individual success. Cook, in his second study, although referring to leadership typologies, provides a unique collection of attributes of the clinical nurse leader. He identified five aspects of clinical leadership unique to nursing. These attributes are described as highlighting, respecting, influencing, creativity and supporting. Highlighting is the ability of the clinical nurse leader to invent new routes to completion that arose from their pursuit of further knowledge underpinned by their inquisitive behaviour. Existing nursing knowledge and procedures are questioned, and from this enquiry, original solutions are produced. Respecting refers to the correct interpretation by the clinical nurse leader of signals from both health care personnel within a defined clinical setting and the organisation that governs that setting. This correct interpretation allows for insightful responses from the nurse leader to be formulated. Influencing is the ability to predict potential in their colleagues that will allow them to independently function and translate that confidence to the individual concerned. Creativity describes the attribute that clinical nurse leaders possess that sees subscription to the shared vision of a health care organisation but also sees the ability to remain calm when chaos may arise from the implantation of that vision. 
Finally and importantly, supporting concerns the capability to support and maintain equilibrium through times of change and uncertainty.

Connelly et al. (2003) produced a list of 54 competencies relating to the role of charge nurse, a role equivalent to a Clinical Nurse Leader. These were then grouped into four categories: clinical/technical, critical thinking, organisational and human relations skills. Connelly et al. assert that having skills and knowledge in each of these categories is necessary to function as an effective charge nurse. The ability to act as a clinical resource, delegate workload, manage crises and change, demonstrate caring, role model and build teams is a sample of the identified competencies.

Stanley (2004), through a pilot study carried out in a paediatric unit in the United Kingdom, uncovers similar skills the Clinical Nurse Leader may possess. The results indicate that ability to cope with change, flexibility in responses to nursing staff, clinical expertise, consideration of staff and supportive behaviour are associated with this role.

In summary, research has captured the attributes of a clinical leader from the perspective of their relations and interactions with their communities as well as identifying other qualities such as clinical expertise. Not only has the role been researched to define the skills and attributes of the CNL, but attempts have also been made to establish the position the role has in the delivery of health care in various clinical settings.

\subsection{Pivotal Nature of the Role}

There appears to be general agreement in the literature reviewed that the role is pivotal to the organisation where it is included. Wilmot (1998) explored how it was in the United Kingdom for charge nurses to shift their role to ward manager. She concluded after interviewing and surveying 47 Charge Nurses plus others about the change to their role that the majority of charge nurses wanted the change seeing the role as key for the future. The paper acknowledged that whilst the new role allowed those in the role to influence practice, change was stressful. Doherty (2003) introduces how the UK equivalent to clinical nurse leader, that of ward sister, was considered pivotal to the review of the 
National Health Service in the United Kingdom. This pivotal nature links to organisational objectives which includes change.

Kan's (2002) New Zealand research concerns itself with understanding the process by which nurse leaders function when leading their nurses through such organisational change. One of the recurring themes that emerged through her exploration was that nurse leaders had great potential to achieve change in the health care environment and due to factors both internal (cultural) and external (societal), this potential was often repressed. Williams (2004), also from a New Zealand perspective, utilised a hermeneutic phenomenological approach to explore the experiences of four Charge Nurses with the view of interpreting their experiences of being new to the role of Charge Nurse. Her conclusions included recommendations to recognise the complexity of the role, to prepare and support those in the role and for organisations to value the Charge Nurses' contribution. Both the Marquis et al. (2003) text and research acknowledge that a clinical leader's ability to cope or interpret change for the sake of those they lead is a marker of effectiveness (Cook, 2001; Connelly et al., 2003; Stanley, 2004). Whilst texts and research have examined the attributes and pivotal nature of the role, the professional development necessary for the role has been also explored.

\subsection{Professional Development}

Gould, Kelly, Goldstone and Maidwell (2001) in a United Kingdom-based research project interviewed 15 Clinical Nurse Managers and posted a survey derived from results of these interviews to a further 182 Clinical Nurse Managers. The survey results indicated that the nurse managers felt clinically confident but lacked certainty in their ability to deal with human resource and budget related issues. Gould et al. concluded that this evidence could inform future professional development of the role. Marquis et al. (2003) delineate what areas of managing or leading should be developed for the future. Energy needs to be expended on the development of enabling, which is allowing nurse leaders or managers to become coaches or mentors. Clinical supervision can be utilised following preliminary education, allowing nurse leaders to operate more effectively, whilst encompassing the necessities of their organisations (Johns, 2003). The research by Johns did note, however, 
that the clinical supervision model has limited impact on the growth of leadership ability but did allow dialogue to problem solve. Sullivan et al. (2003) based on qualitative findings from senior nurses in management inclusive of nurse managers recommend that leadership programmes be structured around such evidence. Krugman and Smith (2003) summarise it is essential to continue to evaluate the effectiveness of clinical leadership programmes. Connelly et al. (2003) recommends real life scenario-based education to be utilised when educating charge nurses. Thorpe and Loo (2003) from a Canadian perspective explore the emerging role of what they termed first line nurse managers or those that oversee the daily running of nursing units. Their study involved a triangulation of investigators utilising interviews and a Delphi study as well as qualitative and quantitative data. They recommend that these first line nurse managers be provided with training and development as well as a "supportive work environment" (p. 329). Thorpe and Loo conclude that any future education should be based on the unique needs of these nurses. Other writers argue that the professional development of those in the role needs to be formal and structured commencing with education on leadership management, finance and quality management (Williams, 2004). Cook and Leathard (2004) expanding on Cook's (2001) research which identified the five previously described key attribute, argue that present preparation for clinical leadership is incomplete. Their reasons include absence of agreed definition or descriptors of clinical leaders, clinical leaders having voluntary programmes which are uni-professional, and that these programmes are "...disconnected from wider organisational development strategies" (p. 442).

\subsection{Conclusion}

The literature review from 1993 to 2004 was the foundation for this study. It was the link between my observation and consideration of the impact the change of health care delivery in the nineties had on clinical leadership in nursing, my beliefs on the evolution of this role and my research objective. The indicative approach to the literature review was purposeful in contesting these beliefs that the research activity had been restricted to theoretical framework derived from non nursing/leadership management theories and this was not only driving education for clinical leaders but describing expected behaviours. It linked to 
the research question of how can the role be further informed and the support be further improved, separate from the research approach that defines the role in relation to such theories.

The results of the review upheld my claim that mainstream leadership and management theories were being utilised for research on nursing leadership. However, the literature review revealed studies on both leadership and clinical leadership that did not utilise such external sources of knowledge. These have produced some unique results when describing how Clinical Nurse Leaders work. The literature review process demonstrated that it was worthwhile when exploring clinical leadership to do just that - seek out those in the role. This provides a pool of data to draw theory and knowledge that may be more pertinent and useful than data analysed using external knowledge. It reinforced to me that action research was the methodology of choice. Action research offered an opportunity for those in the role to define the role and therefore inform the evolution of the role and any future support of the CNL in a New Zealand setting. 


\section{CHAPTER 3. METHODOLOGY}

\subsection{Introduction}

This chapter describes the methodology of action research which was used to explore how the role of CNL could be further evolved and how the support of the role could be further informed. I was interested in working with nurses in the role and to co-operatively inquire about the role believing this approach would produce a more pertinent contribution for future role development and support. My intention was that this study would be undertaken based on the principles of action research, which is participative, qualitative and cyclic in nature. The principles of action research are captured and organised under the broad heading of qualitative research then action research is explored in depth.

\subsection{Qualitative and Quantitative Research}

In planning the study I commenced with the understanding, as described in Greenwood and Levin (1998) that "Action researchers accept no a priori limits on the kinds of social research techniques they use... Formal quantitative, qualitative and mixed methods all are appropriate to differing situations" (p. 7).

There is general agreement by many researchers that qualitative research, often where action research is categorised, supports the existence of multiple realities and a commitment to those participating in research. The qualitative research design usually seeks out participants who have first hand experience of the phenomena under study. Denzin and Lincoln (2005) state: "Qualitative research is a field of inquiry in its own right. It crosscuts disciplines, fields and subject matters. A complex interconnected family of terms, concept and assumptions surround the term qualitative research" (p. 2).

Qualitative research is associated with descriptive, interpretive and critical perspectives or theories. Descriptive research is concerned with correct description of phenomena whilst an interpretive perspective examines how people make sense of their lives through their definition of their lives (Gillis \& Jackson, 2002). The critical perspective, with its ensuing 
theories, assumes that the behaviour of humans is a result of differing groups endeavouring to promote their interests at the cost to less powerful groups of individuals. Denzin and Lincoln (2005) endorse the critical and interpretive perspectives within qualitative designs but acknowledge that seeking out a single definition of qualitative research is neither useful nor appropriate. They express: "The open ended nature of the qualitative research project leads to a perpetual resistance against attempts to impose a single umbrella like paradigm over the entire project" (p. xv).

Conversely, quantitative research adopts the approach that in order to understand a phenomenon it is necessary to quantify it, reduce it to numbers and utilise methods, such as precise measurement or testing of hypotheses. It is associated with the positivist perspective, which supports an objective approach to reduce bias and seeks out facts not sentiment (Gillis \& Jackson, 2002). The empirico-analytical paradigm informs this scientific method with philosophical tenets that include reducing the phenomenon to parts to explain and predict how they function. Quantification is used to translate the data gathered by this type of research into numerical data. The processes used also rely on objective observation within a value free context (Fossey, Harvey, McDermott, \& Davidson, 2002).

Researchers studying clinical nurse leadership have successfully used both quantitative and qualitative methods. I consider both approaches to be useful, depending on the objective of the research, the method of data collection and the intended benefits and scientific value to the existing body of knowledge. Onweugbuzie (2000) encourages both quantitative and qualitative purists to "strive for epistemological ecumenicalism by using mixed methodological approaches" (p. 3). There is usefulness in combining numerical objective data with personal subjective data and adding a critical lens to a response. However, whilst supporting Onweugbuzie's stance, I chose to pursue my inquiry in a study based on the principles of action research, because my initial intention was to assist CNLs in their work. Hope and Waterman (2002) acknowledge that other forms of research also set out to improve situations but they suggest that action research may be viewed as valid as it attempts to improve social situations. 


\subsection{The Beginning of Action Research}

Reason and Bradbury (2006) acknowledge the diverse origins of action research and the drawing of inspiration from pragmatic philosophy, critical thinking, democracy, liberationist thought, humanistic and transpersonal psychology, constructionist theory, systems thinking and, latterly, complexity theory. This diverse range of roots can be illuminated by identifying the domains where the action research approach has been used, from questioning the development of the modern world to questioning organisational changes. Reason and Bradbury describe further how it can be an inquiry relating on a personal level to everyday life or an endeavour to connect with whole communities. Hope and Waterman (2002) concur that action research assumes many forms and "has been laid claim to by more than one school" (p. 123). This field of qualitative research does not draw its explanations from a collection of principles, but rather its fundamental nature includes a dedication to the naturalistic, interpretive approach (Gillis \& Jackson, 2002). According to Hope and Waterman, most researchers locate action research within the realm of critical theory whilst others locate it within the constructivist/interpretivist paradigm.

DePoy, Hartman and Haslett (1999) are clear about what critical theory is not, (a research approach), but they provide scant explanation of what it is. Whether critical theory is philosophical, political or sociological in origins is debated, but they conclude that those who are devoted to critical theory use it to understand the human experience and effect change in society. De Poy et al. explain the origins of critical theory can be traced back to Social Institute of the Frankfurt School in Germany. Critical theorists relocated to the United States following the Nazis rule of Germany and further developed critical theory as knowledge to examine social, historical and political contexts. They conclude that action research and critical theory both place importance on a democratic process. Fontana (2004) describes the critical tradition utilised in nursing research drawing from the Frankfurt school and theorists such as Jurgen Habermas and Paulo Friere. McNiff and Whitehead (2006) urge that critical theory proposes that in order to change a situation you need to understand it, and social situations are generated by people, therefore they can be dismantled and re-constructed. Finally, situations that are taken for granted need to be 
viewed in the context of power relationships. In conclusion, they propose that whilst action research grew out of critical theory it went farther.

The history of action research can be traced to John Dewey (1859-1952), a pragmatic philosopher of democracy and education, who is accredited with the epistemological origins of action research. Greenwood and Levin (1998) claim Dewey's pragmatic philosophy was pivotal to public education in the United States. Tomlinson (1997), when critiquing the contribution of Dewey to the science of education and comparing him with a fellow educationalist Thorndike, claims that Dewey originated the idea that people do not just simply respond to the world and suggested they attempt to transform their energies into habits and behaviours to achieve their goals.

During the course of Dewey's lifetime, Kurt Lewin, a social psychologist, was credited as being an early proponent of action research (Masters, 1995; Greenwood \& Levin, 1998; Sandars \& Waterman, 2005; Koch \& Kralik, 2006). Other writers indicate the development of action research had several roots. Kemmis and McTaggart (2005) argue that action research may date back to Moreno, who was working with prostitutes in Vienna at the turn of the Twentieth Century. McNiff and Whitehead (2006) add that John Collier in 1930 in his role as commissioner for Indian affairs could also be identified as the other early proponent of action research.

Nonetheless, Lewin reiterated Dewey's ideas, and in an article that was published following Lewin's death, he analysed social life and concluded that many channels of social life are circular in nature. Lewin (1946) coined the term action research as research needed for social practice. He clarified and challenged the status quo at that time in his description of action research: "It is a type of action research, a comparative research on conditions and effects of various forms of social action and research leading to social action. Research that produces nothing but books will not suffice” (p. 35). Lewin (1947a) explains that "many channels of social life have not simply a beginning and an end but are circular in character' (p. 147). This, he explains, is characterised by a cyclic process of planning action and evaluation of that action, including feedback to all involved. The 
original plan should not be "frozen" (p. 148) and should allow for flexibility in the response. Lewin, (1947b) in reference to social research, describes the group decision as a "change procedure" (p. 35). The three stages, Lewin theorised, can be defined as firstly the dismantling of former structures (unfreezing), secondly changing the structures (changing) and finally transforming them into a permanent structure (freezing). Greenwood and Levin (1998) claim this concept of change had an influence on the early days of action research. Lewin was responsible for the creation of the role for the researcher as involved in the research process and not a distant observer. They add, however, that action research is not a short term application, rather it is a continuous participative learning process.

Greenwood and Levin (1998) also describe the General Systems Theory (GST) which has its foundation in physics, biology and engineering. Central to this theory is a collection of holistic notions about the world and its assembly. GST sees the world as made up of interacting systems (inorganic, organic and sociocultural) not of separate atoms and molecules. These systems, by way of their interaction, integrate in a diverse manner with the same basic material and produce the vast array of phenomena humans encounter throughout life. They propose that this is different from what they term as the particulate view.

The world is not a neat stratigraphic map beginning with inorganic matter, passing to organic matter and then being transcended by sociocultural forces. Rather the world is a complex, interacting array of systems and system processes, bumping into each other in a variety of ways. (Greenwood \& Levin, p. 70)

Lewin (1946) was not alone in his determination to methodically study a social problem. The historical development of the action research ethos encompassed the founding of the Tavistock Institute in London in 1946 (Trist \& Murray, 1990). This institute drew together a group of psychiatrists, clinical and social psychologists and anthropologists, who developed innovations that related psychological and social sciences to the needs of society. The Institute became famous for a study on miners that explored the introduction of new mining equipment which, surprisingly, did not lead to increased productivity. The 
results indicated that the lack of improved performance could be traced to the incompatibility of the new technology and the workers as a group of human beings who opposed operating as a separate entity. In another study, Einar Thorssrud, a Norwegian psychologist, in conjunction with Tavistock researchers Trist and Emery, scoped a project for a Norwegian setting. This project concerned itself with several experiments focusing on democracy with workers on the shop floor. Although this initial experiment and subsequent ones that took place in Norway were treated as interesting they did not, in the majority of Norwegian industries, translate to change.

Greenwood and Levin (1998) imply these core ideas of industrial democracy dispersed to other sections of the globe. Concepts were formulated that embraced contemporary notions, such as sociotechnical thinking, which was a departure from the Tayloristic thinking of the day evident in the post war years. This philosophy, according to MortonCooper (2000), was that workers were motivated to work by, in the main, economic rewards and were best controlled by a separate authority. Interventions were designed that realised clear links between technology, work organisation and psychological demands of a job, culminating in the idea of semi-autonomous groups within a workplace. This international evolution and the industrial democracy development saw the beginnings of research that would improve the research participants' ability to govern their own situations.

Kemmis and McTaggart (2005) nominate four generations of action research. The activity of the first generation can be in part attributed to Lewin's work. The second generation followed on from the Tavistock group and was the work of the British contingent Stenhouse, Elliot and Adelman. Somekh (1995), when writing on the contribution of action research to the development of social endeavours, explains why Stenhouse and later Elliot were influential in curriculum development within education. She explains Stenhouse came to understand that if teachers were involved in the research into curriculum they could change actual classroom practises. Elliot, in a similar fashion, saw the curriculum as a fluid active process with the teacher's involvement as a crucial component. 
The third generation of action research was Australian critical and emancipatory action research, including the notable work of Carr and Kemmis (1986). Carr and Kemmis were proponents of action research that emphasised personal growth through collaborative critical undertakings to empower the participants to change society. Kemmis and McTaggart (2005) state: "A fourth generation of action research emerged in the connection between critical emancipatory action research and participatory action research that had developed in the context of social movements in the developing world" (p. 560). This generation operated with two key themes; the construction of theories for more action oriented approaches to action research, and the need for participatory action researchers to affiliate with broad movements of society.

Nursing engaged with action research and added to this history. Nursing scholars are reported to have become increasingly interested in action research in the 1980s (Holter \& Schwartz Barcott, 1993). Prior to this 1993 publication, Webb (1990) had speculated that the main interest for nurse researchers in action research was that it extended an opportunity to work with people in a fashion that is non-hierarchical and it could be used to promote change and bridge the theory practice gap in the profession. Furthering this notion, Greenwood (1994) considered action research in nursing as social praxis. Hart and Bond (1995) explained that action research was seen by nurse researchers as a means of narrowing the theory practice gap utilising reflective practice within a collaborative enquiry to achieve autonomy in practice. Taylor et al. (2002), in summarising how nurse researchers have utilised action research, observed that its use has been "varied, and it includes studies aimed at changing work conditions for nurses, helping them reclaim their authority and organizing themselves to be more effective in their practice and to clarify their roles and their status" (p. 327).

\subsection{Agreed Features of Action Research}

Reason and Bradbury (2006) argue that action research is a standalone research approach that is synergistic with other qualitative designs. Greenwood and Levin (1998) admit a definition or even a general overview of action research is hard to find as its origins and development have been complex attracting many theories, methods, motives and problems. 
Although there are impressive differences amongst action research practitioners, there are several basic elements. These include research that endorses participation with a strong emphasis on democracy and action and aim to alter the initial situation to a more selfmanaged one. Differing approaches are adopted by practitioners using action research. Some wish to generate liberty through self realisation and some emphasise political interpretations which vary in intensity of the political agendas. Greenwood and Levin further explain that these differing approaches are quite incompatible. Examples of these incompatibilities being that some rest on Marxist notions, pragmatic philosophy, or social psychology and then they state: "And a few simply advocate that whatever the question, participation is the answer" (p. 8).

Kemmis and McTaggart (2005) explain that although at times action research is inadequately described, the elements generally consist of a spiral of self reflective cycles. These cycles include planning a change, acting and observing the process and as a consequence of the change, reflecting on this, replanning, acting again, reflecting and so on. This cyclic movement had been presented earlier by Dick (1993) a psychologist when stipulating the conditions present in action research project. For Dick the process was cyclic, qualitative and participatory and commences with an intention to produce both action and research outcomes. Dick states:

The purpose in action research is to learn from your experience, and apply that learning to bringing about change. As the dynamics of a social system are often more apparent in times of change (Lewin 1948) learning and change can enhance each other. (p. 14)

Dick suggests that by bringing intention into the process, learning can be maximised. Dick postulates that responsiveness to the situation and attempts to achieve real understanding designate action research as a feasible research strategy.

\subsection{Action Research and Nursing Research}

The use of action research to bridge the theory practice gap by such a wide range of disciplines continues to have merit for utilisation by nursing researchers. Holter and 
Schwartz Barcott (1993) describe the characteristics of action research as being inclusive of three approaches. They are the technical collaborative, mutual collaborative and enhancement approach. The technical collaborative approach has a natural science as its philosophical base, with a defined problem to generate predictive knowledge. The mutual approach has a historical-hermeneutic philosophical base with problems grounded within specific situations which produce descriptive knowledge. Lastly, the enhancement approach stems from the critical sciences based on values clarification and it generates knowledge which is both predictive and descriptive.

Hart and Bond (1995) describe the advantages to the nursing profession of this methodology by constructing a typology of the identifiable characteristics of action research. This typology suggests action research is educative, deals with individuals as members of groups, is constrained within a context, and is problem focused. It includes change intervention, is cyclic, aims to improve and is based on a relationship in which the participants are drawn into the change process.

Dick (1993) suggests that when practitioners use action research they can learn consciously from the process and create partnerships between the researcher and the participants.

The virtue of action research is its responsiveness. It is what allows you to turn unpromising beginnings into effective endings. It is what allows you to improve both action and research outcomes through a process of iteration. (p. 9)

Somekh (1995) claims that action research through praxis addresses the persistent inability of research in the social science disciplines to bring about actual improvements. Somekh continues that using this approach sees knowledge gain fed back into the practice, the unique frame of reference. She also adds that the orientation of action research is realistic and sensible. The researcher operates within the constraints of being a working practitioner and, therefore, there may be limited time in the research process. 


\subsection{Conclusion}

The action research methodology lends itself to studying how the role of CNL can be further informed and how the support can be further improved by allowing those in the role to define the role and continue the inquiry in a cyclic participatory fashion. There has been a substantial amount of international research and a minimal amount of New Zealand research carried out that looks at both the broad topic of leadership in nursing and then specifically clinical leadership. Some of the research on clinical leadership has involved those in the role and has produced unique knowledge.

Action research as the methodology of choice (context bound, participatory, collaborative and reflective) linked clearly to my objective to allow those within the role to influence the future development and dialogue around the role. This methodology endorses the participation I intended, and has a strong emphasis on democracy and action and aims to alter the initial situation to a more self-managed one. It is characterised by planning with intention, acting, fact finding, evaluating and then repeating this process in a cyclic nature. Nursing researchers suggest that action research is educative and non hierarchical, as it works with individuals as members of groups and, although it is constrained within a context, this enables it to be problem-focused. Essentially for me, the CNLs were to be coresearchers. The next chapter outlines how this co-researcher relationship was developed. 


\section{CHAPTER 4. METHODS AND PROCESSES}

\subsection{Introduction}

This chapter details the design of the study as well as the methods and processes used to conduct this action research project. It addresses issues related to ethics, rigour and presents the author's worldview plus the challenge of conducting research in an organisation where you are employed. A two stage design was used; the first involved gaining individual perspectives of the Clinical Nurse Leader (CNL) role. These perspectives were used as a basis for beginning the action research group process. The characteristics of the participants were to be CNLs active in the role who worked in a variety of practice settings within the organisation. The second phase was the presentation of these themes post analysis to the action research group consisting of the same participants.

The two stage design allowed me to collect a data set from individual interviews and then to take this collection to the group as a basis for commencing group work. The interview was the deliberate first start of a cycle. Essentially, the participants would provide a pool of data that would then allow me to analyse it and present the findings back to the group to include, disregard, negate or ignore. Dick (1993) recounts that using a cyclic or spiral approach allows for later cycles to question the findings, making the action research approach "a process of iteration" (p. 11). He endorses this entering with intent influenced by the work of Lewin (1948) who advised that the dynamics of a social system are often more apparent in times of change.

Phase two was the action group process. This commenced when the interview themes were presented for group consideration. The analysis of this data, characteristic of action research, did not occur in a chronological fashion. Themes were debated, rejected, revisited, rejected again and agreed in a fashion far more spiral than linear. Gummeson (2000) argues action research process could not be described as either linear or efficient. It is interactive, aiming at holistic understanding during a project and, as Gummeson 
summarises, events unfold in an unpredictable fashion. Throughout the research project I kept a journal which allowed me to reflect on my position as the facilitator through the action research process as well as account for what was happening within the group process. Dowling (2006) describes this reflection as an examination of the level of awareness of the relationship between the researcher and the context or environment where the research is carried out.

\subsection{Recruitment of Participants}

Firstly, an electronic invitation was sent to the wider group of CNLs within the District Health Board, inviting them to be a part of the research project (Appendix 3) with an information sheet attached (Appendix 4). This initial communication provided detail about the opportunity to participate and what participating would entail. The two phases to the research were explained in the information sheet detailing the intention to include an initial interview and then six to 10 meetings over approximately six months. This attached information included two options. If further information was needed or questions remained I or my supervisors could be contacted. Alternatively, potential participants could attend an information meeting held on a specified date.

The responses I received included eight electronic replies, two replies by phone and one by attending an information meeting. From this initial group of 11 , four had to be excluded as two were in management roles, one was active in a team co-ordinator role and one was a midwife. The remaining seven were contacted and any further information they required was given. They were informed that a tape recorder would be used to record interviews but they could request, at any time, for it to be turned off. They also could withdraw at any time without question. Thematic analysis of the interviews would then be carried out by me as the principal investigator to prepare for second phase analysis and interpretation. The next stage of data collection would occur over six to 10 action research meetings held over six months where this first set of data would be initially presented. The potential participants were informed that at the inception of action research meetings the decision of the group will direct any subsequent data collection process. Seven CNLs consented to participate. 


\subsection{Ethics}

The potential participants were given assurance that all efforts would be made to protect their identity and that they could withdraw at any time without question. These points were included in the information sheet and verbally repeated in the consent process. The fact that the group would determine the direction of the research (action research) was also outlined in this sheet. Information given as part of the individual interviews and group activities would be kept confidential to the researcher and supervisors. Data gathered from the group process would also be confidential to the group.

The consent form (see Appendix 5) addressed the explanation of the research project and issues of withdrawal and confidentiality. As part of the consent process, the CNLs were given an opportunity to consider information relevant to the project (see Appendix 4: Information Sheet). The consent form noted that there would be an opportunity for questions about the research and that these would be answered to the satisfaction of the potential participant. The participants could withdraw at any point without having to give reasons. The content of the research material would be treated confidentially and every effort would be made to protect any identification that may arise from the data. The form included that the data the participant would provide would not be used for any other purpose than as a thesis or in related publications and presentations and that the data would not be released to others without written consent. It was also noted that the participants would check transcripts or meeting notes before the follow up meetings. At the time of consent the participant would agree to abide by ground rules as determined by the group. Finally, as part of the application for ethical approval to Victoria University of Wellington Human Ethics Committee, a statement was included that if, during the course of the project any third party is named every effort would be made to protect the identity of that individual.

\subsection{Rigour}

Koch and Kralik (2006) suggest the rigour of an action research project is related to the author's worldview, the credibility and dependability of the inquiry, the transferability of 
the findings and how believable the study is. My worldview as a researcher equates to one of the positions Greenwood and Levin (1998) include when explaining the differing approaches to action research. After summarising a range of approaches they state: "And a few simply advocate that whatever the question, participation is the answer" (p. 8). This is similar to my worldview as a manager and in part why I have included Wadsworth's "stewardship without control" in the opening of this thesis. I facilitate and chair meetings, attending to the principles of equal participation and will often invite those who may not have had the opportunity to contribute to do so. Additionally, as I teach on nursing study days I regularly use this statement: 'I am interested from any others I have not heard from yet ...I am interested to hear what you think'.

I believe in order to try to advance knowledge and improve conditions surrounding a social situation it is helpful to ask the people in that situation what is going on. I wanted to conduct research that would further inform the evolution of the role of CNL and further improve the support afforded the role. My worldview as a manager and researcher has been informed to an extent by critical theory. McNiff and Whitehead's (2006) explanation of critical theory being that it proposes that in order to change a situation you need to understand it, and social situations are generated by people, therefore they can be dismantled and re-constructed. They propose that whilst action research grew out of critical theory it went farther. They add that situations that are taken for granted need to be viewed in the context of power relationships. I believe that in this inquiry, the context of the DHB where the CNL is working cannot be separated from how that context might relate to the inquiry and the responses from those in the role.

The context where the research was undertaken was a DHB, one of 21 in New Zealand. The role of the CNL is encompassed within the clinical management structure of this organisation. There are other clinical leadership roles in nursing in other DHBs as indeed there are internationally. This inquiry can at the least inform those roles about the usefulness of acquiring further knowledge for role development by co-researching with those in the role. The importance of those participating in the research being represented adequately is related to the credibility of the inquiry. In this study there were two phases to 
the design. The first phase was the interviews which allowed each individual CNL the opportunity to describe their experience of being a CNL. The second phase was the group meetings. The values and interests the seven CNLs brought to both phases of the inquiry were derived from the fact they were operating in the role before and throughout the research. They were well placed, sufficiently sophisticated in their knowledge, to contest the reasonableness of the interview data as well as subsequent data arising through the action research group. The interview data was thematically analysed by myself and presented back to the group as a list of themes. The group was established and ground rules which included balanced and respectful participation were agreed upon.

I simultaneously attended through both phases as Coghlan and Brannick (2005) describe, to the content, process and premise that were taking place. On interview, facilitating writing summaries and reflections I questioned what was going on. I believe that I brought to all stages of the research my belief that whatever the query, participation with those involved is the answer, in addition to what else is happening in this context, including my role and responsibility as researcher. Prior to commencing the research and in the planning as well as the analysis, I considered the role of the researcher who is also an employee within the organisation where the research is conducted. I, as the principal investigator, was also employed as a manager in the DHB where this research was undertaken. My position as a researcher with a long-standing interest in clinical leadership is of relevance to both the interview and action research group phases as well as this position as an insider researcher.

Dowling (2006) proposes that the researcher will have an effect on the phenomenon studied and it needs to be recognised that the researcher is also affected by being in the field. From the establishment of the group and through the group process I was conscious that my role was to ensure equal participation and that all voices were heard. Coghlan and Casey (2001) consider the tension of the researcher an insider, noting that there has been limited analysis of this dual role. They acknowledge, although challenging, nurses who carry out research within their own setting do so because they aim to improve certain aspects of practice, education and management. They refer to role duality as having the 
responsibility as an employer as well as the responsibility as a researcher, which could translate into tension between loyalty to the organisation and loyalty to the research process and participants. I reflected regularly within a journal on my role in the action research meetings, aware of such considerations and Coghlan and Casey's description of being the "insider" (p. 675).

The framing of the project is the key, according to Coghlan and Casey (2001), even to the detail of language used when referring to the aim of the project. To think in terms of issues is the preferred option they suggest. If terms such as problems are used, this may lead to convergent thinking. Equally, they add using the word "opportunity" (p. 678) will lead to divergent thinking, a sense of excitement and potential creativity. I was very aware of some of theses challenges at the outset. Finally, they summarise that one of the most important of issues for the nurse researcher is managing the politics of the organisation.

Undertaking an action research project in one's own hospital is political and might even be considered subversive. In many respects action research is subversive: it examines everything, stresses listening, emphasizes questioning, fosters courage, incites action, abets reflection and endorses democratic participation. (p. 677)

\subsection{Phase One Interview}

During the month of October 2005 I entered the field to commence the interviews with those active in the role of clinical leadership in nursing. This first phase was important to the research as it would provide an opportunity for all seven participants, in a one-to-one interview to say whatever they wanted about the role. In order to facilitate this I used the following opening question in all interviews. "Tell me about your experience as a Clinical Nurse Leader". Throughout the interview I used, where necessary, the following prompts: feelings about the role, interactions with the communities they lead and a prompt to ask them to describe the important features of the role. The length of interview spanned from 40 minutes to 90 minutes as the seven CNLs responded to the inquiry. These initial taped one-to-one interviews were completed in December 2005. Each interview was then 
listened to and transcribed by myself. The CNLs were each given the opportunity to read their transcripts and make changes or comments. None of the transcripts required changing.

\subsection{Analysis of the Interview Data}

Following completion of these interviews a manual thematic analysis of the interview data was carried out by me. The style of analysis used was informed by the writings of Sandelowski (1993) and Tesch (1990). Sandelowski advises in undertaking such analysis that the researcher should aim to create a picture of what is happening.

A representation in the same sense that an artist can, with a few strokes of the pen create an image of a face that we would recognize if we saw the original in the crowd. The details are lacking, but a good reduction not only selects and emphasizes the essential features, it retains the vividness of the personality in the rendition of the face. (p. 3)

Tesch (1990) also uses an analogy with art, and compares the analysis and interpretation of qualitative data to that of an artist in motion. If two researchers are assigned the same qualitative exercise they will most certainly produce different results. Sandelowski (1993) argues searching for similar detail may actually disrupt the quest for capturing the essence. There is, they agree, no one exact way to draw a face. The duty for nursing, Sandelowski suggests, is to find ways to capture and present these reductions or, in this case, a thematic analysis of the interview data to move towards fuller knowledge. The thematic analysis process used in this research allowed me to craft the essence of the interviews, and provide a representation or illustration of the data that the group could recognise.

Commencing in chronological order of interviews, therefore first interview carried out being one and so on, I read the typed transcript. As I did, I assigned a colour, letter or a symbol to each new theme I interpreted and classified as new. This initial thematic analysis was carried out in one complete session. This type of manual thematic analysis is generally thought to be a process which entails reading and re-reading, having the objective or question central focus through this process and coding in some fashion a word or words 
that secure the ideas (Roberts \& Taylor, 2002). They define that when you can no longer reduce the themes without losing the uniqueness of the data then these become your final themes. I arrived at a collection of themes, choosing to refine no further at this point. My rationale for doing this was shaped by the writings of Sandelowski (1993) as well as this being an action research project. Sandelowski considered:

Research is both a creative and destructive process: we make things up and out of our data, but we often inadvertently kill the thing we want to understand in the process. Similarly we can preserve or kill the spirit of qualitative work: we can soften our notion of (rigour) to include the playfulness, soulfulness, imagination and technique we associate with more artistic endeavours or we can harden it by the uncritical application of rules. The choice is ours: rigor or rigor mortis. (p. 8)

My decision to generate a loose collection of themes was also informed by this being the reconnaissance phase of the action research project, a starting point of a group process which I wanted the group to direct. More detailed analysis of the interview themes may have seen the loss of the individual voice within this collection and seen mine dominate. Two excerpts from my journal highlight my thinking in making this decision:

I was acutely aware that the participants in the interview were sharing with me in it appeared in an honest and candid way their experiences within the role of Clinical Nurse Leader. I was acutely aware that I needed to protect their identity but at the same time present their experiences as true and accurate representation of their data. I did at times feel like I had been gifted gems of knowledge and that caused me to consider how to care for these gems.

I deliberately chose not to further refine any less than 24 for two reasons... How did I know what was more important what would be lost in further refinement how did I know? And then later... on the other hand it felt right to let the group decide as too much me in this part really...too much me in the analysis. Tried to do it quickly without too much interpretation and consideration in my head. 
Hand (2003) sees that in using the qualitative approach, the researcher and the research cannot be significantly separated and that detachment is impossible. The researcher both affects and is influenced by the process of carrying out the research. Waterman (1998) suggests that the action researcher, often a practitioner themselves as in my case, strengthens their position by bringing to the fore their preconceived notions and prejudice. It is fair to say that as I carried out this analysis I brought my knowledge from 32 years nursing, three as a student. My background of having worked at this District Health Board for 28 years in a range of roles including acting charge in various clinical settings and with a long standing interest in clinical leadership meant I had extensively considered the role in its entirety, possessing as Waterman describes 'preconceived' ideas about the role. In light of this, I was conscious of not reading my ideas into the interviews; rather I used my knowledge to interpret what was shared through the interviews.

Finally this starting point (the interviews and the subsequent thematic analysis) saw the results (presented in section 5.3) presented to the action research group for further analysis on the role of Clinical Nurse Leader. Phase Two, the presentation of these themes post analysis to the action research group was to follow.

\subsection{Phase Two Action Research Group Process}

Wadsworth (2001) states that facilitating an action research process and attending to both the content and the action research process is "knitting socks on 24 needles at the same time" (p. 421). Coghlan and Brannick (2005) explain the dynamics of action research in a group are complex. One of the key elements of action research that Reason and Bradbury (2006) refer to as important is "the development of relational participation" (p. 350). This relational participation commences at the initial establishment of the group and centres on the type of participation that arises from subsequent group work. This relationship sets up a space for the inquiry to be undertaken, a space where concern for each other, trust, equal influence and shared language is present.

Park (2006) refers to participative research utilising dialogue as an "important methodological link and as occupying a principal position in action research among 
activities pursued because of its existential significance for human life" (p. 84). Dialogue, Park describes, holds a central point in fulfilling the principles of participatory research. In order for exchange of views or debate to occur that would see participants disagreeing with each other a mutual trust had to be established. Reason and Bradbury (2001) view this trust as vital, allowing the participants the capacity to convey their views candidly to the entire group without worry.

The "social space in which .... [participants] can share experiences and information create common meanings and forge concerted actions together" (Park, 2006, p. 84) is central to action research. Achieving this, according to Wadsworth (2006), requires the facilitator to be responsible for ensuring that the group remain focussed on the aim of the inquiry and assists them in capturing and articulating the essence of the group work. Not only is this focus necessary but, as Reason and Bradbury (2006) state, an action research project needs to be: "explicit in developing praxis of relational participation, guided by a reflexive concern for practical outcomes, include a plurality of knowing, engage insignificant work and result in new and enduring infrastructure or sustainable change" (p. 350).

Coghlan and Brannick (2005) refer to the "meta cycle of inquiry" (p. 25) when content, process and premise are all simultaneously attended to through the action research process. The content refers to what is detected, planned and acted on. The process is how the detection or diagnosis is undertaken what actions stems from that and how further evaluation takes place. These authors describe how two action research cycles can work in parallel. At the same time as I was involved in the doing of the project, I was simultaneously diagnosing, planning, and taking action as well as evaluating, how and why actions were taking place. Such activity takes into account the premise which refers to the often non-conscious, causal assumptions that dictate behaviour. They also suggest that the culture of an organisation may have a powerful influence on how issues are regarded and debated. All this taken into account such group activity required myself as the principal researcher to not only constantly ask what is going on here through the meetings but also draw together the key aspects in the written summary of the meetings so that they were not lost between meetings. 
The context in which this research was undertaken was a District Health Board setting. Those who participated were active within the role and were working within the health provider arm of the DHB. Passmore (2006) states: "The workplace is central to our existence" (p. 38). He further suggests that it is therefore not surprising that much research and effort has gone into studying behaviour in the context of the workplace. The CNLs had brought to the individual interviews, and would continue with the action research group to utilise, as Heron and Reason (2001) describe, four types of knowing: Experiential, presentational, propositional and practical. Experiential knowing arises from our encounters with the actuality around us, presentational knowing is the form we give to express these encounters through language, images and the like. Propositional knowing is the distillation of both experiential and presentational into theories or statements and, finally, practical knowing is bringing all three of the aforementioned together that informs the doing of appropriate things in a skilful manner.

\subsection{Action Research Meetings}

The initial meeting was held in December 2005 after the completion of the seven individual interviews. It was held in a central venue within the hospital campus with a title 'meeting' only on the room in order to protect the confidentiality of the participants. Subsequent meetings were held in a different, but also central, venue. These meetings were included in published visible schedules relating to room bookings with only my name attached. This was not unusual practice for me as other meetings I either attended or chaired would often include my name on the published list. Our first meeting covered initial introductions, reiteration of this being Phase Two of the research, and the intention for this particular forum. The intention was to establish how future meetings would be conducted, their length, frequency and whether ground rules would be appropriate to utilise. The group quickly and unanimously decided to conduct this meeting without the use of a tape recorder to capture the dialogue. I asked the question: How can we ensure equal respectful participation? The following ground rules were agreed on (see Figure 1, page 49). 
Nine action research meetings, held approximately monthly, plus one evaluation meeting were held over 11 months. The meetings in their entirety were completed in October 2006.

\section{Analysis of Action Research Meetings}

On completion of interviews and the presentation of themes, the group directed the ongoing analysis of the content related to the role of CNL, in accordance with the principles of action research. In the following chapters this direction is illustrated figuratively from the outset of the research project reflecting a number of factors: the aim of the research, the questions, the methodology chosen, Phase One then the simultaneous flow of content and action points. It also represents my role of facilitator: My query "what is going on here?" and the "transformative moments" (p. 330) of the research as described by Wadsworth (2006).

* Start times: Rooms to be booked 15 minutes prior to official start time to allow debrief at Waikato campus

* Food to be provided by Suzie

* Meetings will be taped with tape turned off if requested

* Group to keep each other safe in their discussions by allowing balanced respectful participation of a courteous manner

* Group to protect confidentiality of others apart from Suzie as principal investigator some members have already informed others of their participation

* Group decided that Suzie may stop discussion if non balanced or discourteous participation appears to be occurring

* Cell phones may be left on silent setting. If any member of the group needs to leave on ring that member must inform the group pre meeting

* Humour is permitted

* Meetings need to be approximately an hour

* Summary of meetings to be in bullet points and circulated pre next meeting electronically through internal WDHB email with agenda Suzie to type

Figure 1: Ground rules agreed on by clinical nurse leaders in action research group

\subsection{Summary}

This chapter has outlined the methods and processes used to conduct this research project including how data was generated and analysed. The recruitment and selection of the seven 
Clinical Nurse Leaders was described, as were the two phases of the study. Phase One was an individual interview with each of the CNLs and Phase Two a series of action research group meetings with myself and the same group of CNLs co-researching. Issues relating to ethics, rigour, my worldview as well as the position of myself in a dual role of researcher and employee in the organisation where the research was conducted have been discussed. Chapters five to eight are concerned with the illustration of data interpretation through the two phases of the research. They contain figures that illustrate the continuing cyclical evolutionary process of the project, including attendance to content, process and premise. These tracings start with the initial objective for the research, subsequent questions plus interpretation of interview and action research group work. The voice of the individual CNL is highlighted as part of the presentation of individual themes with all seven voices informing the themes arrived at in Phase One. Following on from this the group voice of Phase Two is announced which informs the last stage of the project. 


\section{CHAPTER 5. ANALYSIS AND INTERPRETATION OF PHASE ONE INTERVIEWS}

\subsection{Introduction}

This chapter outlines the analysis and interpretation of Phase One of this research. Seven separate interviews with the Clinical Nurse Leaders (CNLs) were held immediately following the obtaining of informed consent and before any action research group sessions were convened. Figure 2 depicts how Phase One of the research followed on from the initial questions, subsequent questions, literature review and choice of methodology. The objectives for the study being how can the CNL role be further informed and how can the support of the role be further improved, with subsequent questions being, what is the role, and who should define it?

To restate the opening question of the interview was: "Tell me about your experience as Clinical Nurse Leader". None of the participants were interviewed twice. All of the participants were ready to answer this opening question immediately and used examples from their practice. The quotations were drawn from all participants with no distinguishing statements included unless permission to do so was gained from the individual. The quotations from the interviews are presented in italics and provide evidence for the reader of what participants had to say about the various themes that emerged. The 24 themes that emerged from the analysis are grouped using the same headings as in the literature review presented in Chapter 2. This regrouping was not undertaken until after Phase One and Phase Two of the field work were completed and the analysis of the group action research process had been done. Table 1 provides a summary of the themes. 
Figure 2: Towards Phase One of the research - the interviews

How can the role be further informed?

How can the support of the role be further improved

How will it be approached?

Who will profit from it?

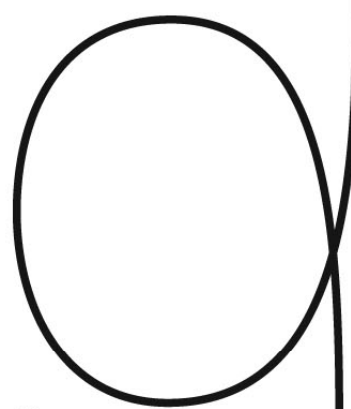

What is the role?

Who should define it?

What is the professional context?

What is the situational context?

Ask those in the role:

"... Whatever the question

Participation is the answer"

(Greenwood \& Levin, 1998, p. 8)

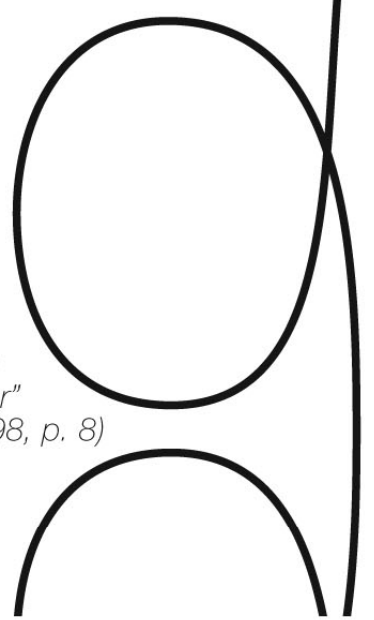

Principles of Action Research:

Participatory, cyclic, qualitative

Interview:

"Tell me about your experience

as a Clinical Nurse Leader

Thematically analyse

... we can preserve or kill the spirit of qualitative work:

we can soften our notion of (rigour) to include the playfulness, soulfulness, imagination and

technique we associate with more artistic endeavours or we can harden it by the uncritical application of rules. The choice is ours: rigor or rigor mortis (Sandelowski, 1993, p. 8)

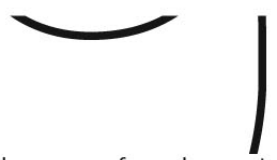

Collection of themes- for phase two establish the action research group and present the themes

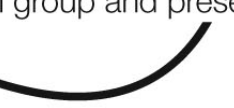




\subsection{Analysis and Interpretation of Phase One Interviews}

The themes analysed from the interviews revealed content relating to the role, the attributes, skills and knowledge requirements for the role, plus the experience of being a Clinical Nurse Leader.

Table 1: Thematic content of clinical nurse leaders' interviews by key groupings

\begin{tabular}{|c|c|c|c|}
\hline ROLE OF CNL & $\begin{array}{c}\text { ATTRIBUTES } \\
\text { OF } \\
\text { CNL }\end{array}$ & $\begin{array}{c}\text { SKILLS } \\
\text { KNOWLEDGE } \\
\text { REQUIREMENTS } \\
\text { CNL } \\
\end{array}$ & $\begin{array}{l}\text { EXPERIENCE OF } \\
\text { BEING A CNL }\end{array}$ \\
\hline $\begin{array}{l}\text { Pivotal/influential } \\
\text { Standards } \\
\text { Legitimate } \\
\text { power/authority } \\
\text { Staff advocate } \\
\text { support } \\
\text { Patients } \\
\text { Complex }\end{array}$ & $\begin{array}{l}\text { Varied/adaptable } \\
\text { Gender } \\
\text { Enabling } \\
\text { Respect/ } \\
\text { consistency/ } \\
\text { fairness } \\
\text { Sense of Humour } \\
\text { Communication }\end{array}$ & $\begin{array}{l}\text { Systems } \\
\text { Professional } \\
\text { Relationship } \\
\text { Professional support }\end{array}$ & $\begin{array}{l}\text { Conflicting management vs. } \\
\text { leadership } \\
\text { Separate/apart } \\
\text { International } \\
\text { colleague } \\
\text { Feedback } \\
\text { Exciting/enjoyable } \\
\text { Privilege/humbling } \\
\text { Hard work \& } \\
\text { emotionally draining } \\
\text { Relationship with manager } \\
\text { Moving away from clinical } \\
\text { skills }\end{array}$ \\
\hline
\end{tabular}

\subsection{The Role of the Clinical Nurse Leader}

The role of CNL was seen as pivotal, possessive of legitimate power, responsible for upholding standards of care, committed to patient care, an advocate for their nursing staff and described as complex. 


\section{$\underline{\text { Pivotal/influential }}$}

All CNLs talked about features of their role. There was a general belief that Clinical Nurse Leaders hold "a very pivotal role on the ward". This pivotal role arises from the various responsibilities that the nurse leaders have. As one CNL said CNLs have "many hats .... Quality and Risk, Health and Safety .... being the accountant being able to look at the general ledger and being able to fathom out what variance means”.

\section{$\underline{\text { Standards }}$}

Implicit in the role are the responsibilities the CNLs have and the degree of responsibility that the role carries. "There's a big sense of responsibility that comes with the role". These responsibilities require the nurse leader to set nursing standards for themselves and for the ward. As one CNL said, "I have set the standard and expectations and people know the standard [they] know what's expected". The role entails more than setting the standard, it involves the CNL supporting staff to meet the standard and when, it is not met, to establish why. One talked of the importance of clear communication of nursing standards to her staff:

because that's what it's all about, having trust in each other and from the leadership perspective making sure they're very clear about what it is they are providing, how they are to provide it and what the standard is.

Meeting standards requires the CNL to monitor the quality of nursing care given. This process of monitoring involves recognising that the standard may not always be met. "I' $m$ very clear about the standard of care here .... we try really hard sometimes we don't [always] get it right but we try really hard to get it right”. Or, as another CNL described, "every now and then when we have meetings, we have to think now what have we been doing c'mon think about what we can improve on".

\section{$\underline{\text { Legitimate power/authority }}$}

Four clinical nurse leaders referred to the use of the authority or legitimate power that the role carries. One CNL clarified that whilst the job carried organisational delegation of 
authority to deal with issues such as performance management of the nursing staff, that did not carry personal significance for them. "I'm not in the job for the power I have over people I'm not in the job to control others". Another CNL recognised the authority invested in the role but saw that as an authority not to be used in isolation "I might be the Charge Nurse but I cannot do anything by myself, it's not a lone job, I cannot do it without the team of nurses".

The nursing staff and patients were key foci for the CNLs whether they were detailing the role itself or the experience of being in the role. All CNLs interviewed included a description of how the CNL supports and advocates for their nursing staff.

\section{$\underline{\text { Staff advocate and support }}$}

The CNLs talked of being an advocate for their staff and the amount of time invested in this responsibility. "Staff management is huge and it often takes a lot of my time". There was general agreement about the importance of the advocacy component amongst the CNLs. "I'm protective of my team cause I won't have anyone criticise them I might discuss things with them but I'm very proud of my team". Others described their staff as their "top priority". Two CNLs described their response to being staff advocate for the nursing staff "the staff are feeling a bit pressured and looking to me" and "I was very much on the floor to support them in their nursing duties in whatever arose during the day”. Finally, one CNL, referring to the advocate component of the CNL outlined the expectation of maintaining confidentiality "you have to keep your staff confidence as well as a lot [of them] come to you with things in confidence".

\section{$\underline{\text { Patients }}$}

Six of the CNLs spoke of the patient as a key focus of the role. They talked about the importance of and responsibility to the patient and the enjoyment associated with this function within the role of CNL. One CNL said "and it's seeing the patient I suppose seeing their continuing clinical story that I feel responsibility for" and another described their love of "patient contact". 
One CNL referred to her strategy of refocusing on the patient to sustain herself in her practice as a Clinical Nurse Leader. "I take it back to the patient and that's what really keeps me on track in my role as a Clinical Nurse Leader”. The same CNL described also:

It's all about going back to your patient care .... because your role is to educate patients and if we don't know how can we go ahead and explain it to patients.... and getting patients to be more responsible and manage a lot more and understand their medications and their health and to prevent them from readmissions to hospital ...we can make a difference and keep them really well.

Another CNL, summarising her thoughts, commented "to me the biggest priority will always be patients".

\section{$\underline{\text { Complex }}$}

Five CNLs described the role as a complex one. They spoke of the complex nature of the role, balancing the demand for acute response to admit patients as core business of a health care provider and patient needs. One CNL described:

so it makes the role very very complex...we have a lot more complex patients. People [patients] are a lot older coming into the organisation a lot sicker so their discharges are a lot more complex, the pressure on the beds is absolutely huge ... you come to work in the morning and your focus is merely on discharges and beds.

One CNL recognised the need to continually communicate through the complexity of service delivery. "We don't have extra staff to manage [bed numbers] so its coming and going and how long you know you're always anticipating and that can be quite hard". The same CNL referred again to this communication later in the interview. She described how the role involved

being the hub of the ward or the speciality .... being a link into all different services and at some stages you're linking all the different teams in making sure that people know what the right hand and left hand are doing so to speak. 
This complexity was described in some detail by two of the CNLs. The complexity was demonstrated using scenarios from practice.

In fact I said on Sunday to a lady in a restaurant that I thought managing a restaurant this neat little café would be similar to managing a ward and I don't know why I said that but its leading the people making those decisions and communicating. And then doing all of this with constant interruptions and that is amazing and I think constantly well every about 3 or 4 minutes you'll be on some track doing something then an interruption fires in .... and that's why I related it to a restaurant that's that kind of that chaos that the theme of the meal is going through and chaos might be in the kitchen but you're welcoming the people to the ward or your restaurant ...I've got the relatives, I've got the patients, I've got the nurses and all of their people their animals their creatures their children and what's going on in their lives I've got the District Nurse phoning up some GP phoning.... someone from $N Z$ city ... and its on the go chatter and chaos.

Another CNL stated that the role of the CNL is a very advanced one.

I don't see the CNL role as a little role that I'm just here I'm just a nurse I'm just managing my staff and that's it I don't see it as that kind of role I see it as being very advanced very multi pronged that's it probably.

Finally, as one CNL summarised, the role copes with many of the changes to the delivery of health care that affects the way clinical environs such as the ones CNLs practise in. The CNL said:

It's a challenging role it changes all the time with the nursing staff themselves the health trends, the politics of health the work dynamics and more challenges with the health system the patient and the family dynamics we're dealing with ... it will challenge me every day. 


\subsection{The Attributes of Clinical Nurse Leader}

All of the CNLs interviewed noted various attributes that they deemed significant or worth including in the role of CNL. Attributes that were outlined included being adaptable, enabling nursing staff, being consistent, communicating effectively and possessing a sense of humour. Some attributes were raised by only a few CNLs, for example gender as a factor that may influence how the role is performed was only mentioned by one CNL.

\section{$\underline{\text { Varied/adaptable }}$}

Three CNLs described the ability to be varied and adaptable as necessary attributes to function in this role. As one CNL said: "To me the role varies from day to day ... it would have to be one of the most adaptive role I suppose I have been part of". Another CNL rated this attribute as key, describing: "The important features of the role certainly being able to be adaptable" and a third CNL referred to the many functions of the clinical nurse leader as requiring the nurse to wear "many hats".

\section{Gender}

One CNL raised gender as an attribute that may influence the function of a CNL, not concluding whether one gender is more effective than the other instead stating: "I think there's a huge gender difference between the male and female Charge Nurse" and moving on to further describe how a male and female Clinical Nurse Leader may approach performance management issues with nursing staff differently.

\section{Enabling}

Four CNLs spoke of the importance of enabling their nursing staff to function autonomously and make clinical decisions. One described her response when nursing staff had approached her for solutions.

Well that's good that you recognise that ... how do you think we can change so that they don't think know that I'm not sending them away to do it on their own, I'm willing to help them and there are other people out there that can help. 
Another CNL described her approach to her staff as an enabling one. She said "and I can see the good in them and I think yeah I can see that and .... to give them solutions". One CNL recognised the need to maintain her nursing staff's responsibility as individual practising nurses distinct from the CNL "and its about keeping it in balance because if you problem solve too much then you take it away from the nurses". Lastly one CNL described how to share a vision with her nurses and encouraging the nurses as opposed to being autocratic in her approach:

but it's saying this is how I want people to be this is how I want you to be, come up and join us and people will aspire to that as opposed to poking them with a stick to try and get them where you want them to be and that doesn't work.

\section{$\underline{\text { Respect/consistency/fairness }}$}

One CNL spoke of the need to be respected consistent and fair when working with their nursing community. They shared how respect was not automatic, but had to be earned.

You need to be consistent .... you want people to respect the position but the respect is one that is earned and I suppose you get respect from giving it as well.

\section{Sense of humour}

Three CNLs concluded that one of their strategies was having a sense of humour. For one this was about the fun of the ward environment. "I like to work on ... a ward that enjoys having fun life is too serious to be taken seriously". The other two spoke of a sense of humour as an attribute.

Humour I think to be able to laugh I think enjoy people ... humour my sense of humour .... and using it every day". And, a "sense of humour that's what you've got to have in this role I tell you it should be the key component of the job description. 


\section{Communication}

The role requires interaction with a wide variety of people and organisational personnel including patients and their families, nurses, doctors and multidisciplinary team members like physiotherapists and managers. Three CNLs referred to ability to communicate as one of the attributes of a CNL. One CNL said

I think communication is a huge thing being able to talk with people at all different levels ... we have a lot of interactions my whole day is spent talking to people and just discussing and drawing information out.

The role also requires communication within complex critical clinical situations as one participant described.

I think there's times when I'm abused not by staff but by patients and their relatives and I stand to those people and I stand strong and I tell them it's unacceptable .... and again communication but a strength within that communication ... I think the ability to communicate is the most valuable.

Agreement was found in the third CNL who stated "good communication [abilities/skills] find that essential". Although being an effective communicator was deemed to be a necessary attribute, to an extent this was weaved into the other skills and knowledge requirements spoken of by some of the CNLs.

\subsection{Skills and Knowledge Requirements of a Clinical Nurse Leader}

Knowledge of systems and processes, relationship management and ongoing professional support were identified by some of the CNLs as necessary for the role. One CNL spoke at length about the level of support she had received and the lack of clear expectations as to how to "comport yourself as a Clinical Nurse Leader."

\section{$\underline{\text { System and processes }}$}

The DHB where the research was undertaken utilises many protocol and procedures that govern both clinical and non-clinical practices. The clinical areas where the CNLs are 
responsible for the nursing care of the patient utilises many policies, for example medicine management which governs the dispensing of specific medicines by certain certificated clinicians to patients. One CNL referred to the importance of such systems and her responsibility as a Clinical Nurse Leader. She said: "They [the nurses] need to understand systems and processes .... it's critical they understand the systems and processes”.

\section{Professional Relationships}

Three CNLs included the professional relationships that the Clinical Nurse Leader manages, with one stating "You know you're dealing with .... all sorts as well as other professionals". Another CNL described the variety of colleagues that the CNL engages professionally with, "it's your relationship with your boss your staff that work with you it's your peers it's other CNLs, it's other departments".

\section{Professional support}

Three CNLs talked of the mentoring model as being useful to support the role. As one CNL said: "I would stress anybody to seek out there's a word for it a mentor". One CNL described her experience of professional development and support within the role and said:

I found that there's not a lot of coaching mentoring help for this role and a lot of it is a little bit by trial and error...it becomes difficult when you're dealing with staff and handling personal relationships.

Another CNL spoke at length of the level or lack of professional support she had received, describing at one point:

you're not really taught how to comport yourself as a Clinical Nurse Leader you hope that what you're doing is what you're supposed to be doing you read the job description but its pretty generic.

The same CNL included how this may also be a frustration.

I suppose it probably is a frustration but it's not having a mentor I suppose when you come into the role someone you can go and talk to about .... and you hope you're doing it right and you hope someone will come and say to 
you hey .... so I think in that respect you're always left wondering as to is this what the organisation wants you to do ... it would be nice if you go and do a course or just went away a day a week for four weeks in a structured way.

The experience of the being a CNL saw the CNLs talk in detail about how it was for them to function in the role including judgement statements about the experience.

\subsection{The Experience of being a Clinical Nurse Leader}

Six CNLs described the tension that occurs between the leadership and management functions of the role. Five described the experience of being a clinical nurse leader as a privileged and humbling one, relating back to their experience again with both their patients and nursing staff. Five also described the role as enjoyable, challenging and exciting.

\section{Conflicting management and leadership}

The role of CNL within this DHB has a generic position description which sets out the nature and scope of the role and includes the primary responsibility of the CNL as being to lead, guide and manage the clinical nursing team in the delivery of safe and effective patient care and outcomes.

Six of the seven CNLs referred to the dual function of leading and managing within their role and, as one $\mathrm{CNL}$, said the role is:

almost a schizophrenic role in terms of that its very fragmented .... sometimes it can be in conflict with itself... you end up with lots of pressure pulling you in different directions and often I think that's why when you're leaving at 7 o'clock at night you see other Charge Nurses trundling down the hill at the same time I think the role is bigger than one person can do.

There was a general belief that these dual functions are often difficult to manage:

The Clinical Nurse Leader role is the kind of conflicting in some ways you've got the leadership role and a management role and we understand that whilst 
they're often interchangeable they're actually often not the same thing and where as one is about efficiency and one is about effectiveness I think sometimes the roles can clash.

One CNL described the challenge of being both and said, "I think the hardest thing about being a Clinical Nurse Leader is being clinical as in our title and also management and often they kind of clash”.

Another described an inability to influence the budget although the position description included this as a shared responsibility between the CNL and their manager:

Ifeel the money is already spent I don't have any input into the budget although there's that thing around capital what you would need but I don't have any control of the ceiling of my budget.

A third CNL described her response to the expectation of dual leadership and management focus:

I spend a high component of my job is often on the floor I am on the floor as in clinical and I'm often hands on and so therefore I have this office with all this paper in this basket that's about this high and to be honest part of that is I need to take responsibility and be a bit strict and go and do some of that paper work.

\section{Separate /apart}

As part of the experience of being a CNL, two CNLs talked of being separate and apart from their team, with one commenting:

you get the phenomena of you walk into a room and people stop talking that people are very aware of where you are and that they have to behave when you're around and so its fascinating because the people that used to work side by side with see you as a force apart.

Another CNL stated how "it can be lonely" being a Clinical Nurse Leader. 


\section{International colleague's interaction}

The recruitment streams for registered nursing staff at this particular DHB are fundamentally new graduate nurses and Registered Nurses trained internationally or from within New Zealand. The Registered Nurse workforce within clinical areas where CNLs' practice in is reflective of these recruitment streams. One CNL spoke of the responsibility of the CNL to communicate expectations to her international nurses and said

as a leader to make sure that those people [international colleagues] really understand what they're doing and the communications but I mean they all strive hard and learn ... they will all have come from hugely different nursing backgrounds and expectations and standards.

\section{Feedback}

Four of the seven CNLs talked about feedback, or the lack thereof, on their performance in the role of CNL. One was interested in obtaining this feedback from the nursing staff, commenting "it's very hard to get feedback about how the staff view you". Two others referred to the lack of general feedback as problematic. The fourth CNL acknowledged that whilst there was a process of regular review, this was not sufficient: "I don't know if feedback is lacking but at the end of the day I must be doing something right cause no-one told me it's time to move on".

\section{$\underline{\text { Relationship with manager }}$}

Three CNLs commented both in general and specifically about the CNL relationship with higher management. One CNL considered "We get a lot of support from the .... managers" and another said "one thing I guess is hugely important is my relationship with my manager I recognise that I have a manager and I always run things past".

\section{Privilege/humbling}

Five out of seven CNLs spoke of the privileged position they are in when practising as a clinical nurse leader and being humbled by this. As one CNL said: 
The nurses are just brilliant population of people the way they flex and float and we do gripe and grumble but on the whole you know we really do put $100 \%$ into our jobs and I know no-one walks off my ward not feeling like they've done a full days work so its really humbling.

Another said:

the good things about my job is actually working with a great team of nurses being able to tap into this wealth of knowledge and just I find it's absolutely mind-blowing to be involved with intelligent people that are committed to making a difference and find that absolutely wonderful. Is it specific to a CNL role? Probably not. It's just nursing. That's the kind of people we are.

This privilege accorded to the role is not only derived from the nurses but also the patients and, in one case, the wider community. One CNL spoke of the trust that patients have accorded her in the role and said;

and some of the things I've been told and the trust that they [patients] give me, it's fantastic. What an honour to be told some of these stories that people tell me. That's amazing trust.

One CNL talked of walking in all worlds:

I just think I'm very lucky to have this job that I'm in because I'm Maniapoto Ngati Maniapoto and I'm very privileged to be able to come back. Ifeel I'm in a privileged position ... I am able to walk in all worlds. My greatest pleasure one day I was in the Emergency Department this young boy came in and I knew him really well and he goes 'Oh you are a nurse. Do you work here? I thought you just worked in all the kitchens the pa kitchens' and I just laughed and thought that was the biggest compliment I could ever have, it's lovely. 


\section{Hard work/emotionally draining}

Three of the CNLs referred to how difficult the role can be as and at times, with two saying “but I do think it sucks up your time, I spend a lot of extra time at work that's not paid for and "at times it's very emotional and it's a lot of work".

\section{Exciting/enjoyable}

Five of the CNLs when responding to recounting their experience as a CNL, spoke of how enjoyable the role is with four of them acknowledging at the same time that it was challenging. One said "yeah its challenging and I think if you have a passion for being a nurse it is a really good position" with another stating "I love it ... I love the role on the whole just because of the challenges". This enjoyment from being challenged came as a surprise for one CNL: "I like the challenge of leading a team now cause I didn't think I really wanted to do this job but I'm surprised how much I love it”.

Two other CNLs saying "I enjoy my role ... I enjoy where I am" and "I enjoy the role and I enjoy the challenges that go along with it".

\section{Moving away from clinical}

The balance of responding to both the leadership and management aspects of the role of CNL was evident again when three CNLs talked of the role of clinical currency. One CNL rated as important maintaining clinical currency in order to be able to assess and support your nurses:

I think my personal feeling is that you have to keep in touch with that [clinical] to know where your staff are at too sometimes and you have to walk the talk sort of every now and then and I couldn't just sit in my office and not do anything.

One CNL, contemplating what this may mean to her future career choices, said "I suppose I'm getting to a bit of crossroads in my career at the moment. I want to maintain the patient contact in a way". Another, lamenting the loss of clinical time, said: "I'd love to have more time to show nurses the craft of nursing cause I love that hands on nursing and I don't have time to do that". 


\subsection{Summary}

This chapter outlined the interpretation of the seven individual interviews that was Phase One of the research. The thematic analysis of the interviews revealed content relating to the role, the attributes, skills and knowledge requirements for the role, plus the experience of being a CNL. The seven CNLs spoke to the role and the experience of being in the role. In general, they saw the role as pivotal and influential with delegation of authority to be responsible for their staff and nursing standards. This same nursing staff and their patients were important to them. This was reflected in how all of them talked about the importance of supporting their staff and advocating for them. Six of them spoke to the importance of and responsibility to their patients and how that was an enjoyable aspect of the role. There was general agreement that the role is complex, assimilating the changes to the patient profile, the delivery of health care and its systems and the environment in which they practise. The CNLs in the majority saw the ability to communicate effectively as a key attribute. This communication was important as a multidisciplinary team member, to liaise with managers and for talking with patients and family. Four CNLs talked of enabling their staff as an attribute. Attributes that were also described included being adaptable, consistent fair and respectful as well as possessing a sense of humour. One CNL raised the issue of gender, not concluding whether female might be more effective than male but describing how the two sexes may approach issues differently.

Skills and knowledge required for the role included the importance of knowing organisational systems and protocols. One CNL described the importance of conveying such knowledge to all nursing staff. The maintenance of professional relationships with other roles for example relationship with peers, managers and staff was raised. Professional support was seen as important with one CNL recommending that all CNLs should have mentors. A CNL spoke of the lack of support and professional development describing it as a frustration. This was spoken to by three others when talking of the experience of being a CNL but was referred to as lack of feedback.

Six of the seven described the tension between attending to clinical leadership and management requirements within the role. The examples given of clinical leadership were 
leading nursing care and the examples of management function were budget and paperwork. This was also reflected when three spoke of having to move away from clinical care to perform, for example office duties. The majority found the role exciting and enjoyable and spoke of being one of privilege. It was, some said, hard work emotionally draining and lonely.

These 24 themes provided a baseline for the opening discussion of the action research group to consider further when researching how the role can or could be further informed, and how the support of the role can or could be further improved. As will be shown in the next chapter, the themes revealed from this analysis of the interviews were introduced to the group as a random list of themes. This was the beginning of Phase Two of the study. 


\section{CHAPTER 6. ANALYSIS AND INTERPRETATION OF PHASE TWO MEETINGS}

\subsection{Introduction}

The analysis and interpretation of Phase Two data is covered in the next three chapters. Phase Two involved nine action research meetings involving myself and the seven CNL participants as an action research group. A tenth meeting was held to evaluate the process for us all. These meetings spanned from December 2005 to October 2006. We, as a group, considered, analysed and debated the reasonableness of the Phase One data derived from the seven individual interviews.

The action research cycle of planning, acting, observing and reflecting (Kemmis \& McTaggart, 2005) is illustrated in these three chapters. The turning points in the action research meetings with indicative content are captured drawing on the literature about action research to highlight what is happening. Direct quotations from the meeting, excerpts of meeting summary notes and observation and reflections made by myself are included. All of these illustrate when the action research group addressed an issue whilst continuing to research what is the role of CNL. This is also, as Coghlan and Brannick (2005) term, the "meta cycle of inquiry" (p. 25) whereby content, process and premise are all simultaneously attended to. The quotations from participants are in italics and direct quotations from my reflective journal are introduced as such. When using my own journal and reflections, a particular focus is on capturing my decisions, actions and thoughts as an insider, outsider, researcher and group participant.

This chapter covers meetings one to three as depicted in Figure 3. Meeting one was concerned with establishing the action research group an important turning point in the research where I was given the responsibility of ensuring balanced participation while also facilitating the group to take ownership of the project. The next meeting was the presentation of the 24 themes to the group. The inclusion of direct quotations from the meetings are evidence of, as Heron and Reason (2006) entitle, "authentic collaboration" (p. 150) and "challenging of consensus" (p. 150). The group was simultaneously deciding 
what do to with the themes, questioning my intentions for this data and seeking further clarification on what action research entails. Meeting three saw the group reduce focus to two themes. This was not a rejection of the collection of themes as such but a statement that while they were all integral to the research only two were best captured as a topic for exploration in their own right. These two were the conflict that occurs between the leadership and management aspects of the Clinical Nurse Leader role and the professional development and support afforded the role. Meeting three saw the change of ownership of the group from myself to all members. Meetings four to nine are described in chapters seven and eight.

\subsection{Meeting One (December 2005): Establishing the Group}

The initial meeting was held in December 2005. I had reflected prior to the meeting that the seven participants were all nursing leaders in their own right and how that might impact on the participatory process of our action research group. I was, however, confident in my skills as a facilitator. It was summer and the group looked tired and hot. Their respective clinical areas were progressing strategies for Christmas inpatient bed reduction plus increased allocation of annual leave, meaning some ward closures and subsequent amalgamation of inpatient areas. Meeting one was about the establishment of us as an action research group and included introductions of all members plus agreement on the ground rules for future meetings. This first meeting was conducted, on request from the group, without the use of a tape recorder.

The respect and concern for each other was evident at this first meeting and was particularly noticeable around the ground rule discussion. My responsibilities included booking the venue 15 minutes prior to official start time to allow the participants to debrief before the action research meeting. This was in response to the fact that the Clinical Nurse Leaders would mostly be coming straight from clinical practice to the meetings. The group decided that it would be more beneficial to them and the research if they had the ability to debrief about their respective days before the group commenced. The group agreed that any meetings (not the debrief time) would be taped but that the tape recorder could be turned off if at any time requested by any of the participants. This was an 
acknowledgement of the often critical/confidential nature of their work and that they would feel safe within the group if they could request the tape recorder to be turned off. The group agreed that I could halt discussion if it appeared there was unequal participation. Humour was to be encouraged. 
Figure 3: Phase Two - first three action group meetings

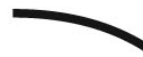

Establish the action research group

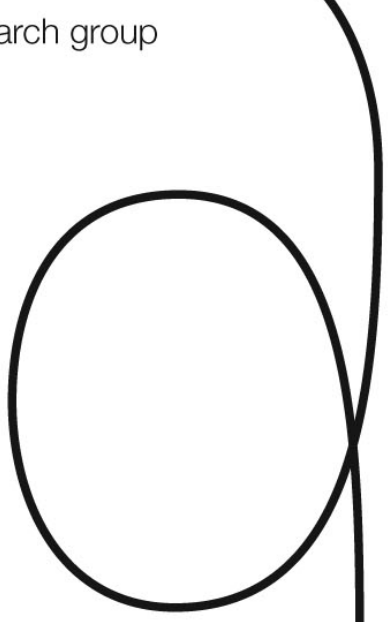

Action research-

Ground rules-how should we manage our research activity?

Group given responsibility of

balanced participation to

principal investigator

"Stewardship without control"

(Wadsworth, 2001, p. 322)

Present 24 themes from interviews What do they mean?

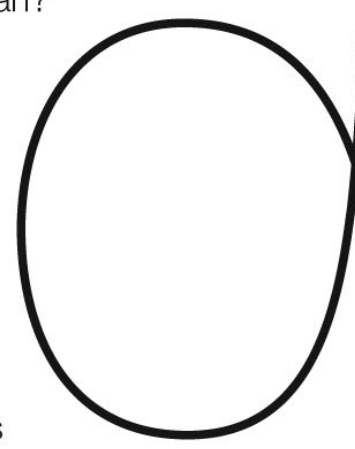

Reduce focus to two themes

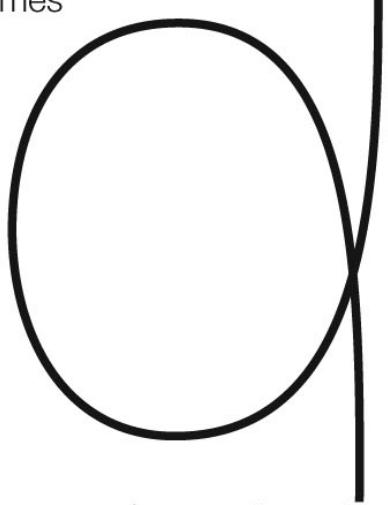

Action research group to next consider the new focus of two only themes from phase one
Discussion on principal investigator role

Systemically/intentionally reflective consideration of themes against context of careers

Change of ownership to all as co-researchers

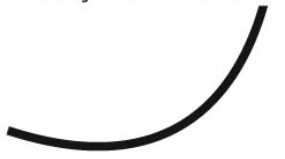


The first meeting closed following an explanation and short discussion from the group about action research as a process and information from me about the early typing of the interviews. I relayed that, during my typing of interviews, I had noticed how the CNLs talked of how the role was challenging and enjoyable, very busy, and conflicting at times between the managerial and leadership components of the role.

Immediately following the meeting, I reflected on the privileged position the group had given me in being able to halt the discussion of the group. This reminded me of Wadsworth's (2001) inclusion of the words of Lao Tzu particularly relating to “stewardship without control” (p. 322).

\subsection{Meeting 2 January 2006: Presentation of 24 Themes}

I presented the 24 themes or constructs derived from the thematic analysis to the group as listed in the order presented in Figure 4. The group was quiet as I read out the themes. I spent some time talking, facilitating and explaining how I thematically analysed the interview data to reach these themes. While I was doing this, I was aware that this meeting was also still about the group becoming established. Equal participation needed to be attended to; a responsibility for me as facilitator to discharge. Equivalent levels of contribution became more evident as the group set about deciding what to do about these themes that had been derived from Phase One.

Group consideration of this standalone representation of the elements associated with the role of CNL is evidenced by the lengthy discussion represented as in the following quotations from meeting two. The group were clarifying their level of participation and ownership of this analysis by asking me what I wanted. Following discussion of both my motive for the research and how to manage the themes, I chose to reiterate that the data from Phase One should be discussed and reflected on by the group. In essence, we were becoming an action research group and this needed to occur so that ownership could shift from myself to the group with us all as co-researchers. As you will read, the group finally agreed to preserve all themes at this point. The comments from both myself (named) and the participants are in italics and, unless stated, are from different participants. 


\begin{tabular}{|l|}
\hline Varied/adaptable \\
Gender \\
Pivotal/influential \\
Standards \\
Conflicting/management/leadership/budget/appraisals \\
Separate/apart \\
International colleague's interaction \\
Legitimate power/authority \\
Staff advocate/support \\
Enabling \\
Respect/consistency/fairness \\
Sense of humour \\
Patients \\
Feedback \\
Complex \\
Systems \\
Professional relationships \\
Exciting/enjoyable \\
Privilege/humbling \\
Communication \\
Hard work/emotionally draining/scary \\
Moving away from clinical skills \\
Professional support \\
\hline
\end{tabular}

Figure 4: The 24 themes presented to the Clinical Nurse Leaders 
Following the reading out of the themes, a participant queried "with those themes do you try and condense them a bit when you write up your thesis or do you just write up all those themes?” I replied:

We decide what we are going to do with all those themes now. If it was just little me yeah ... I think it's amazing data and it's up to the group if that's what you want to do or if you want to send me back and say Suzie compress them so be it ... going back to my original thing I will certainly help and advise and facilitate as much as I know about the research process but we decide what we want to do".

Another participant said "you could do grouping of things .... look at domains and lump some of them whichever theorist".

Coghlan and Brannick (2005) state:

In action research the members of the client system are co-researchers as the action researcher is working with them on their issue so that the issue may be resolved or improved for their system and a contribution be made to the body of knowledge. (p. 11)

As the group decided what to do with all 24 themes, some of the participants again queried my intention for the research. I used the opportunity to reiterate the principles of action research as being ones of participation and democracy. A participant contested that tying the themes to a theorist would be restrictive saying "I think that's boxing it [the themes] in a bit”. Another agreed, stating:

That's perfectly fine but if you have such a wealth of information to be able to create something of your own from this rather than relate it back to a theorist who has been out there forever and you are bringing something new to it ... it seems a shame to squeeze it into a box of someone else's.

Two of the participants then questioned my intention for the collection of themes related to the role of CNL. One asked "but when you finished doing all that and analysed it all did you have your own thoughts?" Before I had answered another asked "do you have any 
thoughts of where you want to go with it?" My response was "I clearly want to go with a group of CNLs" and I continued by summarising the objectives of Phase One and outlining how Phase Two of the research should precede. This outline, as the following quotation shows, reminded the group of what had been discussed at the first group meeting:

because remember at that first meeting about action research about how it is really a participatory process and part one was going to be this which I did and part two was going to be us so my responsibilities to the group was to present this and then as part of the participation action research we all make a decision what we are going to do with it.

Several participants suggested that rather than preserving all 24 themes, the group concentrate on a small number. Another participant however was firm in her response that she did not want to restrict the number of themes. Finally, the discussion reached a point of agreement-an action about the themes. One of the participants, who had not up till this point contributed, said:

I think it's important to identify you .... are talking about the role of the Clinical Nurse Leader and you want to identify how big the role is and how complex the role is. And I think once you start to clump things together it may not come across like that, you might not be able portray what is the hugeness of the role and the complexity but it maybe better to stick with all the themes you have identified.

The group all agreed to preserve the themes in their entirety, as they considered they portrayed how large and complex the role of Clinical Nurse Leader was. Following this consensus, the discussion centred on what the group or individual's responsibility would be in researching and actioning the themes. The timelines of research were discussed alongside whether the themes should be discussed in pairs. At times the discussion diverged then converged back to how to analyse the themes.

Some of the group then hesitated as to the way forward and sought out clarification of the action research process. One participant questioned the action research method, her ability to understand it and how she was struggling with it. Two other participants shared their 
thoughts on the method. One stated "I don't understand it, it is too nebulous not structured" and another just shared that it was the research generally that she was struggling with. Others listened, neither agreeing nor disagreeing, appearing content to say nothing. The discussion continued and at this point one of these participants presented their interpretation of why some of the other participants struggled. She said "and that's because your roles, our roles are structured. Every day has to be planned out as well as dealing with all those interruptions". The implication was that the participants were well used to imposed structure and when there appeared to be no pre-defined direction this, for some of them, was out of the ordinary. Coghlan and Brannick (2005) talk of the importance of the quality of the action researcher and member's relationship being built on trust and concern for each other. This trust Reason and Bradbury (2001) view as vital, allowing the participants the capacity to convey their views candidly to the entire group without worry. Although this was only meeting two, I reflected at this point that the group were achieving candid constructive dialogue.

Meeting two drew to a close with the decision made to initially focus on the first three themes of varied/adaptable, gender pivotal/influential. The group decided to individually consider these in the following weeks to determine to what extent they were reflective of what each of them did in their work as a CNL on a daily basis. This individual determination would then be reported back from their notes or observations to the group at our next meeting.

The following is an excerpt from my journal written at this point, related to the challenge of myself as the insider, outsider, researcher and group participant:

Lot of me in this meeting all my talking at the beginning.... group were very quiet when I read out the themes ... the room much better ... action research methodology again discussed....fine ... group responding to my what do you want to do now unsure process for them ...we are all used to deadlines, directives, can understand how they feel... Settling. 


\subsection{Meeting Three (February 2006): Reduction of Focus}

Meeting three started with attending to the first three of the 24 themes. This intention had been agreed by the group at the previous meeting. These three themes were entitled varied/adaptable, gender, pivotal/influential relating to the role of CNL. The intention had been that all of the participants would consider whether these three were reasonable constructs to include when defining their role. This consideration would be undertaken formally or informally whilst they carried out their daily practice. The participants had decided at the previous meeting to retain all 24 as a representation of "the hugeness of the role and the complexity". Each separate direct quotation (italicised) is attributable to one person at a time unless stated otherwise. I remain the only member of the group identifiable.

The meeting commenced with discussion around the role being varied and the Clinical Nurse Leader needing to be adaptable. There was general agreement that a Clinical Nurse Leader needed to respond to multiple demands. Four participants spoke in detail of this. One described, how after the last meeting, she had written down the jobs she had done on one particular day. Her description read:

I had budgeting, rostering, supervising, monitoring of staff, patient advocacy, consumer relations that were with the family and the patient plus the surgeon. I had compliance, quality and risk, continuous quality improvement by looking at different things so these were just the things in one day that I had to cope with. So it was getting, giving and processing really I remember that I had read that somewhere and that was what it was getting, giving and processing information and that was what my day was all about. It was all just before morning tea.

Another agreed the role was varied but saw it more as the Clinical Nurse Leader having the ability to problem solve, adding:

There is certainly variation in our daily role I could add to that ... mine has been totally problem solving today from quarter to seven this morning until we got it resolved at like about 1100. So you add that on to all the things first 
talked about .... so subconsciously probably every minute of the day you are making decisions all the time .... hugely varied every single day every single hour and people of course outside our roles don't understand that's what happens ... so I think the varied part of that says probably something quite different is it from the adaptability in a way ... so you've got the varied role and being totally adaptable for every single part of that role that you're doing all the time.

Living in "three separate dimensions" was how a third participant described the varied and adaptable nature of the role. The three separate dimensions were; having to problem solve past issues such as incident forms or patient complaints, present concerns of family members of very sick patients, and address future issues like nursing staff roster deficits. The presentation of these dimensions led to a fourth participant recalling an analogy she had heard from a colleague where the CNL had been likened to a signal box at a train station:

I remember quite a number of years ago a colleague of mine who was also in a Clinical Nurse Leader role in .... She said more or less the same thing [as the dimensions] and I have always remembered that she felt like she was a signal box at a train station and all the signals came into her. She had to process them and make decisions around the signals and then send out other signals and responses ...it's always stuck in my head ....You have to analyse the information and then make a decision and a lot of it is based on [your] experience being in the role. If something like this has happened before how are you going to deal with it? ....You try and come up with the best way to deal with the situation so that's how I see the varied and adaptability issue as well.

Gender, in comparison with the other two themes, received scant attention or interest except to agree that the participants had heard that some male Clinical Nurse Leaders used the appointment and time in the role as a "stepping stone" for future promotion. 
Heron and Reason (2006) suggest action research activity consists of convergence, divergence, chaos and order. Meeting three saw divergence away from the discussion on the first three themes and convergence instead on how it was to be a Clinical Nurse Leader. This convergence, divergence and chaotic movement resulted in the group satisfied that it had actually explored many more than the original three themes. The fluid movement of the discussion started as one participant said:

You're expected to nurse. You are the Clinical Nurse Leader you help nurse the patient you help lead the staff. You're that communications point for all the team...but people keep coming to you and feeding that information and to get anything done you need to learn about ....[You're a] kind of jack of all trades when you want to be a master.

The group then talked of not being allowed to have a bad day when in the role, of not being allowed to show the stress or frustration and as one said "we put on this bland face all the time with a smile painted on your face". At this point I chose to facilitate the discussion back to the last of the three themes, pivotal/influential. The dialogue that occurred at this point is presented next.

Suzie: "The CNL role is pivotal and influential and you have to absorb all the stress?"

Participant: "Yeah superwomen supermen. We need to be on top of everything be able to run a cardiac arrest without even starting to break a sweat. Things go wrong you can just cruise in and fix it like magic and that's the expectation sometimes".

Suzie: "Is it the expectation or is it your own expectation?"

Participant: "I mean I can go from an arrest situation, review the death certificate [as] the person is going off the ward, and I am called into a family meeting to deal with the next one". 
The group persevered with the converging to and diverging away from the logical order of discussing the themes, so I decided to establish whether there was group consensus on the relevance of the first three themes to the exploration of the role of CNL. I also wanted to see how the group wished to progress. I asked "OK good people it's getting hot and it's getting late what about the rest of [the themes]"?

Following on from this question, ways to look at the remaining 21 themes were explored. A suggestion by one participant to systematically examine the next four themes in order of recital was made, but was challenged as not being the best way to proceed by another and then subsequently rejected by the group. There was then an attempt to reject the theme relating to professional support but again a counter response from a participant saw it retained. It was at this point that a participant sought my opinion on the progress, asking "Do you think maybe we've have covered some of them in today's discussion?" This participant then proceeded to present a case for the group having already covered several more of the themes.

She noted that "we've talked about communication and we've talked about some professional relationship maybe on a slightly smaller scale .... talked about professional support". When she was questioned by another participant about whether the group had actually discussed such matters, the original participant responded: “You weren't here at the time sorry".

One participant then suggested that the group "just randomly choose another four [themes]". No response was made to this suggestion, however, the group did agree that communication would be a constant in all of the themes. At this point, there was evidence of an early devotion to the theme of conflict between the leadership and management expectations in the CNL role. A suggestion was made to explore the conflict between leadership and management and participants commented. One shared how they had "been looking at a job in another place and the thing is they don't have to do appraisals .... and I thought aren't they a burden". Another participant agreed. The subject of budget as a management component of the role was raised also. This meeting, inclusive of all the 
divergence, convergence and chaos as Reason (2006) describes, finally came to a conclusion as follows:

Participant: "What about professional support? Did we talk about that?"

Participant: Briefly at the beginning we said that when you go into a job you go into the job because you think that you can do it and you might have some skills but you go in with the hope you going to actually get that support from other more experienced people and you don't often get it.

Suzie: "So am I hearing do you want as a group to pick up conflict and professional support?"

All agreed. Koch and Kralik (2006) talk of responsibilities of researchers in participatory action research and include the attendance of the researcher to the dynamics of the group, observing and checking power relations within the group to create a safe environment where relationships can prosper.

My journal entry following meeting three shows that I sensed a change of ownership: Less of me .... thankfully .... still asked some questions ... wonder about my influence by doing that .... group responded quicker and with more certainty to the what do you want to do. [I was] surprised and pleased that they wanted to focus on the conflict leadership/management and professional support [themes] .... pleased that as a group they were decisive at deciding that these were the two themes they wanted to keep ... going.

\subsection{Summary}

This chapter accounts for the first three of nine action research meetings analysing the Phase One data. Phase One data was derived from seven individual interviews that culminated in 24 themes relating to the CNL role. These themes were presented to the group for consideration and analysis. In addition to the presentation of these themes, this 
chapter includes the establishment of the group and the evolving role of myself as researcher responsible for the creation of a group environment that allowed for honest dialogue and equal contributions. The shift of the members from individuals to an action research group is recognised. By the completion of meeting three, the group decided to reduce the focus to two themes, agreeing however that, for example, communication was integral to the role but was encompassed within the role in differing ways and was best not captured as a subject in its own right. Two themes remained as the future focus for the group as we moved into meeting four. They were the conflict that occurs between the leadership and management aspects of the CNL role and the professional development and support afforded the role. These two would be further considered, contested, analysed and checked for reasonableness in the remaining six meetings. 


\section{CHAPTER 7. IN THE THICK OF IT - SHARING AND LEARNING FROM EACH OTHER HOW WE MANAGE AND LEAD}

\subsection{Introduction}

This chapter describes the content and actions of meetings four to seven, where the analysis of the theme relating to the conflict that occurs between the leadership and management aspects of the Clinical Nurse Leader (CNL) role took place. This was a significant, almost turbulent, stage of the research where the group shared and learned from each other as to how they actually manage and lead, describing the reality of practice. Figure 5 represents this stage of the research. During these meetings there were times of, as Heron and Reason (2006) describe, "research cycling" (p. 150), "chaos and order" (p. 151) and what Wadsworth (2006) terms "transformative moments" (p. 330). These moments being when resolution was achieved through the action research group process as to what should be included in the representation of the CNL role. There were also times when some of the group felt powerless as to a way forward.

The excerpts included in this chapter illustrate all the above points. Discussion on budgetary, cost centre responsibilities as well as overall clinical care featured prominently in the meetings as examples of the conflict that occurs between the leadership and management functions. The tension caused by the administrative responsibilities of the CNL, such as writing of appraisals, processing incident forms and attending to the generic organisational requirements was raised. There were repeated references by the participants of the importance within the role of patient care and subsequent clinical leadership. General agreement was reached that the role should dispense with the administrative duties tied to the use of a computer and the actual typing of long documents that need to be completed to satisfy management, and regular appraisal of nursing staff. Solutions were proposed. 
Figure 5: Summary of meetings four to seven

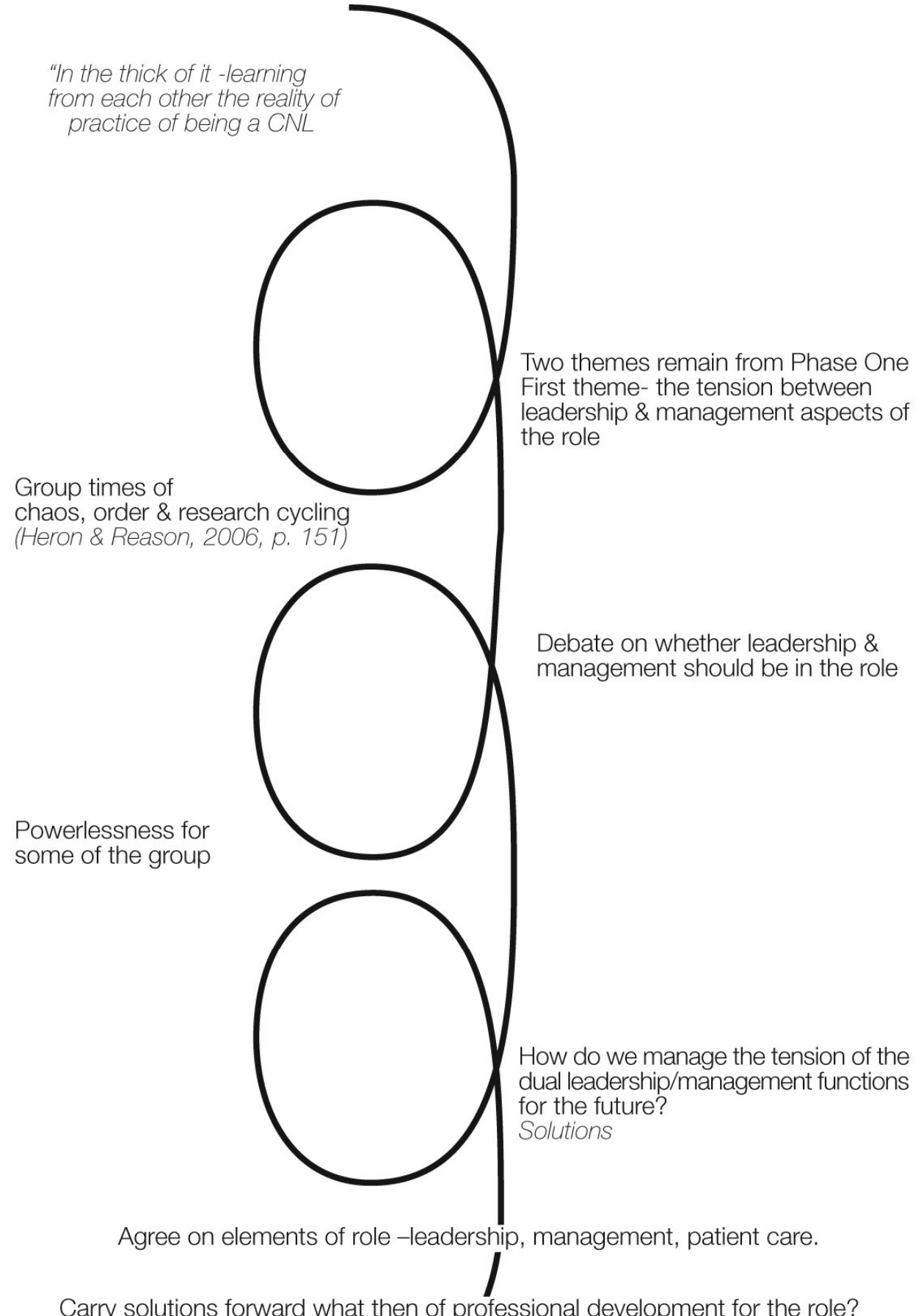

Carry solutions forward what then of professional development for the role?

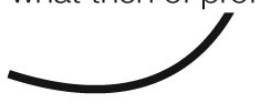




\subsection{Meetings Four and Five: Management versus leadership}

\section{Meeting Four}

Meeting four was held in March 2006. I began the discussion by revisiting the individual interview transcripts surrounding conflict between the leadership management expectations of the role. At the time of thematic analysis of the transcripts I had a sense this conflict created tension for those in the role. A substantial time was spent in this meeting analysing this tension, with the majority of the group not viewing undertaking budget activities as a priority within the role. Park (2006) talked of dialogue being central to the objectives of participatory research such as action research and that there is a need for the creation of what he terms a "social space" (p. 84) whereby participants can craft common meanings and build deliberate actions. The dialogue attached to the consideration of the leadership management aspects of the role like the budget occupied most of this meeting as the group moved to agree on what relevance this expectation may have to the role of CNL. The group agreed it was not a priority for the CNL but some felt there was little the group could do to remove it from their organisational position description.

At the outset to the discussion about the budget accountabilities there was general agreement that the position description did not reflect what actually occurred. One participant raised questions concerning the Clinical Nurse Leader's level of responsibility over the actual budget.
Around budget I actually question do we really have responsibility for a budget because we don't have any input into setting the budget except we have input into capital what we would like in capital expenditure .... and that's neat that we have that and then somebody higher says yay or nay.

Another participant, in agreeing that there were responsibility issues related to budgeting, commented that although the Clinical Nurse Leader's position description states that the role involved managing a cost centre, her experience was that this was not a reality. She implied the role did not have great deal of control over the cost centre of their work area. 
This experience appeared to be a frustration shared by others in the group, with two participants also describing that they had no control over the budget with one stating: " $I$ have not really got control over a budget at all but I've got this budget responsibility". Another elaborated on this point, noting "We don't have any control over our budget we have got the ability to order equipment up to $[\$ X X X] \ldots$ and anything that is above that you have to write a proposal .... [which] can sit on someone's desk for quite a long time before it is approved".

One participant suggested that the position description had to be changed to reflect what the CNL actually does in relation to budget and I asked: "How much input do you have in equipment then if we are saying that perhaps we want to retain that"? This led to dialogue about whether to retain product input from the CNL to management that allowed purchase of large equipment attached to their areas. Another participant cautioned the group about the risks of removing the CNL's input into product purchase. She thought

it would be quite dangerous in some ways for the CNL not to have input into it because if you have people outside of the service deciding what is required and also how much money .... just on the type of equipment.

A third participant agreed that the CNL should have input into choice of product and equipment for their area but as for the overall budget responsibility suggested that the CNL has no input into amount set adding: "and who gave me that figure how do they know"? The dialogue continued with other participants questioning the accountability versus input or control on budget ceiling. "Are we responsible or accountable?" with "that's the other issue" and "I'm accountable for the budget for... but I can't do anything about it". One participant then captured that what was actually happening for some of the Clinical Nurse Leaders was that they were experiencing a tension between managing the budget versus directing patient care requirements. She stated: “We probably don't focus too much on budget we focus on patient care". 
Meeting four finished with a discussion that uncovered the feeling of powerlessness created by the inclusion of the budget accountability within the role. As one participant said:

I think I we could talk forever around it but we're not going to resolve anything and I just feel if the resolution is for CNLs of the future I think we've concluded. I feel we've concluded [the budget theme].... can't take it out of the CNL description.

I asked directly: "Why not"? The same participant answered:

Because we've said that accountants don't know anything about our job so they need us but whether we could have a closer relationship with [the accountants] .... We speak different languages we talk about patient care and they look at dollars.

While at the time this was a "transformative moment" (Wadsworth, 2006, p. 330), it was also a moment symbolic of the feeling of the group having no control over the setting of budget and subsequent accountability in their role. They had agreed they wished to retain components such as review of product and equipment choice but the amount set and any ability to have input into that figure was limited. I suggested that we continued this discussion in meeting five and the group agreed. The meeting closed directly following this discussion.

Park (2006) states that in addition to the more traditional methods of quantitative and qualitative inquiry a non-canonical approach can be used by reaching into the arts to "reveal the more submerged and difficult-to-articulate aspects of the issues involved" ( $p$. 84). Taylor (2006), when discussing reflective processes in research, writes the researcher can be creative in the strategies used. Following meeting four and the group's perceived powerlessness to influence the organisational expectations of the role, I chose a noncanonical approach. The analogy I wrote to capture this powerlessness and tension between the leadership and management aspects of the role is presented in 
Figure 6, entitled "The Race". The Race was my reflection and interpretation at this point and does differ significantly from the interpretation and language used up till now in the thesis. It articulates that the focus of the research, at this point, was the expression by some

I want you to imagine you are about to start a long distance race not an ordinary race or a race that you have ever experienced. It doesn't have legs or laps or even a defined route as you know it. One thing you are certain of is that you would like to start. You start slowly but you soon realize that you will have to speed up to complete before it either gets too cold or too dark to function. So you run faster but then you have a weight thrown at you and others call to you that they want to join in the running but they don't know enough about the race or the route so you stop and explain to them and they thank you but leave their pack for you to carry. So you start running slowly again as the pack is quite heavy. Still more call for your attention and you feel as if you have stood on the spot. They are race officials and urge you to finish as there are others waiting to use the track and they admonish you for not following the rules of the race. You have not left enough room for others to race and even start to question you as to where the rest of your team is.

You become confused and you enquire as to what the rules are but they disappear too quickly to explain those but did tell you that you race well and you may want to become an official by learning how to complete this race. Another official beckons to you and you cease moving again. They enquire why are you racing that way and that your team did not complete the race that took place yesterday correctly and what were you going to do about that. You promise when you finish this race you will teach them new techniques and the official thanks you politely and disappears. Your pack slips but still more runners call to you and again you stop to help and agonise that if you have to do this all day the darkness and the cold will defeat you. You know clearly though that is not a choice as you are expected to complete this race. You are paid handsomely to run.

Time keepers call out your lap times but you are bewildered, as you haven't completed a lap or even a straight line. The route twists and more people stop you, thanking you profusely, lovely kind words, but they also leave your more packs to carry. You don't mind and you want to spend more time with these people and ponder briefly if you could stop altogether. Suddenly there is a hill ahead made of sand and you know you have to climb it somehow very soon. Other runners draw alongside you and seem to be able to chat to you whilst they race then they wave and turn off or so it appears. Still you smile and people standing beside the route and at the bottom of the hill some of whom are your team, applaud you and give you drinks and sun block. Runners behind you call your name and thank you for showing then how they should run this race. You start to climb, your feet sink deeper at each step as you have now about four packs to drag up the hill.

It happens that you do get there, to the handshaking and the congratulations. You smile in acknowledgement. Thankfully you can at least sit down now. You sit at the top of this hill and really want to sleep. Instead you turn to sees others, sitting too just like you and resting against their pack. You know they have raced too and you are comforted greatly by their presence even though none of you can talk. I wonder if they have had any training you think? How do they keep fit? You relax and you know you have done well as you rest against the same amount of packs as the others. Strangely and wondrously you look forward to racing on another day.

Figure 6: The race 
of the group of the inability to influence their practice as a Clinical Nurse Leader both present and future. We were "in the thick of it" so to speak, illuminating the reality for some of the practice of CNL in a New Zealand setting.

\section{Meeting Five April 2006}

In meeting five the group continued to examine the conflict between the clinical leadership accountabilities and the management accountabilities such as the budget. The continued emphasis on this conflict uncovered the frustration some of the participants felt when not being able to totally concentrate on clinical care. There were moments of divergence away from what was being discussed to convergence and moments of clarity. There was frustration expressed that the leadership and management elements within the role often could not be accomplished effectively or efficiently.

Meeting five commenced with one participant expressing her frustration at the dual aspects of the role, that of leadership and management. She said:

I guess for me it's always been a bit of a bone of contention about the conflict in the role because one is clearly about being efficient and one is clearly about being effective within that there is this huge conflict every single day and I guess we all have a bent sometimes towards one or the other. Or one takes over because of the external pressures .... the priorities for me quite often every day are wrong for me personally because my focus is not always about professional leadership. ...You come in the morning and you try and make sure you've got the right number of staff, for the right sort of patients you're looking after, over and above that it's like how many beds have you got?, where are your patients going?, what about this?, what about that?. We haven't got enough products, [there's] broken machinery. ...That isn't what I'd really like to do in a day. ...It would [be] really nice as a senior professional leader to come and say right, I've got that, but I haven't got the right skill mix today. So let's see what you can do about that but you actually 
have to let that go so I find that quite difficult on a day-to-day basis and you don't consciously always think about it like that but that is how it is actually.

At this point there was an emergence of not only conflict of budget responsibility versus management but also that of clinical leadership versus management. This tension between clinical leadership of nurses versus management of nurses was to remain a constant thread on one of the "24 needles" (p. 323) that Wadsworth (2006) refers to when facilitating an action research project.

There was general agreement that the actual title of Clinical Nurse Leader was a misnomer. One participant acknowledged that the title was "brilliant" but that the CNL had to do more than lead clinical practice. The reason given for why the CNL could not devote all their time to such leadership was because time had to be spent fulfilling the management expectations of the role, as the role was "embedded in all this paper". This comment was followed by a participant asking "where do you go?.... One person can't do all this". Another added:

What are we? We're nurses and to lead the nursing practice is what I'm passionate about and to be expert, expert of excellence. I'm not a secretary, I'm not a typist, I'm not a finance person .... but I want to pass on my passion about this craft of nursing, and this paperwork does that make any difference to the quality of care to the patient?

The three others in the group considered this question and agreed they personally didn't make as much difference to the quality of care of the patients as they would like with one stating: "I don't think I make any difference to the patient much at all". Another participant agreed and was adamant that the focus of the role should return to standards of practice.

No, I absolutely agree, I think that is the bit we should focus on, coming back to being Clinical Nurse Leaders because we are passionate about nursing and about standards of practice and maybe being able to make a difference to the patients. 
When I asked what the group wanted to retain and remove from the CNL role there was general agreement that the patient and ward staff focus remain. As one participant said: "I want to retain the patient focus and the ward staff focus". Others added, "I want to let go of the budget stuff.... some of the generic quality stuff some of the generic infection control stuff" and "the health and safety stuff". One participant, however, wished to retain the quality and risk initiatives.

The budget was again raised with a further general acknowledgement that it was not a priority for Clinical Nurse Leaders. One participant rated it as the lowest priority at this time and another responded: "It's interesting though, because I believe that while that's how we view it, I don't believe other people view it quite like that for us". This statement seemed to bring the meeting to a natural close with an action point for one of the participants. The participant was to compare the change in the position description and bring her findings back to the group at meeting six.

\subsection{Meeting Six}

Meeting six was held in May 2006 with the aforementioned participant presenting her findings on the comparison of the two position descriptions of the clinical leadership role. The present day conflict, she wrote, within the role of Clinical Nurse Leader, was caused by trying to lead, manage and carry out direct patient care. If the direct patient care was relinquished by those in the role then dual leadership and management accountabilities could be met more easily. The participant had drawn up a written overview of her findings and the next quotation is part of that:

I believe we all have a passion for clinical input inherent in us and this seems to give us more satisfaction than other aspects of our role and we tend to do this in support of both patients and staff. There is or can be pressure from staff and an expectation that we will assist with clinical care when workloads are heavy or staff cannot be replaced. Some of them [nurses] believe that's also part of our role. Staff are not always aware of the wider aspects of the CNL 
role and they often judge the CNL by the ability of the CNL to work with them in the delivery direct nursing care.

In summing up this overview she had written:

So I guess in all this, my belief now is that the two key functions of our CNL role are leadership and management and quite clearly [this goes]... with the expertise to overview/ supervise the provision of clinical care, not do it.

In addition, she shared a pictorial image (see Appendix 6) she had produced that represented the conflict between the leadership, management and direct patient care.

Following on from this direct comparison, a participant challenged the need to give up direct patient care resulting, in her view, in erosion of her clinical competency. One participant opposed this, seeing the Clinical Nurse Leader needing to be knowledgeable about the clinical standards without being clinically current. Another participant, however, was adamant that the CNL needed to be "on the floor", expanding as follows:

I probably take it from the opposite view of you. You want your Charge Nurse on the floor work with the people. The typing, the setting up for appraisals a lot of the paperwork background that you need to do, you could get someone else to do it at \$18.00 an hour where you take control. And my argument would be that you get someone who is reasonably junior because you get too many senior nurses trying to do the same role.

The group diverged and converged as they contested direct patient care as an element of the role. Convergence seeing general agreement that the typing involved in the role could be carried out by a purely administrative person. Two participants added that they saw the role of clinical nurse leader being involved in direct patient care as fulfilling the leadership by example and role model aspects of the role. Meeting six closed without general agreement as to whether direct patient care should be removed from the role responsibility. 


\subsection{Meeting Seven June 2006}

Meeting seven saw the group moving towards clearer understanding of the key elements of the role. This understanding was arrived at by discussing how they encountered the leadership/management tension in their day-to-day practice and how they managed that. The group were very clear that the role should not include some particular compliance and clerical responsibilities that were presently attached to the management and leadership aspects of the role. Their devotion to the patient remained and the role of an Associate Clinical Nurse Leader was suggested.

One participant summarised for the group what administrative tasks she would like to see removed:

I guess for me to start the ball rolling I think there are things like the quality and risk expectations, the health and safety expectations...certainly the quality and risk and the health and safety stuff and this administrative stuff like the typing in of reports and the typing letters and the typing in of performance reviews and all that sort of stuff. I think [some of this] should actually go to a clerical [person] whether there's a clerical person that is employed.

There was general agreement that administrative tasks as described above should not be a critical element of the role and that it should be assigned to a further resource. After lengthy discussion and recycling the suggestion was made that the most agreed solution for CNLs would be to establish an associate CNL position. This associate role could be fulltime or part-time based on how many full time equivalent staff the Clinical Nurse Leader was responsible for. The discussion where this resolution was gained finished as follows.

One participant supported the suggestion made of an associate CNL versus an administrative non-clinical support person:

I think maybe an associate CNL would be better because I think within our role we ... are leaders and we also have to be responsible for some management and that's just the way it is-managing some complexity but maybe the problem is the role has got too big. 
A further participant endorsed this: "I feel what we are saying is our role has got too big, it's too complex and that maybe it should be carved in two". Participants added: "Then your associate would be based on your FTE because not every [one will need a fulltime one]"and "maybe a smaller area might have a 0.5 ". For others in the group the interest was not so much in the specific title, but in having "an additional person there with the level of skill to support you”. Finally, a participant concluded:

Right at the beginning one of the comments we were discussing was the fact that we took on the CNL role because we thought we could do it. So you applied for it, you got it and you're suddenly thinking where's the support there's no one to go to.

During meeting seven, the group finally committed to what they saw as the critical or key elements to the role of the CNL. This commitment came in response to my asking "What do we all think the key clinical components are to the role or the key components"? Some individuals in the group responded: "Leadership"; "leadership and management"; "patient care"; while others disputed that it could be "leadership and management" on its own. Given this list, I asked whether it could be "Leadership and management and patient care”?

The group responded favourably to this suggestion with general agreement that "We really do have that responsibility to oversee that patient care". This response led to a participant noting that, although the focus of hospitals is on patients, taking care of staff assists this focus.

If you turn the hospital upside down, the patient is the only reason the organisation exists and so quality, health and safety everything like that is there to support our staff to look after our patients so if we get our patients looked after properly everything else should be there backing it up. Unfortunately it's not, it tends to stand in the way of looking after patients and I think that's one of the big issues we have. And I think whether its making sure your staffing is OK and they're getting annual leave so they're not falling sick .... then it's all about keeping your patients safe. Keeping your staff safe. 
"Isn't that leadership leading your team?" and "It's also about being there". Another participant added: "To me I put that into the leadership bucket about leading the team knowing what's happening making sure care is provided and all of that stuff".

Meeting seven closed with the group agreeing that the remaining theme of professional development and support accorded to the role needed to be debated. This was to occur in meeting eight.

\subsection{Summary}

The period that covered meetings four to seven was a significant point in the research. The group analysed the conflict that occurs between the leadership and management accountabilities in the role of Clinical Nurse Leader. Leadership was seen as the role modelling of clinical standards for patient care, and management was attending to budget and generic organisational responsibilities. The group shared and learnt from each other, with examples from their daily practice, about how they managed this conflict. Some of the participants voiced their frustration at their inability to influence the development of the role especially in relation to this tension. As the researcher, I chose a non-canonical approach to illustrate the level of frustration at this point of the inquiry and wrote "The Race". Some acknowledged that even though their position description included accountabilities like budget it was not a priority, patient care was. The group agreed that the title Clinical Nurse Leader was a misnomer as the role stood at that point and due to all the other accountabilities that there was no time to lead clinical practice. The role, some said, was "too big" and "too complex". The role was "embedded in all this paper" and they were not "typists". A comparison of position descriptions by one of the participants acknowledged the tension of trying to be a leader and a manager. The tension, she wrote, was due to the CNL attempting to retain direct hands-on patient care. Consensus was not reached within the group that ceasing direct patient care would solve the tension. Some saw direct patient care as attending the role modelling necessary to lead nursing staff in demonstrating clinical standards. Solutions however started to be created. 
There was general agreement that the patient was the focus for the role and the group agreed that the role was one of leadership, management and patient care. For the future, the role of Associate Clinical Nurse Leader in certain sized clinical areas would be beneficial in supporting the present CNL to achieve these key functions. In order to address the excess emphasis on typing of lengthy staff appraisals and attendance to some organisational requirements, these tasks needed directing to another non-nursing role. Meeting eight, the group agreed, would analyse the professional development and support given to the role. Interestingly, this theme of professional development and support had been agreed some months prior by the group as one of the two themes that were to be focussed on through the action research. However, the conflict between leadership and management had occupied four of the nine meetings. 


\section{CHAPTER 8. COALESCING FOR THE FUTURE CNL COMMUNITY: PROFESSIONAL DEVELOPMENT AND SUPPORT}

\subsection{Introduction}

This chapter details all of the action research group's last meetings. At this point, the group had moved to a clearer understanding about the role and had drawn from their everyday practice as to how they managed the conflict that occurs between the leadership and management functions. The focus had shifted from powerlessness, an impediment of earlier meetings, to sharing strategies and how others experience their reality. They listened and learned from each other as critical companions. The role, as defined by the group, was one of leadership, management and patient care. Amongst the move to better understanding of their role they had demonstrated concern for the future communities of Clinical Nurse Leaders (CNLs). This was to be further advanced in these, the last of the action research meetings.

These meetings were remarkable by the fact that group consensus was quickly gained on what shape the professional preparation and development for the CNL should take. Figure 7 summarises what was discussed and the action points taken. The contesting, recycling and the debating that featured in meetings four to seven was absent as the group showed a concern for the future CNL workforce.

Meeting eight was held in July 2006. The purpose of the meeting was to analyse the professional development and support given and required of the role of CNL. Meeting nine was the last action research meeting and was concerned with a professional development proposal that evolved out of the meetings. I had put together this proposal and would present it to the group for endorsement or rejection. Meeting 10, held in October, was the evaluation of the overall research process. 
Figure 7: Summary of last action research meetings-Phase One and Two complete

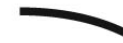

What shape should the professional development support related to role of CNL be?

What is current professional development and support against present practice

Proposal for preparation professional development \& support agreed on

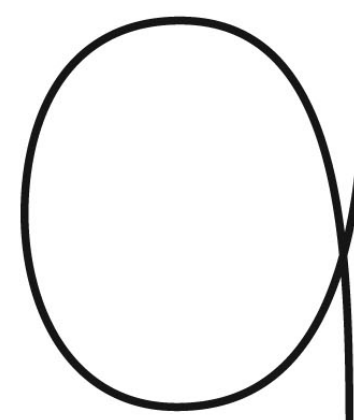

Concern for the future community of CNLs

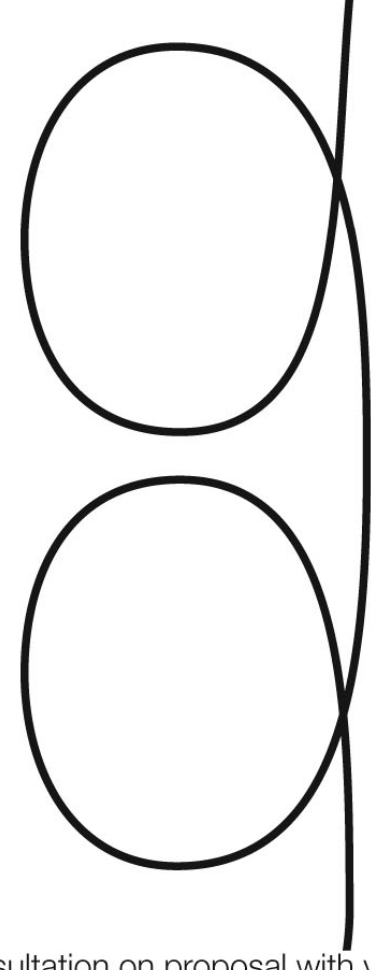

Group reached

consensus quickly Solutions

How do we communicate proposal?

Agreed to begin consultation on proposal with view to implementation Phase one and two finish

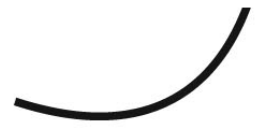




\subsection{Meeting Eight}

This meeting examined what professional development and support should be afforded the role of the CNL. One of the participants proposed initial gauging of previous experience to inform future professional development. This assessment would be in the form of a needs analysis or questionnaire sent to either the new or existing CNLs. There was general agreement that the CNL should be given information on organisational processes, for example, human resource training for performance management of staff. The orientation to the role, the participants suggested, should include both the use of and terminology attached to information technology. The use of spreadsheets, rostering software and the systems that held patient-related information, for example diagnostics or inpatient tracking, were raised. An appointed or chosen mentor was suggested, particularly in the orientation phase.

The role of feedback, not only at initial induction into the role but also ongoing, was important for the CNL. One participant commented: “you don't do [receive feedback] unless you do something wrong" and then went on further to say:

I didn't know what I was doing was OK until .... walked in and said you know you're doing an $\mathrm{OK}$ job ... And that was all .... just giving you the bit of encouragement that you're doing alright and I suppose there should be something that .... structure something that's official that there's a process [for feedback]

This led the group to talk about the essential skills for the role (as one participant said "people skills .... it's the nature of our work") and the timing of the education, both for the new clinical nurse leader and those already in the role. The yearly performance appraisal was not deemed sufficient as a basis for a professional development model for the CNL. As one participant summarised: "I think you always need it, you always need that support". Two further participants agreed: one explained "because we are working in a changing environment that evolves all the time so there's always something". The frequency of the professional development was significant with general agreement that it needed to be regular both at commencement and once the CNL was established. A 
suggestion was made by one participant that an informal appraisal should be undertaken at three months into the role. Another participant considered that such an appraisal process would result in an opportunity for feedback and agreement on future professional development. A third participant felt annual education sessions were insufficient because "you're up here and you have say a performance issue or a learning deficit you can't get in 'til the end of the year what use is that"?

The orientation of the new Clinical Nurse Leader and the role of their future nursing staff or teams in this orientation were also raised. A suggestion was made: "Someone doing some team prep [preparation] work to ensure the team you're going to lead ...” by one participant who was overwhelmingly supported to the extent that she was unable to finish her statement. The responses included: "That's a very good idea”; “that's lovely”; "that's brilliant" and "that's very good".

One participant acknowledged that the transition into the role of CNL and the establishment as leader of a nursing team can be difficult. She said: "That [starting in the role] can be a very rough time". Another participant describing it as "huge". This led to further discussion about the importance of the Clinical Nurse Leaders' relationships with the nursing teams. Some participants shared that at times this can be a difficult relationship. The need for a mentor was again raised, but, this time, mentors were considered to be important not only for the initial orientation of a CNL but also as an ongoing support. The meeting concluded with a participant summarising the discussion.

And trying to break down the myth about the manager, it doesn't matter what your title is when you have a group of people you're leading you'll always be the manager and it's trying to break that barrier. Well actually I'm just like them.

\subsection{Meeting Nine}

Meeting nine was the last of the planned action research meeting and was held in August 2007. Prior to this meeting I had reflected on all the outcomes the action research group had achieved in exploring how to inform further the role and how to improve the support 
of the role. I knew that I would take some time to write our findings up in the form of my thesis. It was at this point I decided to put a proposal to the group drawing together all the solutions, particularly from meeting eight, in order to create a potential action for the future. This action or proposal related to the professional development and support of the role and would not be dependent on my timelines as a student. If the group agreed it was worthwhile then I, in my organisational role, would commence the consultation with my appropriate managers and commence implementation. Meeting nine commenced with the presentation (see Figure 8) drawn up on a whiteboard. Prior to the meeting, I had sent the group electronic notification of my intention to present a proposal.

The first section of the meeting was occupied with an explanation of the proposal. The two part proposal was a culmination of our solutions from our research relating to professional development of the Clinical Nurse Leader. Part A was to pilot a professional development model with four Clinical Nurse Leaders from within the District Health Board (DHB). These four would be chosen with varying experience and from different settings in the DHB: One with greater than five years in the role, one less, one from a satellite hospital and one from the primary health setting. These four would look at their present position descriptions and identify any gaps they felt they had and these would be put to their respective managers as opportunities for ongoing education. The most frequently used organisational position description was an overview of the accountabilities. From these accountabilities, a skills list would be created. This skills list would be prescriptive. Levels of familiarity with, for example, rostering system, performance management and patient allocation systems would be asked of the CNL. Furthermore, if the CNL agreed, an independent facilitator would meet with nursing teams to facilitate discussion on the team's understanding of the role of Clinical Nurse Leader. This would be a strictly rolerelated discussion. Nursing staff could, if interested, pick up one of the CNL's portfolios. 
PART A (Pilot)

Participants:

$\mathrm{CNL} / \mathrm{PD}$

match

Offer :
4 CNLs active in role

$\mathrm{X} 1 \mathrm{CNL}>5$ years

$\mathrm{X} 1 \mathrm{CNL}<5$ years

X 1 T Hospital

X 1 Primary Health

(n)

Assess present skills against PD? what opportunities

further skill update against the skills list

$\sqrt{ }$

D/W Ops/Manager as to what to access

Create:
Independent facilitator to $\mathrm{d} / \mathrm{w}$ nursing team their understanding role

గ

Develop interested gp. of nurses in wd. /dept create $\mathrm{S} / \mathrm{N}$ CNL support gp.
CNL Gp.

Profile

CNL group Intranet site

Photo background, interests of role -potential mentors/support

Establish Senior nurse lounge on campus

\section{$\underline{\text { PART B }}$}

If new appointment occurs access to all above

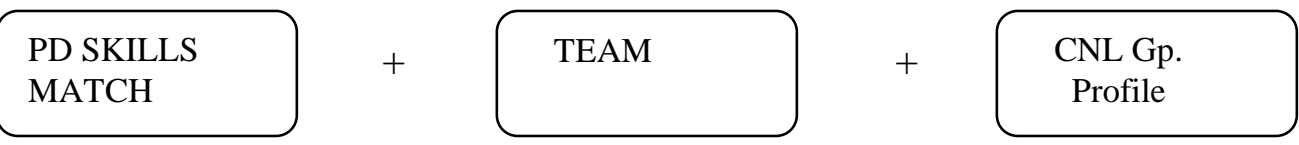

Figure 8: Proposal - preparation, professional development and support/Clinical Nurse Leader role 
Parallel to these initiatives an intranet site, inclusive of a photo and profile, would need to be established for the CNL group in the DHB. This profile should include how long they had been employed as a CNL, their areas of interests, plus any committee or project work they had undertaken. This site could also have the potential for ongoing networking and support amongst the group. A further proposal would need to be put to the DHB to establish a lounge that CNLs could use when they wished, either in their breaks or after they had completed their clinical day. Part B related to new appointments that may occur in the interim. A new Clinical Nurse Leader would be offered, in conjunction with their manager, the position description analysis plus skills list. In addition, an introduction to a more senior CNL as a mentor would be provided.

On completion of this explanation, I reiterated that the proposal was created from all of our ideas from research process. This included the discussions, questions asked, changes suggested and group endorsement of the proposal achieved. Initially, a participant questioned whether the name of the lounge should be the Clinical Nurse Leader Lounge, and whether the lounge should only be restricted to those who had this as their title. This participant was concerned that there was a risk of the lounge becoming "elitist". To prevent elitism happening, she suggested it should be called Senior Nurse Lounge. There was general agreement in the group that the name should change. The group then discussed if the proposal would be suitable for those who act up into the role temporarily. It was suggested even if the tenure was only in terms of weeks, another CNL could be appointed as a support. It was agreed that the longer appointments covering maternity leave would benefit from access to the position description as well as another CNL as a support.

Following on, a participant commented: "You have done very well with all that information". Another asked "Did it come out like ping or .... did this idea come ping or it is just something that has grown over time?" I relayed how the idea did develop suddenly but came from a period of immersion through all our research. My reply included:

and then suddenly the other night I thought this is our last meeting we've got all these ideas surely we can start to do something now with them", continuing later “and all of our work about mentoring professional development it's all of 
our ideas and that's really very satisfying cause that's what we were supposed to achieve through all this [action research].

The details of the proposal were discussed with participants agreeing that breaking down the position description was useful. One said: "I like the idea of breaking down the job description because ... I know when I first looked at it $[\mathrm{I}]$ had no idea really .... and they are deliberately broad". Further feedback on the proposal led to another participant saying: "It's quite mind-blowing, it's quite overwhelming and fantastic to think that somehow that's come out of us in seven eight months".

I explained that if the group agreed with the proposal, a consultative approach would be used as the next step towards implementation. This approach could involve any of them if they wished and would be in the form of short presentations to nursing directorate and at appropriate managerial forums. One participant queried who would be responsible for "driving" the proposal as they did not have a lot of extra time. My present role was Operations Manager for Education and Support so I informed them that, after appropriate consultation with my manager, it would fit well within my present role. The group agreed a general electronic invitation with attached information explaining the proposal would be sent out to the DHB's CNL group and I would facilitate that process. The meeting closed with the participants agreeing it was a positive move to consult and implement the proposal instead of waiting until the completion of my thesis. Some of the closing comments included:

Participants: "Exciting”; "I think you've done a great job actually”; “...it's been great"; "Yes it has".

Participant: "Amazing learning for me in the process and this is accomplished".

Suzie: "Thank you all very, very much ... I actually see this is a beginning". 
I reminded the group at the closure of the meeting that an evaluation meeting on the process was still to be held. My reflections follow, demonstrating that the researcher will have an effect on the phenomenon studied and it needs to be recognised that the researcher is also affected by being in the field (Coghlan \& Casey 2001; Dowling, 2006).

Tired group .... lots of me in this meeting as in participant wanted to give them something which I thought worthwhile from all our work not only so it will help CNLs, but so they could be proud of all of their ideas ... brilliant ... straightforward for me to pull them together ... Quiet thoughtful bit of sadness ...wanted to be business like bowing out back to more of what style they are used to ...wanted to get out quick without too much consideration time for us all...memorable moment though ... thought that... Thanks hugely.

\subsection{Meeting 10 Evaluation}

A final meeting was held on 5 October 2006 to evaluate how the process and the action research methodology had been for the group. Three members of the group were unable to attend. One had contacted me electronically to comment how she had enjoyed the process and the meetings. At this meeting, two of the participants stated that at the outset and separate to the meetings they questioned how much could really be gained out of what they termed as such a vague process. One said:

Well I think sometimes as we went through the process I got a little bit lost and I was thinking gosh you know where we are heading or what were we trying to say cause we had the question but it was trying to come up with I suppose not the answers but the way we found the role and some of it was quite difficult at times. The challenge of it to get it clear, get my head around it. I didn't realise what it was we were trying to achieve, I found that [out at].... the last meeting and probably the one before that... [It was then that] things really started to fall into place.

Another participant said: 
I think like .... I mean initially I struggled hugely with no structure it felt like where are we going?, why are having all these meetings?, and what's going to happen?.... It took a little bit of time [to learn] that that was OK. I think you're [CNLs] so used to going to things and being structured like we have a meeting and its structured and often we try and have the outcome before we've even got the question so I found that quite difficult.

Others added: "Yeah ... the point I found it very hard [was] at the start" and I was like a fish out of water and as time went by it got easier with the process. I did find it hard coming in at the start picking up the threads again but I found I was able to do it easier and easier as time went by. ... It might be because of what's happening out there you come in you sit down and .... where are we again, so it was good at that last meeting it ... pulled all the threads together and it was great.

One of the participants felt that it was therefore her problem and that I as primary investigator seemed to be comfortable and confident in the process. Another participant spoke of what an "amazing journey" it had been for her. Furthermore, she would miss the group meetings when they finished. A third participant described how proud she was of the work produced at this stage, referring to the proposal around preparation and professional development for the role.

The group then discussed how it was different from how they operated within their role of Clinical Nurse Leader and, as one said: "Maybe it's we want outcomes, we want them quicker". Another added:

It's interesting because in my opinion ... we look at the outcomes first because if you have a complex patient going home you're actually that end coming backwards right saying we've got to achieve that what do we do not we need to do this to achieve that cause you start in the morning this one is going home what does he need...Yeah you're right.

I spoke of the challenge for me as the primary investigator and said: 
The challenge for me was I knew you were all leaders in your own right and you wouldn't, and I predicted that you probably wouldn't, like it and you didn't. And so that was cool and I was cool with that, but equally as much I expected you to say where are we going, because that's not normally how we operate. The actual methodology comes from all sorts of disciplines, it's used in psychology, education and social science and it is a really good way to get those in their own community to actually affect change for themselves within their own community that's why I like it. It's not about me researching on you it's about me researching alongside you ... it's [a] sort of social research.

The group then thanked each other and I summarised both the consultative and communicative process for the future. The meeting was closed following a display of humour from one of the participants who said: "So dare I say it, where to next"? I replied "Shall I say it's up to you"?

\subsection{Summary}

The last stages of this action research, exploring how the role of CNL could be further informed and the support of the role further improved, saw the group working swiftly. They demonstrated concern for the future CNL. Preparation for the role, support and ongoing professional development was crucial for those either newly-appointed CNL or in existing positions. Meeting eight saw agreement on the worth of either the new or existing CNL assessing their learning needs and the preparation of their respective nursing team. Access, timing and frequency of education were important, with yearly performance appraisals and annual education sessions insufficient. A mentor either appointed or selected was also endorsed.

Meeting nine agreed on a proposal that outlined a preparation and professional development model for the CNL. The proposal included inviting four further CNLs of differing experience and settings to participate in a year long pilot. The group agreed that the proposal should be started prior to the writing of my thesis. The proposal expanded meeting eight's outcomes and had four key points. Firstly, the learning needs analysis that 
the CNLs completed against their relevant experience would include a skills list reflective of the skills needed within the organisational position description. It would be quite prescriptive in nature, asking the CNL how familiar they were with, for example, the computer system or performance management of nursing staff. Secondly, the CNL would be offered the opportunity to have an independent facilitator meet with their nursing team to discuss what the nurses considered the role of the CNL to be. Thirdly, the support structure required would include the establishment of a District Health Board intranet site that had both photos and profiles of the existing Clinical Nurse Leader group. Lastly, the group agreed that a request would be put to the DHB to establish a Senior Nurse Lounge where CNLs could go for breaks or on completion of their day. If a newly-appointed CNL commenced, they would be given information about the position description and advised about the need for a mentor.

Meeting 10, the final meeting, saw five of the group involved in an evaluation meeting and one further participant provide written feedback. The participants verbalised how they struggled initially with the action research process as it was foreign and different to the way they worked in their Clinical Nurse Leaders role. However, they appreciated the end outcomes, particularly relating to the agreed proposal and, for some, they enjoyed their own personal growth throughout. They enjoyed the debriefing prior to the meetings and for some they would miss both this aspect and the meetings.

This chapter is the conclusion of the analysis and interpretation of Phases One and Two data plus the research project overall. The remainder of the thesis presents a discussion on the findings and what insight or implications they have for others, what is presently known about clinical nurse leadership, and for the DHB in which this research was set. Recommendations are made alongside the challenges and limitations of the project, as well as suggestions for future research. 


\section{CHAPTER 9. DISCUSSION, RECOMMENDATIONS AND REFLECTIONS}

\subsection{Introduction}

This final chapter commences with an overview of the thesis to this point as a basis for the discussion, recommendations and reflections on the findings that follow. The chapter contains insights gained through this research about clinical nurse leadership and identifies opportunities for future research as well as the challenges and limitations of the project. The chapter presents recommendations for local stakeholders, including management and Clinical Nurse Leaders (CNLs), the nursing directorate and nurse educators in the District Health Board (DHB) which arise from the research. The challenge of conducting research in the same organisation where you are employed is examined with reflections drawing the thesis to a close.

\subsection{Thesis Overview}

This action research project examined the attributes and features of the role of the CNL within one District Health Board in New Zealand. The research objectives were twofold: to explore how the evolution of the CNL role could be further informed; and to establish what CNLs considered would support improvement for them in their role. The questions from these objectives were what is the role and who should define it? The study was based on the principles of action research; it involved participation, and had a strong emphasis on democracy and action. Seven nurses, active in the Clinical Nurse Leader role and from a variety of practice settings, consented to be part of the research. They would define the role and add to the discussion on its evolution and support.

The project was divided into two phases. Phase One was a face-to-face interview with each of the CNLs about their experience as a clinical nurse leader. Phase Two involved these seven CNLs joining with me to form an action research group. This group met on a monthly basis for ten months to work as an action research group with the data derived from the interviews. 
Key aspects of the context of this research were the DHB where the CNLs were employed and the position of nursing and nursing leadership within New Zealand. The DHB is a crown agent charged with responding and giving effect to health related policy from the New Zealand government. The focus of each DHB is to utilise their allocated resource to improve, advance and safeguard the health of their population (New Zealand Health and Disability Act, 2000). The Clinical Nurse Leader functions within one specific clinical setting and is some management layers away from the board that governs the District Health Board function. The CNLs are responsible for leading and managing nursing teams, for the maintenance of clinical standards in their area, and for giving effect to how nurses deliver on and comply with DHB policy. They are the conduit for the patient-related information, the key person that patient, family members, managers and the multidisciplinary team approach or contact. Essentially, when they are there they are expected to know what is going on in their area for their patients and, if they do not possess such details, know where the details can be obtained. When they are not there they are accountable for what goes on in their absence. Although the DHB where the research was carried out employs approximately 5,000 people, the CNL is a recognisable face of the organisation. The public knows that where there are patients, there will be someone, usually a nurse who is in charge whether it be a ward, clinic or mobile team. The function of the CNL role is typically described within the organisation position description and Chapter One described one such example. This example described the CNL as having 10 areas which they were accountable for, with 69 performance measures which their performance is evaluated against. The selection process for appointment into the role, subsequent orientation plus ongoing professional development of each CNL varied in length and content across the DHB.

The professional and situational context which the CNLs practice within has altered significantly over the past 30 years. Since 2001 all nursing programmes preparing for Registered Nurse status have been delivered by tertiary education providers with the newly graduating nurse having a degree (Keith \& Peat Marwick, 2001). The expectations of the skill set of the registered nurse and of the CNL have also changed. Increasingly there is a requirement for those in senior positions to possess sound business and financial planning 
skills as well as being able to undertake quality assessment. As the CNLs in this research attested, these skills are necessary to demonstrate being accountable for how nursing services impact on the health dollar. This added fiscal responsibility can be traced back to the country's health reforms of the 1990s. This era marked a significant change in the delivery of health care. DHBs were to operate based on a cost competitive market model and as a result of this change in operation, senior nurse positions like the Director of Nursing and the then Charge Nurse were reviewed.

Whilst the change to the delivery to health care has altered so too has the patient profile that access services within the DHBs. CNLs, in conjunction with their nursing teams, increasingly care for aging communities and increasing complex social situations of some patients. These changing patient profiles have seen physical infrastructure altered to include standard notification within hospitals that verbal or physical abuse will not be tolerated from the public. In addition, CNLs in remote rural settings lead and educate their teams on personal safety.

Findings from the Phase One interviews with the CNL revealed themes relating to the role, attributes, skills and knowledge requirements of the Clinical Nurse Leader. Some of the themes were representative of struggle and uncertainty, others were not. Some were directly opposite to each other (e.g. exciting/enjoyable compared to hard work/emotionally draining) demonstrating both the tensions and triumphs of being in the role. 24 themes were identified; this large number of themes is a standalone representation as to the complexity of the CNL role.

In Phase Two the action research group was established. The 24 themes were presented as a list at the second meeting to start the group action and reflection. Four of the nine meetings concentrated on the reality of practice and the tension caused by the leadership plus management mix within the role. The role was one of leadership, management and patient care. The group agreed that a supportive role alongside the CNL would be useful, for example an associate, as the present ability to achieve all that the organisation expected of the role was constrained. This constraint, or the reality of practising in the role, could be 
lessened by removal of accountabilities deemed not to be a priority, like the typing of long documents.

The last two meetings were concerned with preparation and ongoing professional development for the Clinical Nurse Leader. Their own professional development, the group established, was essential support for those in the role. The group agreed on a preparation and professional development proposal that would be put to the DHB where the research had been completed. This proposal included individual assessment by the $\mathrm{CNL}$ of their learning needs against the organisational position description. The proposal would also recommend that the DHB establish a senior nurse lounge, and set up an intranet site as a mechanism for CNL communication. This intranet site would profile each Clinical Nurse Leader employed by the DHB. In addition the CNL could have their respective nursing team explore what was their understanding of the role. The expectation of the group was that the proposal was to be progressed independent of the thesis.

\subsection{Discussion}

In general, the research findings resonate with the existing literature. I was particularly interested in the relationship this research had with previous works. Studies such as Tourangeau and McGilton (2004) who utilised a non nursing Leadership Practice Inventory Tool to assess nursing leadership and Welford (2002) who suggested that transformational leadership (a theory produced by a non-nurse Burns, 1978) are examples of these. I believed studies that relied on such theories, whilst informing the discussion around clinical leadership, were not the only approach. This concentration on what type of mainstream leadership behaviour is effective may not be useful for Clinical Nurse Leaders. It is known from such works, derived from non-nursing leadership theory, that certain agreed traits may be effective characteristics to display within the role of CNL. Kan (2002) warns, however, this may be to the detriment of developing clinical leaders. She suggests that devotion to emulating the so-called characteristics of an effective nurse leader may in fact promote the unattainable and unachievable for those in the role. Research that had not relied on such non-nursing theories and involved those in the role or their teams produced appropriate and arguably more attainable recommendations for those in this leadership 
position. The CNLs in this research were co-researchers defining the role and creating solutions for future communities of clinical nurse leaders. This study addressed some of the knowledge gap as identified by Hyrkäs and Dende (2008). They suggested, in their editorial, that a body of work had yet to be completed that encapsulates the essence of the role as well as the setting the clinical leaders of nursing function within and exactly where or how the impact is experienced.

The interviews with the CNLs contained content concerning the role, attributes, skills and knowledge requirements and the experience of being in the role. Cook (2001) found that a CNL's core set of attributes include respecting and influencing. Respecting is when the CNL is open to others' perspectives and influencing is the ability to assist others to understand others' attitudes. While in this research the word respecting was not used, it was assumed in how the CNLs talked of their profile. Being influential, however, was referred to but unlike the perspective of Cook, the focus was on enabling staff as opposed to assisting.

Other researchers highlighted that the role is pivotal in the successful implementation of present and future health care strategies (Clegg, 2001; Doherty, 2003; Drach-Zahavy \& Dagan, 2002; Drummond, 2002; Kan, 2002; Williams, 2004). Again, this set of interviews highlighted the pivotal nature of the role as well as the legitimate power and authority that the role carries. This means the CNL needs to have knowledge of all aspects of their respective clinical area. The action research group meetings raised the key place the role occupies being the conduit for patient information for family, multidisciplinary team and management, the responsibility as patient advocate, allocation of newly-admitted patients, budget accountability and rostering of nursing staff. This pivotal place meant that, on occasions, CNLs attend a series of events within a matter of hours. Such events could include assisting at a critical clinical situation like a cardiac arrest, overseeing the documentation necessary to accompany a deceased patient's transfer from the ward, and attending a complex family meeting concerning another patient may occur. This pivotal presence occurs in a pressured health environment. As Heller et al. (2004) state: 
The role of front-line managers has become more challenging during the past decade. In today's turbulent healthcare environment, nurse managers are expected to provide leadership on units that have high staff vacancy and turnover rates, patients with higher acuity levels and higher incidence of chronic diseases, more limited financial resources and support staff and increasingly complex technology and reporting requirements. (p. 204)

General widespread agreement that the role involves conflict is reported in the literature. Firth's (2002) study involving ward managers, the British equivalent of CNL, described how ward managers found the balancing of clinical and managerial responsibilities "problematic" and a cause of "conflict" (p. 489). This current research also contained content relating to conflict that occurs between the leadership and management aspects of the role both at interview and throughout the action research group work. We now know more about this tension. The administrative responsibilities to type up staff appraisals and progress incident forms are time consuming and take the CNL away from the clinical leadership aspects of the role. The responsibility of a cost centre was not a priority for some CNLs and left them feeling powerless to do anything about it. Patient care and overall responsibility for clinical care were their priorities. The patient should be retained as the focus and the administrative tasks should be devolved out of the role. Solutions to the CNL workload were explored and raised the need to scope the size of the role in each area and to establish the feasibility of an associate Clinical Nurse Leader position being developed. West, Lyon, McBain and Gass (2004) agree that there can be role overload and the role can only progress quality of patient care if role expectations are made clear at the outset. Latterly Mills (2005) describes the extra pressure on the nurse leader roles as one of "role conflict and lack of role clarity in increasingly complex organisations" (p. 20).

The tension caused by the leadership/management functions, as derived from the organisational expectation of the CNL role, remained a constant thread throughout this research. It was one of the 24 themes from the initial interviews, one of the remaining two after the action research group reduced the focus and the one that occupied four of the nine action research meetings. Clinical leaders in nursing impact on quality of patient care 
delivered but need support mechanisms and role expectations made clear at the outset (Stanley, 2006). He states: "The result can be conflict, confusion, challenges to the clinician's values and beliefs, or ineffective leadership and management, leading to diminished clinical effectiveness, or even dysfunctional ward or units, and therefore poor quality patient care" (p. 31).

One of the participants summarised similarly:

What are we? We're nurses, and to lead nursing practice is what I'm passionate about and to be expert, expert of excellence. I'm not a secretary, I'm not a typist, [and] I'm not a finance person. (Meeting 5)

Professional development is deemed important in support of the CNL role (Cook, 2001; Sullivan et al., 2003; Connelly, Nabarette \& Smith, 2003). Education, commencing at undergraduate level, needs to include leadership, management, finance and quality assurance (Williams, 2004; Mills, 2005). Cook and Leathard (2004) deem preparation of the role inadequate. They conclude: "much learning about leadership is undertaken once a person has been designated as a clinical nurse leader, rather than in preparation for the position" (p. 440). They add current clinical leadership programmes are in the main disconnected from the wider organisational direction. Thorpe and Loo (2003) suggest that not enough attention is given to meeting the individual needs of nurse managers (Canadian term to generically describe those in roles similar to the clinical nurse leader). They propose that nurse managers should be involved in their education planning. SpenceLaschinger, Purdy, Cho and Almost (2006) suggest that organisational support plays a role in retaining nurse managers.

The current research uncovered the lack of preparation and ongoing support experienced by the seven CNLs. This research again added more knowledge not only about the suitability of the professional development afforded the role but also the content, timing and self assessment by the CNL about what education is needed. In the interviews, the limited feedback about how they were doing when first in the role was highlighted, as well as the varying levels of access to professional support, for example a mentor. The action research group were clear that the present preparation, support and professional 
development afforded the role could be further developed and that the support needed to be continuous. The professional development model created from this research is based on a learning need analysis against the position description carried out by the CNL themselves. This arose from the group raising the lack of regular feedback on performance, particularly in the orientation stage. The yearly performance review was not seen as an effective tool to plan education and a suggestion was made to undertake an informal review at three months into the role. The position description would allow those already in the role, and those beginning, the ability to rate their understanding of the key functions of the role and develop, in conjunction with their manager, an individual plan. The details could include such topics as education around human resource management or around computer tasks or software necessary to function in the role in a large organisation. The nursing staff understanding of the role of CNL also was an area suggested for further development also.

This focus and partnership with those in the reality of clinical leadership practice was valuable. Significantly, the group agreed that the major components of the role are leadership, management and patient care. Conflict occurs between the management and leadership functions of the role but the group agreed patient care was still vital to the role. The CNLs defined the role and offered new solutions for the future community of CNLs in the DHB. These new solutions addressed the tension that occurred when there is both leadership and management accountabilities within the organisational expectation of the role. This tension is already described by existing literature aforementioned. The solutions included a specific professional support model and a scoping exercise to be applied to all clinical settings to see the feasibility of an Associate Clinical Nurse Leader. These outcomes were arrived at after the constructive distillation of data surrounding the role by the group and the focus on two aspects that surfaced when in the role in a DHB setting. The group listened and learned from each other and then coalesced for the future of CNLs. The situational context or environment of this research, the role of the CNL within the District Health Board and the DHB structure, was pivotal to and within the inquiry. The findings surfaced the strategies those in the role use for managing the organisational expectations of the role. When researching the role within this context with those in the role, I was and remain reminded of the tension that occurred in New Zealand between the 
humanism of nursing and the managerialism of the cost corporate market model in the 1990s (Bamford \& Porter-O'Grady, 2000; White, 2004). For example, a DHB articulates its outcomes in terms familiar with the cost corporate model reflected in the CNL's position description, including terminology like performance measures and accountabilities. Nursing measures are communicated in terms of humanism with a holistic approach adopted to patient care. This is derived from their professional context and curriculum that shapes the student to achieve degree status as a Registered Nurse to practice. Nursing is grounded in the humanities and science, not in business. Significantly White adds: "The professional and business cultures not only have a different values base but have their own language systems" (p. 184).

This research revealed this mismatch between the profession of nursing and the culture of business, in this case the CNLs' expectations and the organisation's requirements of the role. Qualitative and quantitative research approaches are often described as occupying completely opposite positions, much like the CNL and the organisation, with differing expectations and language attached to outcomes. Although Onweugbuzie (2000) is referring to these two research paradigms, his term of adopting an ecumenical approach for better outcomes in research resonates and may be what is needed here. An ecumenical or combined approach to seek better understanding of each other's role may well enhance the relationship between the profession of nursing and the culture of business such as in DHBs.

\subsection{Insight and Recommendations for Stakeholders}

\section{The District Health Board and Clinical Nurse Leaders- Inextricably Linked}

The action research group explored a key role that could not be separated from its context, the District Health Board. The research findings were related to the role of a CNL responding to their environment. The $\mathrm{DHB}$, as a funder and provider of health services to its population, employs senior nurses to fulfil this function within its clinical management structure. Both the DHB and the CNL have responsibilities that fall out of their inextricable link. 
The CNL is responsible for the running of a clinical area with a DHB formal position description attached to the role. This position description is a document that serves to both outline function and measure performance within the CNL role. Their responsibilities include, but are not limited, to walking alongside patients throughout their health journey, contributing the nursing perspective of patient care to the multidisciplinary team and guiding nursing staff in clinical standards. This guidance incorporates the organisational expectation of performance management of the nursing staff, as well as rostering of the same staff to allow for up to 24 hour cover of the inpatient area. The role also carries a traceable accountability to quality and risk initiatives of the organisation as well as the ward budget.

The DHB is responsible for employing the CNL and the written expectations of their role contained within their position description. The main insight this project offers for the DHB where it was undertaken is that much can be done to improve both the CNLs' and the DHB's understanding of each others perspective. Discussion between the CNL and the DHB can take place and collaborative inquiry can be undertaken going forward with a collective responsibility to key issues. To reiterate, the CNLs involved in this research agreed the role was about leadership, management and patient care and that individually in interviews and as an action research group patients and nursing staff were very important to them. This point of overall responsibility for patient care is significant. The organisation would benefit from establishing if the role of CNL, across all areas, does govern clinical standards and is totally responsible for patient care.

Collectively, the DHB and the CNLs need to extensively review the position description and the number of nursing staff each CNL is responsible for, and look at the potential for scoping an associate CNL dependent on the size of the area. There have already been encouraging beginnings as the DHB has endorsed the group's proposal relating to the professional development model at its early stage including the establishment of an intranet site and, more recently, the creation of a Senior Nurse Lounge. 
This work needs to continue, as the reality is that one cannot do without the other as the majority of New Zealand nurses, including CNLs, work within a DHB setting. They therefore cannot develop in isolation from each other. White (2004) recommends:

Nurses need to be assisted to reframe their understanding of the expression of the nurse-patient relationship and nursing practice in the contemporary healthcare system and to see themselves as caring and connected knowledge workers who bring humanity to an otherwise often dehumanising technically focused illness-cure system. (p. 207)

The DHB would benefit from such reframing in order to understand how nurses are prepared at undergraduate level. This is where their CNLs develop from. This, in part, explains why the CNLs through nine meetings and an interview maintained the importance of the patient. Not the budget, roster, quality and risk accountabilities, but the patient and their nursing staff. They are a nurse, a nurse, a nurse and, as White (2004) suggests: "The focus on nurse-patient relationship, to the virtual exclusion of other relationships, has left nurses in a position of vulnerability" (p. 208). This position of vulnerability can be altered by such collaborative work as suggested. The CNL would benefit from a deeper understanding of the DHB as a crown agent, the DHB's responsibility to its population and how that responsibility is translated to various roles in this market model. Then, as White goes on to suggest, New Zealand nurses would do well to continue to develop their understanding of the political processes that influences health care delivery, such as the nineties health reforms and she states: "to work with governments and opinion-makers persuasively with a rich blend of evidence and story" (p. 216).

\subsection{Directorate and Nurse Educators}

The professional development model that is based on individual learning needs assessment by the CNL and extension of knowledge to their nursing staff and the role of a mentor, was indicated as important by the group. This is of relevance to the DHB's executive nursing officer, senior nurses and education team as well as nursing degree programmes. The undergraduate nursing curriculum needs to prepare the nurse for the reality of the health 
sector and the sector needs to be involved in curriculum development addressing specifically the two positions of business culture and nursing culture. The present education for the role is influenced by and restricted to non-nursing leadership models and management philosophy. This research adds to an impressive amount of nursing-led research on a nursing role. It is timely to consider the review of education offered to the CNL in this DHB to be underpinned by this collection of nursing-led research on a nursing role.

\subsection{Challenges and Limitations}

Action research was the methodology I chose to pursue my inquiry within this DHB. I, as the principal investigator, was already employed in a nursing management role at the District Health Board. Coghlan and Brannick (2005) state:

Sharing the power of knowledge production with the researched subverts the normal practice of knowledge and policy development as being the primary domain of researchers and policy-makers. Action researchers work on the epistemological assumption that the purpose of academic research and discourse is not just to describe, understand and explain the world but also to change it. The issue is not so much the form of the knowledge produced or the methodology employed to gather data/evidence but who decides the research agenda in the first place and who benefits directly from it. (p. 7)

Koch and Kralik (2006) ask the following questions of an action research project: Is the inquiry useful? How do we know we have a quality research practice? Has it made a difference and are actions sustainable?

The group initially struggled with the action research process but achieved remarkable insight and outcomes. Separate to this uncertainty, as Dick (2001) describes, a climate of support was established. This climate within the action research group saw frail and conflicting data contested. Themes were rejected, remaining ones discussed and realities of practice applied. Dick explains in an action research process language and dialogue form a large part of the data, allowing participants access and involvement to challenge the 
researcher. The group's outcomes surrounding the role of CNL related robustly to relevant recent research and, in addition, the group defined the role producing a unique proposal related to preparation and professional development.

The position of being an "insider" (Coghlan \& Casey, 2001, p. 675) if undertaking research where you were employed, was a view I was aware of before entering the field. I was not only employed in the organisation but I also had functioned in clinical leadership roles. I did not find it a limitation. The participants were willing to share their experiences with me in a frank and honest manner. This candid approach was maintained throughout the action research group work. I am not convinced that we would have reached the outcomes as described if I was an "external agent" (Coghlan \& Casey, p. 675) to the group. This research was carried out to work with CNL colleagues to further inform the evolution of the role and the professional support afforded the role as well as for my own personal development. Coghlan and Brannick (2005) refer to insider action research as first, second and third person research. First is research undertaken that contributes to the researchers own personal development. Second person research is with colleagues on issues of mutual concern and third person research sees the development of theory from such a collaborative research experience. Coghlan and Brannick describe how the insider has valuable information about the culture of their organisation but caution being too close to the data as this may mean not enough questioning on the researcher's part. Journaling was a regular process for me and that allowed me to be both non-canonical and honest about my pre-understanding. I constantly asked myself in the group work, what is going on?

One criticism of action research is that it is only locally relevant. Freshwater (2005) contests and states "social and political context will have some resonance with other organizations, while the local factors may differ slightly; the principles underpinning the transformatory approach to theory and practice are transferable to any clinical situation" (p. 220). I agree with Freshwater as there are clinical leadership roles in nursing throughout the other DHBs in New Zealand. While each may have different organisational position descriptions it is likely that the findings of this study will have some relevance. 


\subsection{Future Research}

This research project has allowed for those active in the role to be co-researchers in a project that looked at how the evolution of the role of CNL could be further informed and how the professional support of the role could be further improved. This exposition clearly lends itself to further research which concentrates on context, that of a District Health Board structure, and connection to that context from the CNL role. The responsibility within that structure and expectations that fall out of the strength or weaknesses of this connection should be further explored. This could take place following the collective effort of both the DHB and the CNL group to review the role in relation to responsibilities and scope based on the findings of this research. Once this is complete and an associate role installed in certain areas, this intervention could be evaluated from both those in the role and the organisation. Do the organisation and the CNLs agree this role is one of the major recognisable clinical faces of the DHB to their public? Does the DHB agree the CNL is the conduit to the communications of all the multidisciplinary team and patient or family enquiries? How much does a CNL know about the link between their role and the function and responsibility of the DHB and in particular the provider arm? Is the role a depository for organisational expectations that are necessary to respond to as part of their DHB structure and accountability to the public? And, if it is, how much preparation goes into managing the added responsibilities? Questions such as these could underpin the agreement on what future research would add to further understanding about the inextricable link between the situational context of a DHB and the professional context of nursing. Nationally this research could be shared, as the role of Clinical Nurse Leader (now Clinical Nurse Manager - see post script) is consistently used throughout New Zealand. The findings of this research would warrant an examination of the joint expectations of the $\mathrm{CNL}$ and their respective organisations. At the least, an analysis of the preparation and professional development attached to this role would be useful throughout New Zealand to compare educational programmes. Internationally, further research on the significant place of patient care within health care organisations and who is ultimately responsible for that could be explored. How to minimise the agreed conflict experienced in the role between 
leadership and management aspects of the role could be examined further, unpacking just what are the components of such conflict.

This chapter summarised the thesis as a whole, presenting a discussion on how the findings relate to recent relevant literature and what new knowledge has been added to the research on the role of CNL. How the role can be further informed and how the support of the role can be further improved has been addressed. What the role is has been answered, as defined by those in the role; the patient and their care identified as significant by the CNLs. Their leadership of their nurses is also important to them. A comparison to Bamford and Porter-O'Grady's (2000) work where the tension caused by the craft of nursing practising against the backdrop of the culture of business in New Zealand and work is included. The role seems to symbolise the humanism of nursing and the context in which it is practiced; the DHB symbolises the cost corporate model of health care. This is, however, the practice reality as the majority of New Zealand CNLs work within this structure. Keith, Peat and Marwick (2001) advise this market-driven model is likely to continue and nurses will have to adapt. White (2004) advises nurses in general may need assistance to reframe their understanding of nursing within this corporate model. A more ecumenical approach to the relationship between the CNLs and the DHB is suggested as a way forward.

This chapter highlighted the main insights that this project offers for the stakeholders, that is the DHB, CNLs, executive nursing leaders, senior nurses and education teams. It acknowledges that the DHB where the research was undertaken has already embraced part of the research outcomes, namely an intranet site, early adoption of a preparation and professional development proposal for the role and acceptance of a proposal to establish a Senior Nurse lounge. This research project could be extended and the proposal to continue to concentrate on the link between the situational context, that of the DHB and the professional context of nursing, has been made. 


\subsection{Closing Reflections}

I commenced this research intending to explore clinical leadership in nursing within a District Health Board setting in a study that was based on the principles of action research, that is research which is cyclic, qualitative and participatory. The role of Clinical Nurse Leader in the District Health Board matters. It matters to the organisation, it matters to the patients and it matters to me. Due to the nature of action research the evolution of the project was unpredictable but it was expected that myself at the outset as principal investigator alongside the participants would be involved in a responsive, emergent, flexible and reflective approach. Firstly, the professional preparation for the CNL role has been previously influenced and restricted to known leadership models and non-nursing management philosophy. In addition to this limited influence, there has been a very minimal amount of New Zealand research carried out on this role. I commenced this research aiming to inform any further evolution of the role and to improve the support afforded the role. I decided that those in the role would define the role and be coresearchers.

Action research with my colleagues has been challenging and complex, fascinating and, to some extent, an episode of discovery. It reaffirmed the way I know others and how that might appear and what that translates into, as Wadsworth describes, spoken or unspoken, conscious or subconscious. It also uncovered how I behave as a result of that knowing. I am reminded of the opening words of this thesis which finishes "exercise stewardship without control". As a group, we completed a significant piece of research that explored the role of CNL without any control over how the research would unfold or what would be the outcomes. That is the beauty of action research. The qualitative nature of the research allowed for not only an opportunity to display just exactly how it is to be in the role of Clinical Nurse Leader but also to include both the challenges and privileges that this methodology affords the principal investigator. It was, as I said at the outset, to be a time of growth. I entered the research with my expectations of the group and in order to demonstrate reflexiveness and thus strengthen the validity, I recorded my perspective as we worked as a group. 
I was entrusted with narratives that were deeply moving and personal about how it was to function in the role. These were powerful pieces of dialogue which spoke to the role, the reality of the practice under such expectations and how they all made sense of these. I witnessed the tiredness and the sense of apathy that they could not make a difference. I equally saw their commitment and obvious enjoyment of the role and the research, hence the reflections contained in "The Race". Whilst at times, in the thick of it, the group expressed such apathy the solutions reached and the outcomes achieved were remarkable. The in-depth analysis of the role achieved by those in the role that this methodology afforded us resulted in useful, significant outcomes. This research will, I believe, contribute to making a difference. My comments in the final action research meeting reflect this belief.

I thank you all for the trust and for the gems of wisdom you gave me... I know we did a good job for our colleagues and those who will be the future CNLs that will walk down the hill to their cars tired but so secure that they made such a difference to their staff and their patients. To our group rest now and know you all were magnificent. I did not have the answers but gloriously and proudly we had the answers.

\section{$\underline{\text { Post Script }}$}

The professional development proposal, which included preparation and ongoing professional support plus an intranet site and senior nurse lounge was presented, as an agenda item at Operations Managers' forums; nursing directorate and senior nurse forums (see Appendix 7). All supported the professional development concept. This concept was electronically circulated to the CNL group with an invitation attached to meet with me if they wished to use the model. Four CNLs responded to the invitation. Three existing CNLs drew up a learning development plan for themselves and one further CNL discussed how ongoing work with the nursing team may be facilitated.

The intranet site has been established, entitled CNM Network, with photos and profiles of CNLs included. This is to be extended to other areas outside of the larger hospital. This project is well supported by the information technology and communication experts in the 
DHB with future plans for it to be an interactive site. The proposal for the establishment of a Senior Nurse Lounge was first sent to the Chief Operating Officer then the Director of Nursing plus the nursing directorate. Following this, it was presented to the campus redevelopment committee who indicated their support and commitment to include senior nurses in their campus allocation of senior staff lounges for 2009. Lastly, the title of Clinical Nurse Leader was changed to Clinical Nurse Manager as of February 2007 following a national project that looked at senior nurse titles within district health boards in New Zealand. 


\section{APPENDICES}

\section{APPENDIX 1: $\quad$ HUMAN ETHICS APPROVAL}

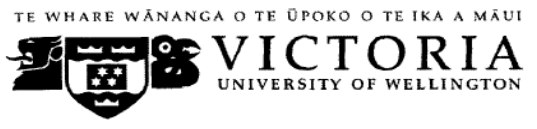

\begin{tabular}{|c|c|c|}
\hline MFMORANDUM & Phone & $0-4-4635676$ \\
\hline & Fax & $0-4-4635209$ \\
\hline & Email & Allison.kirkman@vuw.ac.nz \\
\hline
\end{tabular}

\begin{tabular}{l|l}
\hline TO & Suzanne Gardner \\
\hline COPY TO & Dr Katherine Nelson \\
\hline FROM & Dr Allison Kirkman, Convener, Human Ethics Committee \\
\hline & \\
\hline DATE & August 31, 2005 \\
\hline PAGES & 1 \\
\hline
\end{tabular}

SUBJECT Approval: No 107/2005 - Clinical leadership in nursing within a New Zealand setting.

Thank you for your application for ethical approval, which has now been considered by the Standing Committee of the Human Ethics Committee.

Your application has been approved and this approval continues until 30 April 2007. If your data collection is not completed by this date you should apply to the Human Ethics Committee for an extension to this approval.

Best wishes with the research.

Aliison Kirkman

Convener 
1A: Extension to human ethics approval

$\begin{array}{ll}\text { From: } & \text { "Allison Kirkman" <Allison.Kirkman@vuw.ac.nz> } \\ \text { To: } & \text { "Suzie Gardner" <GardnerS@waikatodhb.govt.nz> } \\ \text { Date: } & 7 / 03 / 2007 \text { 21:01:02 }\end{array}$

Subject: RE: Ethics extension

Dear Suzanne

This extension is approved

Best regards

Allison Kirkman

Convener, HEC

Dr Allison Kirkman

Associate Dean (Students) \& Senior Lecturer in Sociology

Faculty of Humanities \& Social Sciences

Victoria University of Wellington

Te Whare Wananga o te Upoko o te Ika a Maui

Box 600 , Wellington

$\mathrm{Ph} 463$ 5676, Fax 4635209

http://www.vuw.ac.nz/fhss

<https://webmail.vuw.ac.nz/exchweb/bin/redir.asp?URL=http://www.vuw.ac.nz/fhss>

From: Suzie Gardner [mailto:GardnerS@waikatodhb.govt.nz]

Sent: Wed 7/03/2007 4:30 p.m.

To: Allison Kirkman

Cc: Kathy Nelson

Subject: Ethics extension

Dear Allison

RE: Approval : No 107/2005-Clinical Leadership in nursing within a New

Zealand setting

I would like to apply to the Human Ethics Committee for an extension to

my approval as described above to December 2007

\section{Kind regards}

Suzanne Gardner

28 Huntington Drive

Hamilton

CC: 


\section{APPENDIX 2: $\quad$ LETTER OF PERMISSION: CEO}

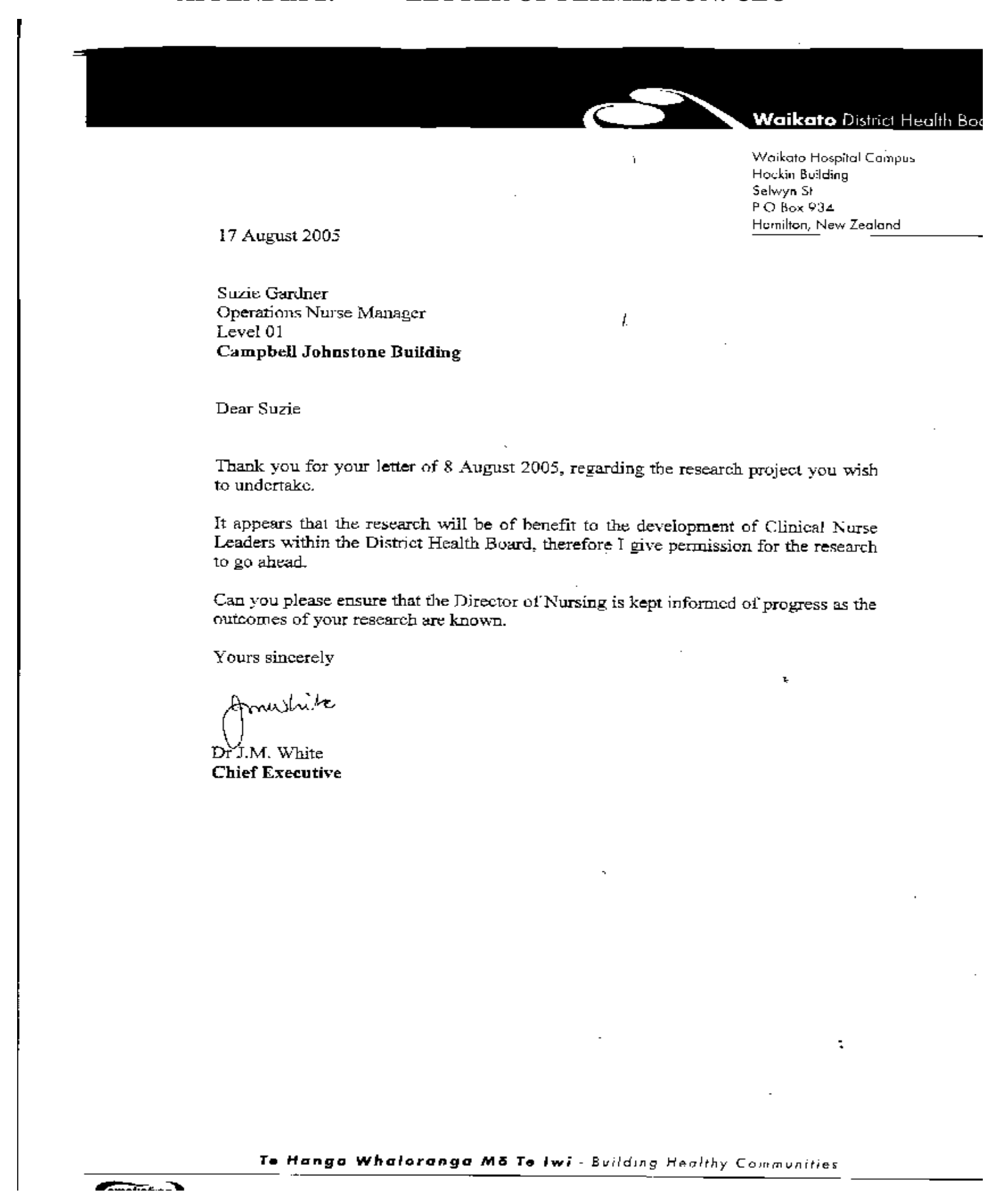




\section{APPENDIX 3: $\quad$ ELECTRONIC INVITATION}

$\begin{array}{ll}\text { From: } & \text { Suzie Gardner } \\ \text { To: } & 9 / 6 / 0511: 03 \\ \text { Date: } & \text { Invitation to participate in research } \\ \text { Subject: } & \end{array}$

Please circulate to Clinical Nurse Leader group only including T's and Community Services - with thanks

Dear colleagues

As some of you are aware I am about to undertake a research project for my Master degree. I am writing to invite you to be involved in my research which is looking at nursing leadership within a clinical setting. Please find attached an information sheet explaining the proposed research project and feel free to contact me to discuss any queries you may have regarding my research

Suzie Gardner

Operations Nurse Manager

Education Support \& Professional Development

Ext. 5876

gardners@waikatodhb.govt.nz

CC: 


\title{
APPENDIX 4: $\quad$ INFORMATION SHEET
}

\author{
VICTORIA UNIVERSITY OF WELLINGTON \\ Te Whare Wananga o te Upoko o te Ika a Maui
}

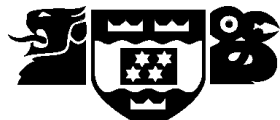 \\ Information Sheet for a Study on Clinical Leadership in Nursing within a New Zealand District Health Board setting}

\section{Researcher:}

Suzanne Gardner (Suzie): Graduate School Of Nursing \& Midwifery, Victoria University of Wellington

I am a Masters student in Nursing at Graduate School of Nursing Victoria University of Wellington. As part of this degree I am undertaking a research project leading to a thesis. The project I am undertaking is a study based on the principles of action research exploring clinical leadership in nursing within a District Health Board setting. This research has been approved by Victoria University of Wellington Ethics Committee and the Chief Executive Officer of the Waikato District Health Board.

I am inviting nurse leaders, as defined by their Waikato District Health Board position description, presently practising in either a clinical nurse leader or charge nurse role to participate alongside me in this study. The study will be undertaken based on the principles of action research that is research which is cyclic, qualitative and participatory. The research project will consist of two stages of data collection involving 8-10 participants.

The first phase will involve a one on one interview, approximately an hour long, exploring clinical leadership. Following on from this a thematic analysis will be done to provide the basis for the first of 6-10 meetings. The direction of the research will then be determined by the group. You can withdraw at any time without question. If you volunteer participation will span over approximately six months and will entail regular meetings of one to two hours. The agenda and venue will be determined by the group and the contents will be taped.

All efforts will be employed to protect the identity of the participants within the research thesis. This action research project will form the basis of my thesis, which will be submitted for examination to Victoria University of Wellington and deposited within both the University library and the District Health Board library. It is intended that one or more articles will be submitted for publication in scholarly journals. All written material will be destroyed two years after the end of the project.

All participants will be sent a summary of research findings and depending on the outcome, the group may decide to give a joint presentation at a conference.

If you have any questions or would like further information there are two options:

1) Please do not hesitate to contact myself and/or my supervisors- see below for contact details

OR 
2) Attend an information meeting on the ... at ... whereby I will be explaining action research and what it means to be a participant in an action research project.

The closing date for recruitment of participants will be ...

\section{$\underline{\text { Supervisors }}$}

Dr Katherine Nelson - Lecturer

Graduate School of Nursing \& Midwifery Victoria University of Wellington $\mathrm{Ph}: 044636138$

Email: Kathy.Nelson@vuw.ac.nz

Dr Pamela Wood - Associate Professor

Graduate School of Nursing \& Midwifery Victoria University of Wellington Ph: 044636650

Email: Pamela.Wood@vuw.ac.nz

Principal Investigator

Suzie Gardner

Operations Nurse Manager Education, Support, Professional Development

C/- Level 01

Campbell Johnston Building

Waikato Hospital

078398899 ext 5876

pager 20372

Email: gardners@waikatodhb.govt.nz

Suzie Gardner

Operations Nurse Manager

Education Support Professional Development

LO1 Campbell Johnston Building

Waikato Hospital

Signed 


\section{APPENDIX 5: $\quad$ CONSENT FORM}

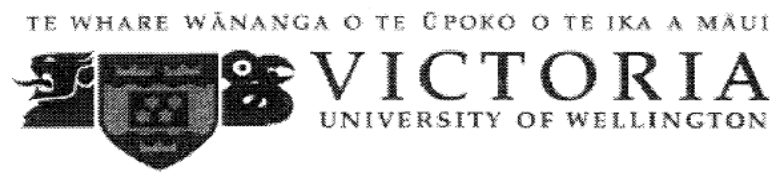

\section{VICTORIA UNIVERSITY OF WELLINGTON CONSENT TO PARTICIPATION IN RESEARCH}

Title of project: Clinical Leadership in Nursing within a New Zealand setting

- I have been given and have understood an explanation of this research project. I have had an opportunity to ask questions and have them answered to my satisfaction. I understand that I may withdraw myself from this project without having to give reasons or without penalty of any sort at any point.

- I understand that any information as part of the project and within the project group will be kept confidential to the researcher and the supervisors. The published results will not use my name and that no opinions will be attributed to me in any way that will identify me. I understand that the tape recordings of research meetings will be electronically wiped at the end of the project and all paper files after two years

a I agree to abide by the ground rules as determined by the group.

a I understand that I will have an opportunity to check the transcripts or meeting notes of the action group meeting before the follow up meeting.

a I understand that the data I provide will not be used for any other purpose or released to others without my written consent.

ㅁ I would like to receive a summary of the results of this research when it is completed

I I agree to take part in this research.

Signed :

Date :

Name of participant

(please print clearly) 

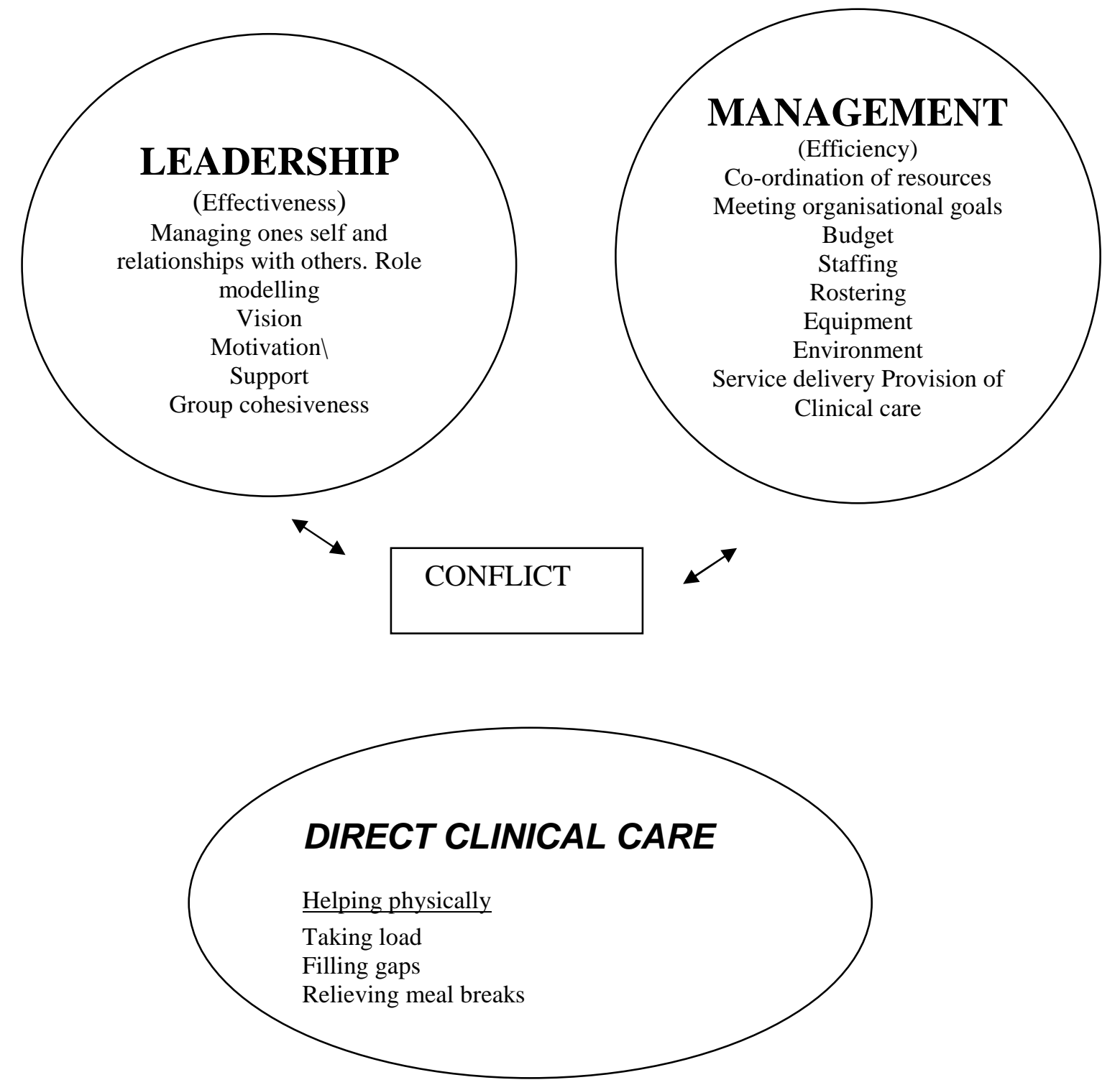


\section{APPENDIX 7: $\quad$ PROFESSIONAL DEVELOPMENT PROPOSAL}

\section{Clinical Leadership in Nursing Within A New Zealand Setting}

Principal Investigator Suzie Gardner (Ops Mgr Clinical \& Nursing Service) Student of Grad. School of Nursing \& Midwifery

Victoria University, Wellington

021549635

Aim of research:

"To explore clinical leadership in nursing within a District Health Board setting in a study based on the principles of action research, that is research which is cyclic, qualitative and participatory."

Comm'd Dec 2005 completed Dec 2006 Thesis for examination April 2007.

Please note the following proposal arose as part of the outcomes from above research.

This is not a summary of the thesis as in draft form only at present as of Jan 2007.

\section{Background}

- $\quad$ Principal Investigator Suzie Gardner student of Grad. School of Nursing \& Midwifery Victoria University Wellington enrolled in Master of Nursing

- "To explore clinical leadership in nursing within a District Health Board setting in a study based on the principles of action research, that is research which is cyclic, qualitative and participatory." Ethics application to VUW HEC

- $\quad$ Gained approval from VUW and also Dr Jan White CEO WDHB,recruit \& consent process- + DON aware ,update to present CEO to be given

- Comm'd Dec 2005 with 2 parts to data collection: one on one unstructured interview with 7 CNL's ,6-10 meetings held over six months $=10$ meetings held over $11 \mathrm{mths}$

- AR methodology permeated industrial psychology, management and educationalists.

- $\quad$ Mid 1800's John Dewey -philospher of democracy \& education, Kurt Lewin = study systemically a social problem co-operatively with intention to solve and generate new knowledge. Picked up by psychology, management and education and latterly nursing.

- $\quad$ First draft to be sent Dec 1st. submit for exam April 2007.

- However one of the topics that we, as a group wanted to present pre exam was a proposal to pilot Preparation,Prof. Dev \& Support for the CNL within the WDHB = drawing together all ideas related to both from the group over a period of 10 months.

\section{Cont'd. $\quad$ Clinical Leadership in Nursing Within A New Zealand Setting}




\section{Proposal}

- Two parts

$\underline{\text { Part } \mathbf{A}}=$ pilot with length of $12 \mathrm{mths}$ choose $4 \mathrm{CNL}$ 's active in role

$\mathrm{X} 1 \mathrm{CNL}>5 \mathrm{yrs}$

$\mathrm{X} 1 \mathrm{CNL}<5 \mathrm{yrs}$

X 1 T Hospital

X 1 Primary Health

All above do a analysis of their skills against their PD (skill list suppl'd)

CNL decide against this \& PD where opp.for further dev. is and d/w Mgr as to when can upskill

$+\mathrm{CNL}$ gp profile increased $=\mathrm{CNL}$ gp intranet site $($ photo, $\mathrm{b} / \mathrm{g}$ interests $)=$ Potential mentors/support

+ Nursing Team independent fac to $\mathrm{d} / \mathrm{w}$ CNL's nursing team understanding of role of $\mathrm{CNL}=$ interest gp. Of nurses within area to dev. SN/CNL support gp to learn about various aspects of role

\section{Extra for Part A}

Senior Nurse Lounge on WH campus

\section{$\underline{\text { Part B }}$}

If new appt to CNL role occurs new CNL gains access to all

PD skills match + Team work + SN/CNL support + CNL gp profile

Evaluation of pilot

Questions

For any further enquiries/comments relating to this summary please contact author Suzie Gardner on email GardnerS@ waikatodhb.govt.nz or work mob; 021549-635

Thanks 


\section{APPENDIX 8: $\quad$ FURTHER CEO PERMISSION}

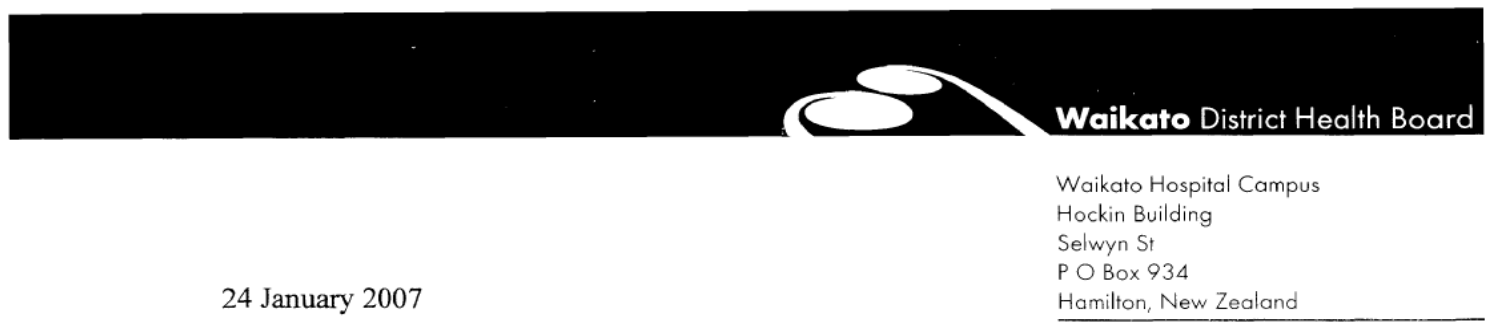

Suzie Gardner

Operations Nurse Manager Education \& Support

Clinical \& Nursing Services

Level 03

Campbell Johnstone

Dear Suzie

Following on from our meeting of 18 January 2007, I wish to confirm in writing, my agreement for you to include in your thesis:

1) The reproduction of a diagram representing the management structure and frontline staff connection (which includes the CNL position) contained in a Waikato DHB document entitled "A Guide to the Structure and Committees of Waikato DHB including Provider Division Health Waikato".

2) General reference to the Waikato DHB Strategic Plan in order to explain the functions of the DHB.

All the best with your research and study.

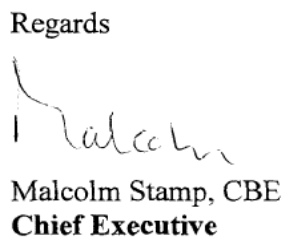

Chief Executive 


\section{REFERENCES}

Antrobus, S., \& Kitson, A. (1999). Nursing leadership: Influencing and shaping policy and nursing practice. Journal of Advanced Nursing, 29(3), 746-53 doi: 10.1046/j.13652648.1999.00945.x

Bamford, A., \& Porter-O'Grady, T. (2000). Shared governance within the market-oriented health care system of New Zealand. International Nursing Review, 47(2), 83-8 doi: 10.1046/j.1466-7657.2000.00013.x

Bowles, A., \& Bowles, N. (2000). A comparative study of transformational leadership in nursing development units and conventional clinical settings. Journal of Nursing Management, 8(2), 69-77 doi: 10.1046/j.1365-2834.2000.00151.x

Burns, J. (1978). Leadership. New York: Harper \& Row Inc.

Burns, J.P. (2001). Complexity science and leadership in healthcare. Journal of Nursing Administration, 31(10), 474-482.

Carpenter, H.M. (1971). An improved system of nursing education for New Zealand: Report. Wellington, New Zealand: Dept. of Health.

Carr, W., \& Kemmis, S. (1986). Becoming critical: Education, knowledge and action research. Geelong: Deakin University Press.

Chiok Foong Loke, J. (2001). Leadership behaviours: Effects on job satisfaction, productivity and organizational commitment. Journal of Nursing Management, 9(4), 191-205 doi: 10.1046/j.1365-2834.2001.00231.x

Clark, M. (2006). Workforce statistics 2006 update [PowerPoint slides]. Paper presentation at Nursing Council of New Zealand Forum. Retrieved September, 2008 from http ://www. nursingcouncil.org.nz

Clegg, A. (2001). Occupational stress in nursing: A review of the literature. Journal of Nursing Management, 9(2), 101-6 doi: 10.1046/j.1365-2834.2001.00216.x

Coghlan, D., \& Brannick, T. (2005). Doing action research in your own organisation (2nd ed.). London: Sage Publications Ltd.

Coghlan, D., \& Casey, M. (2001). Methodological issues in nursing research: Action research from the inside: Issues and challenges. Journal of Advanced Nursing, 35(5), 674-682 doi: 10.1046/j.1365-2648.2001.01899.x

Connelly, L., Nabarette, S., \& Smith, K. (2003). A Charge Nurse workshop based on research. Journal for Nurses in Staff Development, 19(4), 203-208. 
Connelly, L., Yoder, L., \& Miner-Williams, D. (2003). A qualitative study of Charge Nurse competencies. MEDSURG Nursing, 12(5), 298-306.

Cook, M.J. (2001). The attributes of effective clinical nurse leaders. Nursing Standard, 15(35), 33-36.

Cook, M.J. (2001). The renaissance of clinical leadership. International Nursing Review, $48(1), 38-47$.

Cook, M.J., \& Leathard, H. (2004). Learning for clinical leadership. Journal of Nursing Management, 12, 436-444 doi: 10.1111/j.1365-2834.2004.00420.x

Denzin, N.K., \& Lincoln,Y. (Eds.). (2005). The SAGE handbook of qualitative research (3rd.ed.). Thousand Oaks, CA: Sage Publications Inc.

DePoy, E., Hartman, A., \& Haslett, D. (1999). Critical action research: A model for social work knowing. Social Work, 44(6), 560-569.

Dick, B. (1993). You want to do an action research thesis [84 pages]. Retrieved November, 2004, from http:www.scu.edu.au/schools/gcm/ar/art/arthesis.html

Doherty, C. (2003). Modernisation: The role of ward sisters and charge nurses. Nursing Standard, 17(52), 33-35.

Dowling, M. (2006). Approaches to reflexivity in qualitative research. Nurse Researcher, 13(3), 7-21.

Drach-Zahavy, A., \& Dagan, E. (2002). From caring to managing and beyond: an examination of the head nurse's role. Journal of Advanced Nursing, 38(1), 19-29 doi: 10.1046/j.1365-2648.2002.02142.x

Drummond, K. (2002). The perceived attributes of the clinical leader in the acute hospital setting. Unpublished master's thesis for Master's degree, Auckland University of Technology, Auckland, New Zealand.

Duffield, C., Franks, H., Wood, L., \& Brisley, P. (2001). The role of nursing unit managers in educating nurses. Contemporary Nurse, 10(3-4), 244-250. Retrieved October, 2008 from http://www.contemporarynurse.com

Firth, K. (2002). Ward leadership: Balancing the clinical and managerial roles. Professional Nurse, 17(8), 486-489. Retrieved October, 2008 from http://www.professionalnurse.net

Fontana, J. (2004). A methodology for critical science in nursing. Advances in Nursing Science, 27(2), 93-104. 
Fontana, A., \& Frey, J. (2005). The interview: From neutral stance to political involvement. In N. Denzin \& Y. Lincoln (Eds.), Handbook of qualitative research $\left(3^{\text {rd }}\right.$ ed., pp. 695-727). Thousand Oaks,CA: Sage Publications,Inc.

Fossey, E., Harvey, C., McDermott, F., \& Davidson, L. (2002). Understanding and evaluating qualitative research. Australian and New Zealand Journal of Psychiatry, 36(6), 717-732 doi: 10.1046/j.1440-1614.2002.01100.x

Freshwater, D. (2005). Action research for changing and improving practice. In I. Holloway (Ed.), Qualitative research in health care (pp. 210-228). Berkshire: Open University Press.

Gillis, A., \& Jackson, W. (2002). Research for nurses: Methods and interpretation. Philadelphia : FA Davis Co.

Gould, D., Kelly, D., Goldstone, L., \& Maidwell, A. (2001). The changing training needs of clinical nurse managers: Exploring issues for continuing professional development. Journal of Advanced Nursing, 34(1), 7-17 doi: 10.1046/j.13652648.2001.3411735.x

Greenleaf, R.K. (2002). Servant leadership: A journey into the nature of legitimate power and greatness $\left(25^{\text {th }}\right.$ ed.). New Jersey: Paulist Press.

Greenwood, J. (1994). Action research: A few details, a caution and something new. Journal of Advanced Nursing, 20, 13-18.

Greenwood, D.J., \& Levin. M. (1998). Introduction to action research: Social research for social change. Philadelphia: Sage Publications Inc.

Greenwood, D.J., \& Levin, M. (2005). Reform of the social sciences and of universities through action research. In N.K. Denzin \& Y.S. Lincoln, (Eds.), The SAGE handbook of qualitative research ( $3^{\text {rd }}$ ed.). (pp. 43-64). California, USA: Sage Publications.

Gummeson, E. (2000). Qualitative methods in management research. (2nd ed.). California, USA : Sage Publications.

Hammer, M., \& Champy, J. (1993). Re-engineering the corporation: A manifesto for business revolution. New York: Harpercollins.

Hand, H. (2003). The mentors tale: A reflexive account of semi-structured interview. Nurse Researcher, 10 (3), 15-27.

Hart, E., \& Bond, M. (1995). Action research for health and social care. Buckingham: Open University Press. 
Heller, B., Drenkard, K., Esposito-Herr, M., Romano, C., \& Tom, S., \& Valentine, N. (2004). Educating nurses for leadership roles. Journal of Continuing Education in Nursing, 35(5), 203-210.

Hennessy, D., \& Hicks, C. (2003). The ideal attributes of Chief Nurses in Europe: A Delphi study. Journal of Advanced Nursing, 43(5), 441-448 doi: 10.1046/j.13652648.2003.02741.x

Heron, J., \& Reason, P. (2006). The practice of co-operative inquiry: Research 'with' rather than 'on' people. In P. Reason \& H. Bradbury (Eds.), Handbook of action research (pp. 144-154). London: Sage Publications Ltd.

Holter, I., \& Scharwz Barcott, D. (1993). Action research: What is it? How has it been used and how can it be used in nursing? Journal of Advanced Nursing, 18, 298-304.

Hope, K., \& Waterman, H. (2002). Praiseworthy pragmatism? Validity and action research. Journal of Advanced Nursing, 44(2), 120-127.

HPCA Update. (2003). HPCA Health Practitioners Competence Assurance Act 2003, 1. Retrieved November 2006 from http://www.moh.govt.nz

Huerta, S. (2003). Recruitment and retention: The magnet perspective. Chart, 100(4), 4-6.

Hyrkäs, K., \& Dende, D. (2008). Clinical nursing leadership-perspectives on current topics. Journal of Nursing Management, 16(5), 495-498 doi: 10.1111/j.13652834.2008.00919.x

Johns, C. (2003). Clinical supervision as a model for clinical leadership. Journal of Nursing Management, 11(1), 25-36 doi: 10.1046/j.1365-2834.2002.00288.x

Kan, M. (2002). Identifying paradox: A grounded theory of nurse leadership in overcoming organisational change resistance. Unpublished thesis for Doctor of Philosophy in Management, Victoria University of Wellington, Wellington.

Kanter, R. (1977). Men and women of the corporation. New York: Basic Books.

Keith, Peat Marwick Consulting. (2001). Strategic review of undergraduate nursing education. Wellington, New Zealand: KPMG.

Kemmis, S., \& McTaggart, R. (2005). Participatory action research: Communicative action and the public sphere. In N. Denzin \& Y. Lincoln (Eds.), Handbook of qualitative research ( $3^{\text {rd }}$ ed., pp. 559-603). Thousand Oaks, CA: Sage Publications, Inc.

Koch, T., \& Kralik, D. (2006). Participatory action research in health care. Victoria, Australia: Blackwell Publishing Asia Pty Ltd. 
Krugman, M., \& Smith, V. (2003). Charge nurse leadership development and evaluation. Journal of Nursing Administration, 33(5), 284-292.

Kupperschmidt, B., \& Barnhouse, J. (2006). The Clinical Nurse Leader (CNL): Staying at the bedside; filling in the gap and impacting patient and staff outcomes. The Oklahoma Nurse, Dec. 2005, 16-18.

Laurent, C. (2000). A nursing theory for nursing leadership. Journal of Nursing Management, 8(2), 83-88 doi: 10.1046/j.1365-2834.2000.00161.x

Lewin, K. (1946). Action research and minority problems. Journal of Social Issues, 2, 3446.

Lewin, K. (1947a). Frontiers in group dynamics: Channels of group life; social planning and action research. Human Relations, 1(2), 143-153.

Lewin, K. (1947b). Frontiers in group dynamics: Concept, method and reality in social science; social equilibria and social change. Human Relations, 1(2), 5- 41.

McCormack, P., \& Hopkins, E. (1995). The development of clinical leadership through supported reflective practice. Journal of Clinical Nursing, 4, 161-168.

McNiff, J., \& Whitehead, J. (2006). All you need to know about action research. London: Sage Publications Ltd.

Malterud, K. (2001). Qualitative research: Standards, challenges and guidelines. Lancet, 35(9280), 483-488.

Marquis, B., \& Huston, C. (2000). Leadership roles and management functions in nursing: Theory and application ( $3^{\text {rd }}$ ed.). Philadelphia: Lippincott.

Marquis, B., \& Huston, C. (2003). Leadership roles and management functions in nursing: Theory and application ( $4^{\text {th }}$ ed.). Philadelphia: Lippincott.

Melling, S., \& Hewitt-Taylor, J. (2003). Professional issues: New flexible healthcare roles and the purpose of nursing. British Journal of Nursing, 12(21), 1264-70.

Mills, C. (2005). Developing the ability to lead. Nursing Management-UK, 12(4), 20-23.

Ministry of Health, (2002). Health of older people strategy. Wellington: Author. Retrieved July, 2008 from http://www.moh.govt.nz

Ministry of Health, (2002). He karowai oranga: Maori health strategy. Wellington: Author. Retrieved July, 2008 from http://www.moh.govt.nz 
Ministry of Health, (2001). The primary health care strategy. Wellington: Author. Retrieved July 2008 from http://www.moh.govt.nz

Moiden, N. (2002). Evolution of leadership in nursing. Nursing Management-UK, 9(7), 2026.

Morton Cooper, A. (2000). Action research in health care. Oxford: Sparks Computer Solution Ltd.

New Zealand Nurses Organisation, (2007). DHB/NZNO Nursing and midwifery multi employer collective agreement. Retrieved September, 2008 from http://www.nzno.org.nz

New Zealand Public Health and Disability Act, (2000). Retrieved November, 2006 from http: www.legislation.govt.nz

Nursing Council of New Zealand, (2002). Guidelines for cultural safety, treaty of Waitangi and Maori health in nursing \& midwifery education and practice. Wellington: Author.

Onwuegbuzie, A. (2000). Positivists, post-positivists, post structuralists and post modernists: Why can't we all get along? A framework for unifying research paradigms. Paper presented at the annual meeting of the Association for the Advancement of Educational Research, November 18 2000. Retrieved September 2008 from ERIC- Education Resources Information Center.

Oroviogoicoechea, C. (1996). The clinical nurse manager: A literature review. Journal of Advanced Nursing, 24, 1273-1280.

Park, P. (2006). Knowledge and participatory research. In P. Reason \& H. Bradbury (Eds.), Handbook of action research ( $2^{\text {nd }}$ ed., pp.83-93). London: Sage Publications Ltd.

Passmore, W. (2006). Action research in the workplace: The socio-technical perspective. In P. Reason \& H. Bradbury (Eds.), Handbook of action research ( $2^{\text {nd }}$ ed., pp.38-48). London: Sage Publications Ltd.

Porter-O'Grady, T. (2003). A different age for leadership new context, new content: Part 1. Journal of Nursing Administration, 33(2), 105-110.

Reason, P., \& Bradbury, H. (Eds.). (2001). Handbook of action research: Participative inquiry and practice. London: Sage Publications Ltd. 
Reason, P., \& Bradbury, H. (2006). Introduction: Inquiry and participation in search of a world worthy of human aspiration. In P. Reason \& H. Bradbury (Eds.), Handbook of action research (2 ${ }^{\text {nd }}$ ed., pp.1-14). London: Sage Publications Ltd.

Roberts, K., \& Taylor, B. (2002). Nursing research process: An Australian perspective, $\left(2^{\text {nd }}\right.$ ed.). South Melbourne: Nelson Thomson Learning.

Sandars, J., \& Waterman, H. (2005). Using action research to improve and understand professional practice. WorkBased Learning in Primary Care, 12, 294-305.

Sandelowski, M. (1993). Rigor or rigor mortis: The problem of rigor in qualitative research revisited. Advances in Nursing Science, 16(2), 1-8.

Schulz, A. (2004). Role of research in reconstructing global healthcare for the $21^{\text {st }}$ century. Nurse Administration Quarterly, 2, 135-143.

Somekh, B. (1995). The contribution of action research to development in social endeavours: A position paper on action research methodology. British Educational Research Journal, 21(3), 339-356 doi: 10.1080/0141192950210307.x

Spence-Laschinger, H., Purdy, N., Cho, J., \& Almost, J. (2006). Antecedents and consequences of nurse managers' perceptions of organizational support. Nursing Economics, 24(1), 20-29.

Stanley, D. (2004). Clinical leaders in paediatric nursing: A pilot study. Paediatric Nursing, 16(3), 39-43.

Stanley, D. (2006). Recognizing and defining clinical nurse leaders. British Journal of Nursing, 15(2), 108-111.

Stanley, D. (2006). Role conflict: Leaders and managers. Nursing Management, 13(5), 3137.

Stordeur, S., D'Hoore, W., \& Vandenberghe, C. (2001). Leadership, organizational stress, and emotional exhaustion among hospital nursing staff. Journal of Advanced Nursing, 35(4), 533-542 doi: 10.1046/j.1365-2648.2001.01885.x

Sullivan, J., Bretschneider, J., \& McCausland, M. (2003). Designing a leadership development program for nurse managers: An evidence-driven approach. Journal of Nursing Administration, 33(10), 544-549.

Taylor, B., Bulmer, B., Hill, L. Luxford, C., McFarlane, J., Reed, J., \& Stirling, K. (2002). Exploring idealism in palliative nursing care through reflective practice and action research. International Journal of Palliative Nursing, 8(7), 324-330. 
Taylor, B. (2006). Reflective practice: A guide for nurses and midwives, ( $2^{\text {nd }}$ ed.). Buckingham: Open University Press.

Tesch, R. (1990). Qualitative research: Analysis and software tool. Hampshire: The Falmer Press.

Thorpe, K., \& Loo, R. (2003). Balancing professional and personal satisfaction of nurse mangers: Current and future perspectives in a changing health care system. Journal of Nursing Management, 11(5), 321-330 doi: 10.1046/j.1365-2834.2003.00397.x

Tourangeau, A., \& McGilton, K. (2004). Measuring leadership practices of nurses using the Leadership Practices Inventory. Nursing Research, 53(3), 182-189.

Trist, E., \& Murray, H. (1990). (Eds.). The social engagement of social science:A Tavistock anthology. London: Free Association Books.

Upenieks, V. (2002). What constitutes successful nurse leadership? A qualitative approach utilizing Kanter's theory of organizational behaviour. Journal of Nursing Administration, 32(12), 622-632.

Upton, S. (1991). Green and white paper, your health and the public health. Wellington: Ministry of Health.

Wadsworth, Y. (2001). The mirror, the magnifying glass, the compass and the map: Facilitating participatory action research. In P. Reason \& H. Bradbury (Eds.), Handbook of action research: Participative inquiry and practice (pp. 420-432). London : Sage Publications Ltd.

Wadsworth, Y. (2006). The mirror, the magnifying glass, the compass and the map : Facilitating participatory action research. In P. Reason \& H. Bradbury (Eds.), Handbook of action research: Participative inquiry and practice (pp. 322-334). London : Sage Publications Ltd.

Waikato District Health Board, (2002). District strategic plan (2002-2011). Hamilton: Author.

Waikato District Health Board, (2005). Position description Clinical Nurse Leader. Hamilton: Author.

Wallis, S. (1998). Changing practice through action research. Nurse Researcher, 6(2), 515.

Waterman, H. (1998). Embracing ambiguities and valuing ourselves: Issues of validity in action research. Journal of Advanced Nursing, 28(1), 101-105. 
Webb, C. (1990). Action research: Philosophy, methods and personal experiences. Journal of Advanced Nursing, 14, 403-410.

Welford, C. (2002). Transformational leadership in nursing: Matching theory to practice. Nursing Management-UK, 9(4), 7-11.

West, B., Lyon, M., McBain, M., \& Gass, J. (2004). Evaluation of a clinical leadership initiative. Nursing Standard,13(19), 33-41.

White, J. (2004). The commodification of caring: A search for understanding of the impact of the New Zealand health reforms on nursing practice and the nursing profession. Unpublished Doctor of Philosophy in Nursing, University of Adelaide, Adelaide, Australia.

Williams, A., McGee, P., \& Bates, L. (2001). An examination of senior nursing roles: challenges for the NHS. Journal of Clinical Nursing, 10, 195-203.

Williams, P. (2004). The experience of being new in the role of Charge Nurse. Unpublished Master's thesis, Auckland University of Technology, Auckland, New Zealand.

Willmot, M. (1998). The new ward manager: An evaluation of the changing role of the charge nurse. Journal of Advanced Nursing, 28(2), 419-427.

Yoder-Wise, P., \& Kowlaski, K. (2006). Beyond leading and managing: Nursing administration for the future. St Louis: Elsevier Mosby. 